\title{
Adolescent Girls Initiative-Kenya: Health and Life Skills Audio Training Script, Wajir
}

Population Council

Follow this and additional works at: https://knowledgecommons.popcouncil.org/departments_sbsr-pgy

Part of the Demography, Population, and Ecology Commons, Family, Life Course, and Society Commons, Gender and Sexuality Commons, and the International Public Health Commons How does access to this work benefit you? Let us know!

\section{Recommended Citation}

Adolescent Girls Initiative-Kenya: Health and Life Skills Audio Training Script, Wajir. Nairobi: Population Council, 2017. 


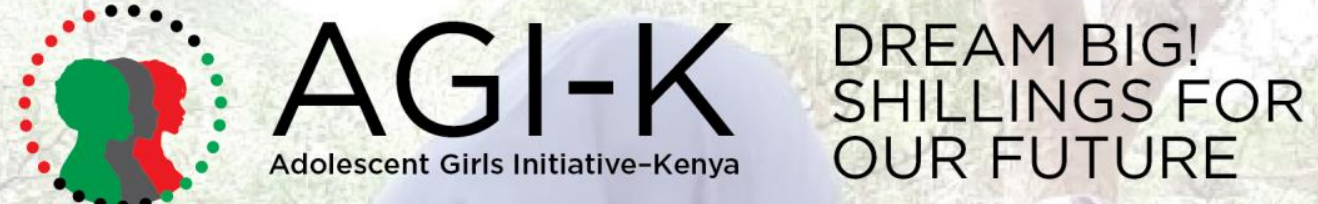

\section{HLS $\begin{aligned} & \text { AUDIO } \\ & \text { SRAINING } \\ & \text { SCRIPT }\end{aligned}$}

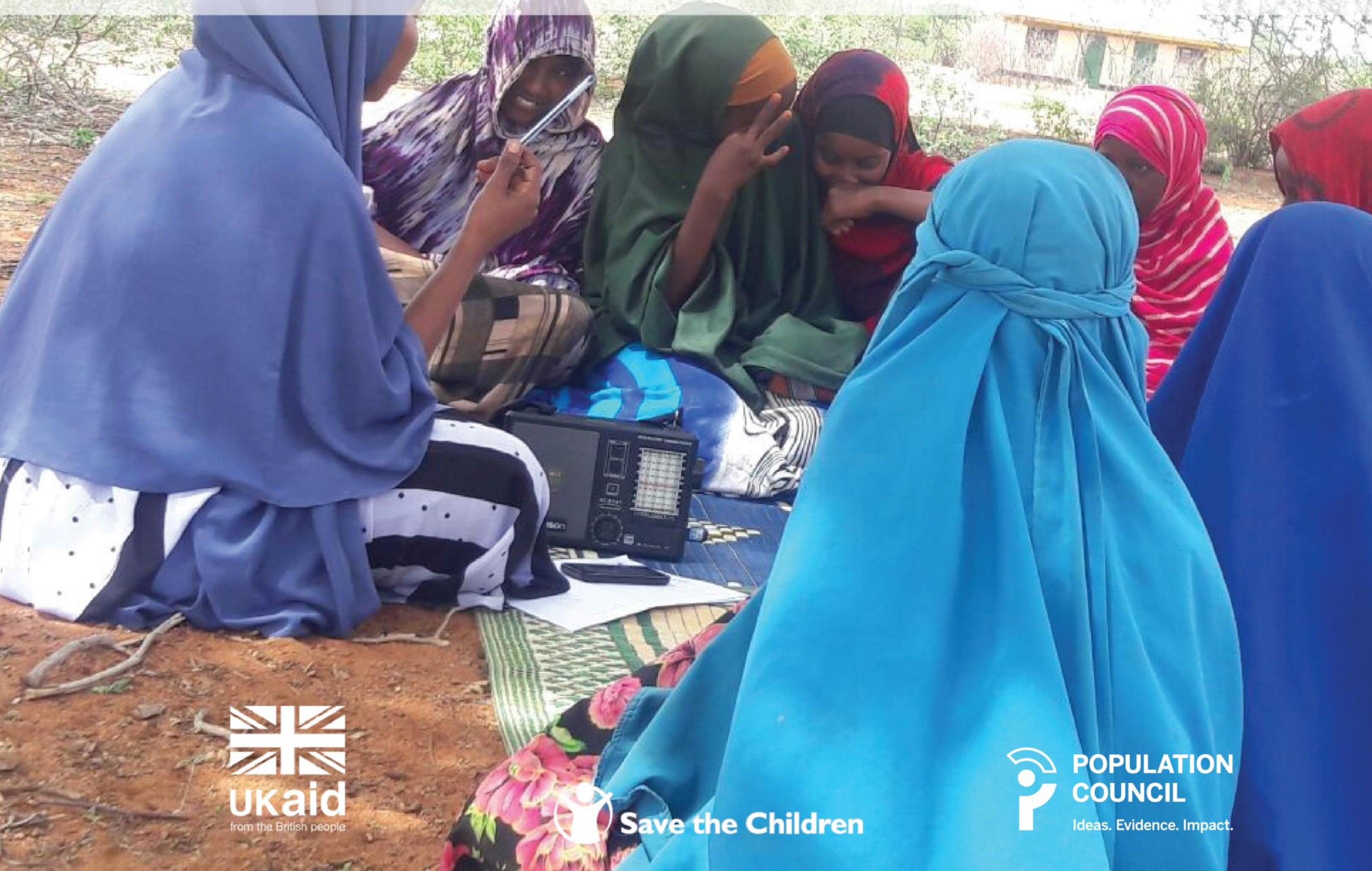




\section{POPULATION \\ counclL \\ Ideas. Evidence. Impact.}

The Population Council confronts critical health and development issues-from stopping the spread of HIV to improving reproductive health and ensuring that young people lead full and productive lives. Through biomedical, social science, and public health research in 50 countries, we work with our partners to deliver solutions that lead to more effective policies, programs, and technologies that improve lives around the world. Established in 1952 and headquartered in New York, the Council is a nongovernmental, nonprofit organization governed by an international board of trustees.

Population Council

One Dag Hammarskjold Plaza

New York, NY 10017

Tel: $212-339-0500$

Fax: 212-775-6092

www.popcouncil.org

Email: publications@popcouncil.org

Written permission from the Population Council is required for any reproduction or distribution of more than fifty (50) copies per year, any electronic reproduction or any major change in content.

For inquiries regarding rights and permission, please contact publications@popcouncil.org

Sections of this book may be reproduced, translated or adapted with minor changes to meet local needs, provided they are distributed free or at cost and not for profit and provided that any changes maintain the integrity of the book. Please inform the Population Council of plans to translate these materials into another language and provide one (1) copy of the publication.

Please include the following statements on all section reproductions:

Reprinted from Population Council: Adolescent Girls Initiative-Kenya, Audio Training Script.

(c) 2017 The Population Council, Inc. 


\section{Introduction ${ }^{1}$}

The Adolescent Girls Initiative project-Kenya (AGI-K) helps young, vulnerable adolescent girls build their social, health, and economic assets. AGI-K tests combinations of interventions in health, violence prevention, wealth creation, and education to determine which package of interventions delivers the most impact and at what cost. The project was led by Population Council and implemented in two marginalized areas 1) Kibera in Nairobi and 2) Wajir County in Northeastern Kenya by Plan International and Save the Children respectively.

Implementation of the health intervention was through the asset building approach which seeks to build adolescent girls' social and health assets with the objective of mitigating their vulnerabilities. Girls aged 11-14 joined Safe Spaces groups of 25-30 girls which met once a week under the guidance of a female mentor and at the convenience of the girls. The girls were trained on topics related to health, life skills and nutrition and given the opportunity to interact to build strong relationships with other girls in their community.

This scripted guide was designed to support the delivery of the health, life skills and nutrition sessions in Wajir. The shift from face-to-face training to audio sessions was in response to challenges with mentor capacity in this very remote, rural, underserved setting. The scripts were adapted from the written Wajir health, life skills and nutrition curriculum, translated into Somali language and recorded in form of audio ${ }^{2}$. The audios were helpful in guiding mentors to effectively facilitate sessions among girls aged 11-14 but can be adapted for girls in other age categories.

\section{Purpose and use of the guide}

This guide can be used to enhance learning of health, life skills and nutrition topics in a fun and engaging manner. The scripted sessions are useful in developing audio facilitation tools for facilitators that need support to effectively deliver training content. The audios act as an effective tool to open dialogue among participants from reserved communities that do not discuss reproductive health and sexuality issues openly.

It is recommended that mentors/ facilitators should undergo a comprehensive in-person training on thematic areas; health, life skills, nutrition and facilitation techniques - depending on the program needs. The training is useful in building their skills and knowledge on the program thematic areas. For purposes of reinforcing learning, Wajir or Kibera health and life skills curricula can be used/ adapted to train mentors/ facilitators since scripts in this guide were adapted from the curricula. Training should include practical sessions on how to facilitate using the audios.

\footnotetext{
1 Go Girls! Community-based Life Skills for Girls: A Training Manual. Baltimore, Maryland. Developed under the terms of USAID Contract No. GHH-1-00-0700032-00, Project SEARCH, Task Order 01; Adolescent Reproductive Health Project (KARHP), PATH, Population Council (2005). Tuko Pamoja: Adolescent Reproductive Health and Life Skills Curriculum; Johns Hopkins Bloomberg School of Public Health/Center for Communication Programs (2011).

2 Contact Population Council at publications@popcouncil.org to obtain the recordings in Somali language.
} 


\section{Adaptation process and recording of audios}

The scripted sessions in this guide can be adapted to suit program needs and translated into a local language that resonates with the participants and facilitators. During translation and recording efforts should be made to ensure that the content in the original/ adapted scripts is not distorted. Quality of content can be enhanced by engaging a translator, reviewer of the translations and audios.

Pre-testing of some audio sessions with the target group is recommended as part of quality assurance prior to rollout of the tool.

Facilitation aids in form of visuals can be used to aid facilitators to explain complex concepts. For instance, sessions on the process of menstruation and fertilization among others.

\section{Structure of sessions}

The manual has 28 scripted sessions that are outlined in form of a narration. The step by step narration is organized in a systematic format that guides the facilitator on how to delivery content and conduct interactive learning exercises. The sessions therefore positions the facilitator and participants as central and active persons in the learning process. At the end of each session, key learnings are summarized in form of a narration. This approach is crucial in ensuring that the target group gains correct and factual information.

Each session is outlined as follows;

$\checkmark$ Session Title: the session title names the main topic covered in the session.

$\checkmark$ Session objectives: provides an overview of session and purpose.

$\checkmark$ Reflection on the previous sessions: provides an opportunity for participants to remind themselves what they learnt in the previous session and for the facilitator to clarify any confusing issues.

$\checkmark$ Materials required: Outlines training aids needed to effectively carry out exercises in the session. Facilitators can utilize facilitation aids inform of pictorials - were applicable.

$\checkmark$ Time: provides a general timeframe of each session.

$\checkmark$ Energizers: can be carried out as the first activity in each session. However, the facilitator can pause the audio at any point to conduct an energizer. The energizer can be led by the facilitator or a participant.

$\checkmark$ Activities: have been organized in a simple step by step interactive format. The activities have been designed to address session objectives.

$\checkmark$ Pause function: each scripted session has a "pause" function that guides the facilitator on points of pausing the audio for purposes of engaging participants in specific activities. The facilitator has the liberty to pause the audio at any point of facilitation to clarify any confusing issues, respond to questions or conduct an energizer.

\section{Pre-session Preparation}

Prior preparation to each session is crucial. Being prepared for the learning session will give the facilitator confidence to effectively facilitate the session. Preparation entails listening to the entire audio session, practicing and preparing of relevant training materials. 


\section{Contents}

Introductory Sessions

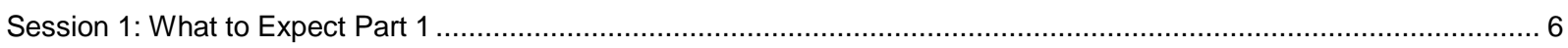

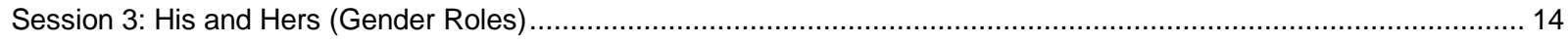

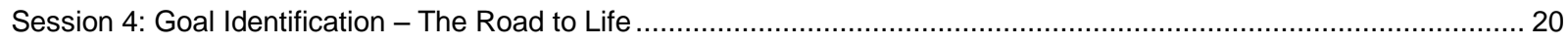

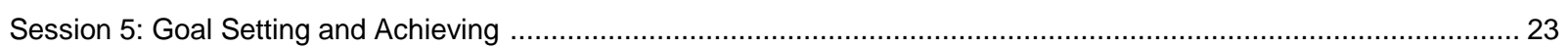

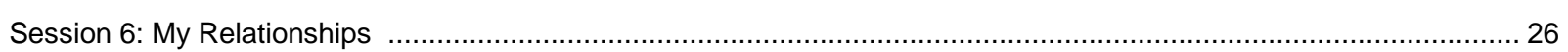

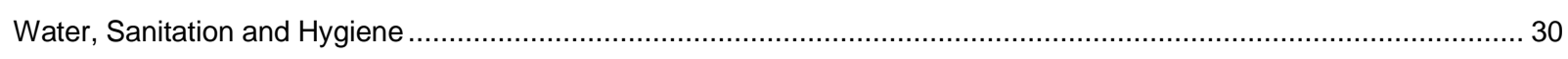

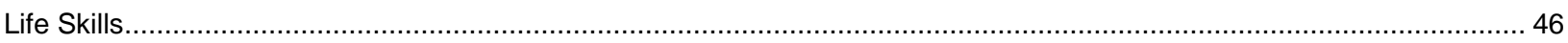

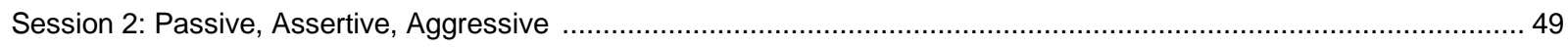

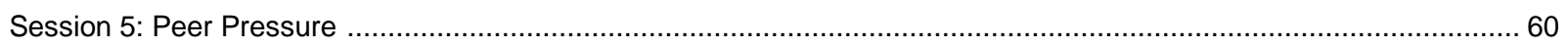

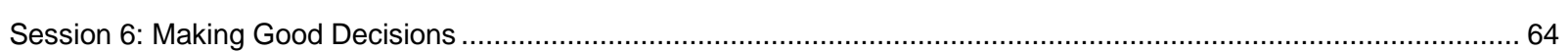

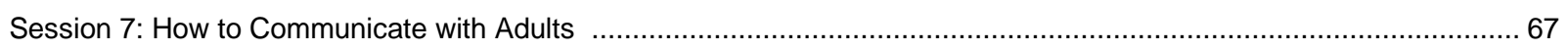

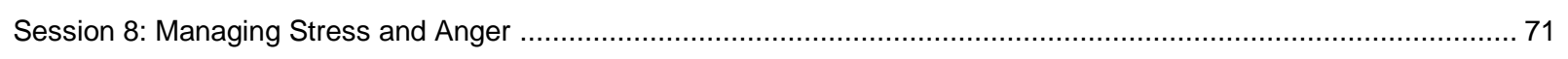

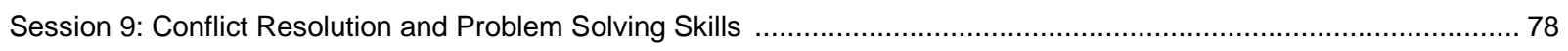

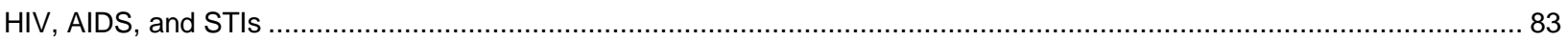

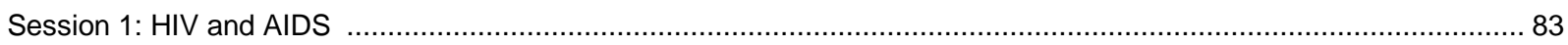

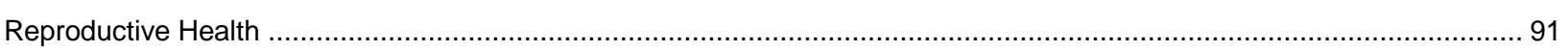

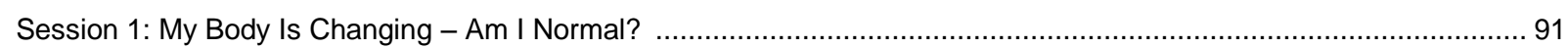

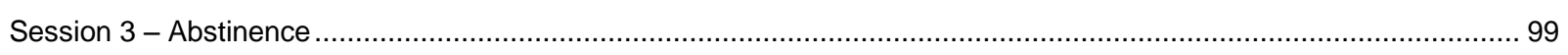

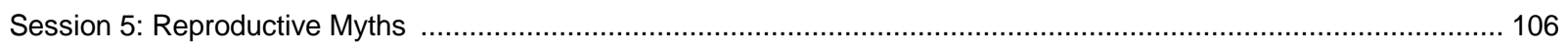

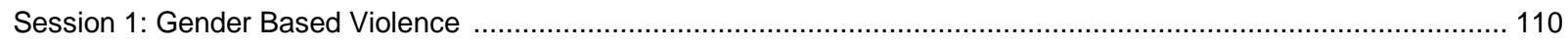

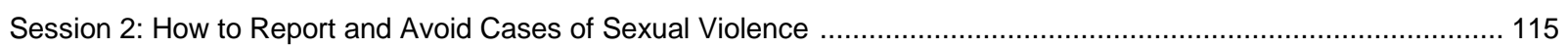

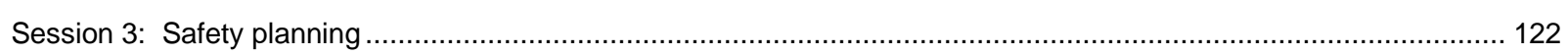

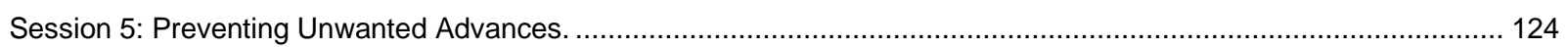

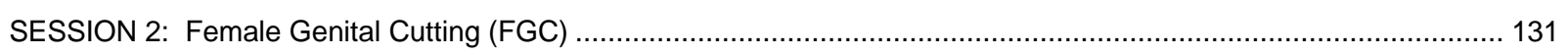

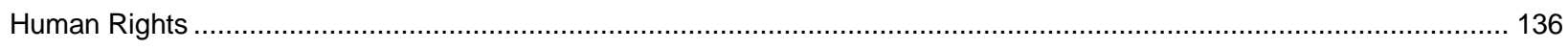

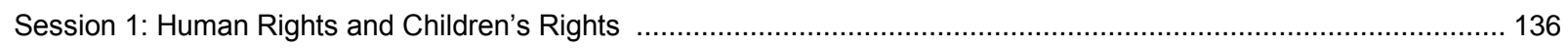

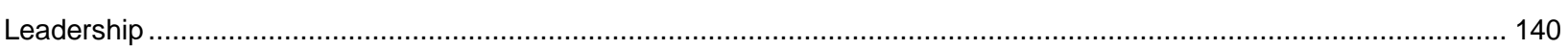

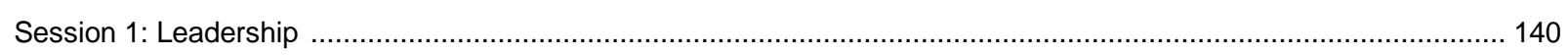

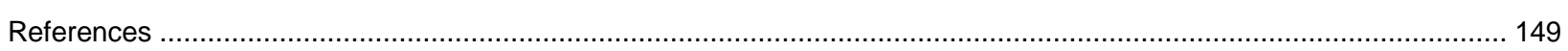




\section{Introductory Sessions}

\section{Session 1: What to Expect Part $1^{3}$}

Narrator: Welcome to the program and the first Safe space meeting. In this first meeting, we will talk about empowerment, understand what is covered in the program and why and understand

the expectations for participation.

Narrator: The session will take about 2 hours

Narrator: Mentor, for this session, you will need note books and pens for the participants, a blackboard and chalk or a flipchart and markers, you will also need a talking stick or a rolled-up piece of paper. Finally, you will need a comprehensive list of local community resources and their contact information for;

1. Sexual/reproductive health services

2. How/where to report gender based violence

3. Psychosocial counseling referral for any vulnerable girls who have been violated.

4. Legal services

It may be helpful to produce index cards with images of these community resources

(11) Narrator: We will begin the session with a short game which is also known as an energizer. Mentor, pause and lead participants in an energizer. Remember, you can pause this recording at any point to engage participants in an energizer.

(II) Narrator: Thank you for participating in the energizer. We will now begin our first activity which is getting to know each other. Mentor, pause and divide participants into pairs.

Narrator: I hope we are all in pairs. Now, one of you will act as a reporter and the other as a person being interviewed. You will be expected to report what you have learnt about your partner to the group. Mentor, please write the following questions on a blackboard or flipchart as I read them out;

\footnotetext{
3 Johns Hopkins Bloomberg School of Public Health/Center for Communication Programs. 2011. Go Girls! Community-based Life Skills for Girls: A Training Manual. Baltimore, Maryland. Developed under the terms of USAID Contract No. GHH-1-00-07-00032-00, Project SEARCH, Task Order 01.
} 
1. What is your name?

2. What is your hobby?

3. What is your favorite food?

4. How do you hope to gain from participating in these forums?

(II) Narrator: Mentor, pause, explain the exercise and allocate participants 10 minutes to interview each other.

(II) Narrator: Mentor pause and ask participants to sit in a circle.

Narrator: Now everyone will introduce their partner to the whole group using the information obtained during your interview. Mentor, if participants are hesitant to talk you can use a "talking stick" to get things started. This entails the passing of a talking stick (a cane, sticks, or rolled up piece of paper) to one participant. The participant with the talking stick shares, while everyone else listens. Then the participant passes the stick to another participant and that person talks while everyone else listens... and so on.

2 Narrator: Mentor, while the participants share, write what they hope to get out of these meetings on the blackboard or flipchart. After everyone has answered, read out the list and comment on which of the participants' expectations are covered in this program and which are not.

(II) Narrator: Mentor, you can now pause and allow each pair to introduce themselves.

Narrator: I hope we now know each other. We will now move to the next activity which is introduction to safe spaces and the idea of empowerment.

(II) Narrator: What do you think is meant by the word "empowerment?" Mentor, pause and allow participants to discuss for about 5 minutes.

Narrator: Per the dictionary, empowerment is: "making someone stronger and more confident, especially in controlling their life and claiming their rights."

(II) Narrator: What do you think empowerment might look like in your own life? Mentor, pause and allow discussions for about 5 minutes. 
Narrator: Empowerment in our day to day life might mean being able to stand up to someone who is treating you unfairly and being confident to share your opinions.

Narrator: The goal of our safe spaces meetings and the program is to provide a safe and fun learning environment where girls can be equipped with life skills and knowledge about their health and money management. The knowledge and skills that they gain in these groups, together with the friends that they will make, will help them maintain a happy and healthy life, and feel confident and empowered, including financially, asserting their rights and protecting themselves from harm and threats to their health.

II Narrator: Your involvement in this program is voluntary. Do you have any questions up to this point? Mentor, pause and respond to any questions and clarify any confusing issues.

Narrator: Each safe space meeting will include interactive activities that will take about one hour. Each meeting will address a different topic (e.g., communication, relationships, nutrition). Meetings will be safe places for you to discuss topics and questions that they many not otherwise get to talk about with adults and they should not feel embarrassed about anything that is discussed, any questions they may have, or any experiences they want to share. You are expected to attend each week. If a girl misses several sessions in a row, the mentor will follow up to find out if that girl is all right. The activities are participatory. Participants are asked and encouraged to talk, share, discuss, have fun and play at each meeting.

II Narrator: In this last activity, the mentor will divide us into small groups according to our age groups. This groups will be our safe spaces groups. Mentor, pause and divide the two groups (11-12; 13 - 14): Group A: 11 -12 year olds and Group B: 13 - 14 year olds. This is to help younger girls from feeling intimidated by the older girls and to prevent older girls from feeling that they are 'too old' for the program as there are girls much younger in the group.

Mentor, please note that groups should have a minimum of 15 girls and a maximum of 35 girls. Mentor, pause and divide the groups.

Narrator: The group you are now in will be the group you will meet during all the project sessions.

II Narrator: In this next activity, you will sit in your newly formed groups and draw a map of your community including the various resources that girls can access. Mentor pause and ask each group to sit in its own space then distribute one piece of flipchart paper and colored markers to each group. 
III Narrator: Draw a small map of the place where we are meeting today. Draw 5-6 examples of the things that are at this location, such as buildings, paths, trees, water points, other landmarks etc. The map should show key items/objects, and their relative location from one another. Mentor, pause, explain the activity and allocate 10 minutes for the activity.

II Narrator: From the map, you have drawn, which places do you spend the most time and why? Mentor pause and allow each group to share their response.

(II) Narrator: Mentor pause and distribute another flip chart and markers.

Narrator: Now, please draw a map of your larger community and village. The map does not have to be perfect; it just needs to give a

III general idea of the main places and where they are in relation to each other. Mentor, pause an allocate participants 15 minutes to draw the map.

II Narrator: I would like you to now agree as a group which places are safe or unsafe. You can mark each safe place by drawing a small star on their maps. You can put more stars to represent varying degrees of safeness (the safer the place, the more number of stars and the less safe a place is, the less number of stars). Mentor, pause, explain the activity and allocate the groups 5 minutes.

II Narrator: How long does it take to walk to the safest places from your homes? (This may vary depending on the locations where you live.). Mentor, pause and allow each group to share.

(II) Narrator: How do you feel about the safety of the place we are meeting today? Mentor, pause and allow each group to share.

III Narrator: Mentor, if participants agree that the location of today's meeting is safe, ask the group to agree to continue to meet in this location for future safe spaces sessions. (If the two groups (11-12 and 13-14 or in-school and out of school) are supposed to meet in separate locations, have each group agree on the safety of their respective location). If participants can think of a safer (or more convenient) space to meet, consider this alternative and make any necessary arrangements to secure the space for regular safe spaces meetings. Mentor, pause and lead the activity.

III Narrator: In our last activity of today, I would now like us to form groups based on those who share the same path to the safe space (meeting venue). Mentor, pause and lead the group formation exercise. 
Narrator: Please write the following questions on your note books and discuss in your groups of those you share the same path;

1. What things do we like the most from our path?

2. What dangers are there in the path?

3. Where do you feel safe and comfortable in the path?

4. Where will you meet in the path to come together to the safe space?

5. What's the safest path to follow to come to the safe space?

(II) Narrator: Mentor, pause and assign the groups 15 minutes for the activity. Once they finish the exercise, ask one member of the group to draw a big star on the community map, the point the group will meet on the path to the safe space.

Narrator: Mentor write the following questions on a flipchart and discuss with the participants;

1. What moments do girls walk together in the community?

2. When and how have you seen, a girl helping another girl?

3. Why is it important to know the other girls participating in his safe space?

(II) Narrator: Mentor, pause and discuss the questions.

Narrator: We have now come to the end of our first session. We will consider the logistics of the places you have suggested as safe spaces and communicate to you or your parents on the date and venue where we will be meeting for our regular meetings. I hope you have enjoyed the meeting and made new friends. See you soon! Bye bye. 


\section{Session 2: What to Expect - Part 24}

Narrator: Welcome to our second safe space meeting. In this session, we will agree on ground rules for our group and list community resources where we can access reproductive health service, gender based and other services.

Narrator: The session will take about one and half hours.

Narrator: Mentor, for this session, you will need;

1. Flipchart/ black board and markers

2. A comprehensive list of local community resources and their contact information for:

3. Health services

4. How/where to report sexual or domestic violence, including early and forced marriage

5. Psychosocial counseling referral for any vulnerable girls who have been abused or raped

6. Legal services

(It may be helpful to draw cards with images of these community resources.).

(II) Narrator: We will begin the session with an energizer. Mentor, pause and invite a participant to lead the rest in an energizer. Remember, you can pause this recording at any point to engage participants in an energizer.

(II) Narrator: I hope you enjoyed the energizer. We will now begin our first activity. Do you know what ground rules are? Why do you think it is important to have ground rules? Mentor, pause and lead the discussion.

Narrator: We need ground rules to help us understand the limits and freedoms that we have, to help us work together, to ensure productivity and respect each other.

(II) Narrator: What are some real-life situations when it is important to have rules? Mentor, pause and lead the discussion.

\footnotetext{
4Johns Hopkins Bloomberg School of Public Health/Center for Communication Programs. 2011. Go Girls! Community-based Life Skills for Girls: A Training Manual. Baltimore, Maryland. Developed under the terms of USAID Contract No. GHH-1-00-07-00032-00, Project SEARCH, Task Order 01.
} 
Narrator: We need rules to govern us for example when people steal from each other, when there is a meeting and everyone talks at the same time, when someone speaks and others make negative comments about their contribution to the conversation, when everyone must contribute to household chores, among other examples.

Narrator: Ground rules are set to help you feel safe participating in these meetings. While this is a participatory program, you will not be forced to participate more than you want. You can feel confident that this is a safe environment in which to share your thoughts and feelings, and that sharing your own questions or stories can help other girls who may have experienced or wondered about similar things. Ground rules help ensure that everyone will have a chance to be heard without judgment or ridicule, and their personal space and privacy will also be respected.

(II) Narrator: What are some ground rules you would like to set for these meetings? Mentor, pause and lead the discussion remember to record all rules on a flipchart/ black board and keep / stick on a safe place them for reference throughout the entire program.

Narrator: Other rules you might want to include are what is said is not repeated anywhere else (needs to be confidential); everyone should participate only if they want to; no putting someone else down for their feelings, opinions, or experiences; be respectful and listen and do not interrupt.

(II) Narrator: What are some interactive punishments you would like to set for those who break the ground rules? Mentor, pause and lead the discussion. Remember to write all responses on a flipchart paper/ black board and keep/ stick them on a safe place for reference throughout the entire program.

Narrator: some interactive punishments could be; the one who breaks the rules must do 10 frog jumps, or write on the blackboard or flipchart (or say out loud) three things they have learned so far today, or sing one verse of a song or any other that you would like to agree on as a group.

(II) Narrator: You will now vote to agree on these rules by raising their hands. This vote will serve as a contract, meaning that the group has agreed to follow these rules in each girl's group meeting. Mentor pause and lead the voting exercise. If one or more girls do not raise their hand, ask why and discuss what should be changed to the rules for everyone to agree to them.

Narrator: In this last activity for today, we will brainstorm on the different resources and contacts in our community.

(II) Narrator: Mentor, pause and distribute the notebooks and pens to each girl. 
N Narrator: I hope we all have received pens and books. You will use them throughout the safe spaces meeting so remember to carry them whenever we meet.

II Narrator: Which resources are currently available to you which are related to your health, safety, and well-being - such as where you can go if you have a health problem, if you have a problem that you want to talk to someone about, counseling, sexual and gender based violence services? Mentor, pause and lead the discussion. Remember to record all responses on a blackboard or flipchart.

Narrator: Mentor, you can now share with the participants your list or cards with images of local resources and contact information that you have gathered before the session. Emphasize the importance of turning to the services available in the community whenever participants, members of their families, or friends need assistance.

Narrator: Mentor, if participants have mentioned any other resources that are not already included on your prepared list, let them know that you will follow-up on getting any additional contact information needed for those, and that you will provide it to them at the next meeting.

Narrator: I hope we know all have information on where we can get important services and other resources in our community. This marks the end of our session for today. See you next week, same time and same place. 


\section{Session 3: His and Hers (Gender Roles) 5}

Narrator: Hello, welcome to today's session on gender roles. By the end of the session, we will be able to Identify how gender expectations can help or limit us, plan how to step out of restrictive gender roles and name people who have stepped outside their gender role to succeed.

Narrator: Mentor, for this session you will need a blackboard and chalk OR flipchart and markers.

Narrator: The session will take about 1 hour and 30 minutes.

II Narrator: Mentor, pause and ask the participants to share what they learned in the last session. Be sure to clarify any confusing issues.

(II) Narrator: We will begin today's session with an energizer from a volunteer. Mentor, pause and request a volunteer to lead the energizer.

(II) Narrator: I hope the energizer was fun! Mentor, ask participants to share what they learnt during the last session. Remember to add anything that they have left out and clarify any confusing issues. You can now pause, listen and provide feedback.

(II) Narrator: Mentor pause and divide the participants two groups. You can divide them by asking them to count 1-2 then group all number ones together and all number twos together. Once you have divided the groups, distribute one piece of flipchart paper and markers to each group.

Narrator: Girls, I hope you are all in groups. Now, please listen carefully as I explain the task for each group. Group one, write (or tell) a story of what a typical adolescent girl living in Wajir does from the time she wakes up to the time she goes to sleep.

Narrator: Group two, write (or tell) a story of what a typical adolescent boy living in Wajir does from the time he wakes up to the time he goes to sleep.

5Johns Hopkins Bloomberg School of Public Health/Center for Communication Programs. 2011. Go Girls! Community-based Life Skills for Girls: A Training Manual. Baltimore, Maryland. Developed under the terms of USAID Contract No. GHH-1-00-07-00032-00, Project SEARCH, Task Order 01; Kenya Adolescent Reproductive Health Project (KARHP), PATH, Population Council. 2005. Tuko Pamoja: Adolescent Reproductive Health and Life Skills Curriculum; USAID. 2006. Doorways I: Student Training Manual on School-Related Gender-Based Violence Prevention and Response. 
II Narrator: Pause and clarify the activity. Then ask the two groups to choose one person who will present their story to the larger group once they finish the task. Give the groups about 15 minutes to complete the task.

(II) Narrator: Mentor, pause and invite the two groups to share their story.

Narrator: Thank you very much for sharing your story. Now, I would like to ask all of you a few questions related to the stories that have been shared by the groups. Please pay attention.

(II) Narrator: The first question is, how are the typical days of an adolescent girl and boy different? Mentor, pause and discuss the responses.

II Narrator: The second question is, what main activities does an adolescent girl do in her life and which ones do a boy do in his life? Mentor, pause and discuss the responses.

(II) Narrator: The last question is; would it be possible for girls to complete the activities that the boy usually does? Would it be possible for boys to complete the activities that the boy usually does? Mentor, pause and discuss the responses.

Narrator: Thank you very much for participating in the group work. We will now do an exercise to discuss the term "gender roles" and learn how someone's gender roles are different from his or her sex.

(II) Narrator: Girls, what sex are you? Mentor, pause and listen to the feedback.

Narrator: Well done, your sex is female. Your sex is whether you are a male or a female. It is the biological, physical fact of being born a boy or a girl.

Narrator: What are your gender roles? That is, what are you expected to do?

Narrator: Correct, some of the thinks you are expected to do as girls is to cook, take care of children, sew clothes, herding cattle, fetching water, keep the household clean, among others. 
Narrator: Gender roles are any expectations of a person based on their sex, that is what society or a culture expects from you based on whether you are male or female. It is how the community wants you to behave and think based on whether you are a man or a woman. For Example, A girl from Wajir and a girl from Nairobi have the same sex, but their gender roles are probably different because they were raised in different cultures. An adolescent girl from Wajir may be asked to tend to the cattle, while an adolescent girl from Nairobi may be on a football team.

(II) Narrator: I am now going to ask you a few question regarding gender roles so listen carefully. Question one, do girls communicate differently than boys in this community? Mentor, pause and discuss the responses.

II Narrator: The second question is, are girls able to make decisions as much as boys? Mentor, pause and discuss the responses.

(II) Narrator: The final question is, are girls able to make the same kinds of decisions as boys? Mentor, pause and discuss the responses.

Narrator: We will now do a role-playing to help us think about gender roles in Wajir. Throughout the AGI-K program we will do many role-plays. Each time I ask you to do a role-play in a group, you must first:

$>$ Discuss the situation as a group, then

$>$ Agree on a storyline, next

$>$ Agree on who does what making sure everyone is involved, then

$>$ Practice, and finally

$>$ Act out for the group.

Narrator: Mentor, pause and divide the girls into two groups by asking them to 1-2 then group all number ones together and all number twos together.

Narrator: I hope you are all in groups. Group one, create a 2-minute role play based on the short story am about to narrate. Please be attentive.

Narrator: A mother and her daughter wake up in the morning. The mother grabs a broom and starts sweeping the compound while the daughter grabs a bucket and goes to fetch water. After sweeping, the mother starts washing clothes while the daughter gets back with water and starts washing the utensils. The daughter then goes to school or madrasa. When the daughter gets back from school, the mother asks her to help prepare food for the family. 
(II) Narrator: Mentor, pause and explain the activity.

Narrator: Group two, create a 2-minute role play based on the short story am going to narrate

Narrator: A father and his son wake up in the morning. The father spends the morning tending for his cows and camels while in the afternoon he attends a council of elders' meeting while the son goes out to herd goats and sheep. In the evening when the father comes back home he joins his friends to play 'jara' listen to the radio and chew 'miraa'. The son returns the goats and sheep home then joins his friends to play in the field

(II) Narrator: Mentor, pause and explain the activity. Then give the two groups 15 minutes to prepare their role plays. Once they finish preparing the roles plays, ask each group to present to the larger group.

II Narrator: Girls, did the roles plays show the real life of girls and boys in your village or should something be changed? Mentor, pause and discuss the responses.

(II) Narrator: Mentor, pause and draw two blank boxes on the blackboard or flipchart. Write "girl" above one box and "boy" above the other box.

Narrator: Thinking about what was presented in the role-plays and your own life experiences, what can you say girls are 'encouraged' or 'expected' to do by culture, country, community, family, peers, etc.?

(II) Narrator: Mentor, pause and listen to the responses and write them inside of the "girl" box.

(II) Narrator: Girls, what are some things that girls are 'discouraged' from doing, or not 'expected' to do? Mentor, pause and listen to the responses and write them on the outside of the "girl" box.

Narrator: Now, I would like to ask you a question related to boys. Thinking about what was presented in the role-plays and your own life experiences, what can you say boys are 'encouraged' or 'expected' to do by culture, country, community, family, peers, etc.?

(II) Narrator: Mentor, pause and listen to the responses and write them on the inside of the "girl" box.

(II) Narrator: The final question is, what are some things that boys are 'discouraged' from doing, or not 'expected' to do? Mentor, pause and listen to the responses and write them on the outside of the "boy" box. 
Narrator: Boys and girls are often expected to act a certain way just because they are boys or girls.

(II) Narrator: Is there something inside the boys' box that you wish was inside the girls? Why? Mentor, pause and discuss the responses.

(II) Narrator: Is there something inside the girls' box that you wish wasn't there? Why? Mentor, pause and discuss the responses.

(II) Narrator: Is there something outside the girls' box that you wish was inside it? Mentor, pause and discuss the responses.

Narrator: I am now, going to narrate to you a story about a girl called Fatuma who did something different and became a doctor. Please pay attention because I will ask you questions after the story.

Narrator: Fatuma has four brothers and no sisters. Her brothers all performed well at school. However, she was performing better than all of her brothers at school. Her brothers felt very uncomfortable about her success at school. They told her that she was only a girl and that the best that could happen to her was to get married and become a housewife. Fatuma had a goal and dreamt of becoming a doctor. When she shared her dream with people in her village they laughed and said, "Women can't be doctors!" After years of studying and hard work, she went to university. At university, she chose a subject that women from her community usually do not study: medicine. She became the first woman from her village to be a doctor. Now, everyone is proud of her success and she serves as a role model for both boys and girls.

(II) Narrator: Is there someone from your community who has overcome difficulties to achieve his/her goal? Mentor, pause and discuss the responses.

(II) Narrator: What was their goal? Mentor, pause and discuss the responses.

(II) Narrator: What difficulties did he/she face? Mentor, pause and discuss the responses.

(II) Narrator: How did he/she overcome the difficulties? Mentor, pause and discuss the responses.

(II) Narrator: Lastly, what was the end result? Mentor, pause and discuss the responses. 
II Narrator: Girls, we have now come to the end of today's session. Please feel free to ask your mentor any questions. Mentor, pause and respond to the questions.

Narrator: Thank you very much for your active participation. See you next week. 


\section{Session 4: Goal Identification - The Road to Life}

Narrator: Hello, today, we will talk about our goals in life.

Narrator: Mentor, for this session you will need a blackboard and chalk OR flipchart and markers.

Narrator: The session will take about 1 hour and 30 minutes.

(II) Narrator: We will begin the session with an energizer. Mentor, pause an invite one of the participants to lead the rest in an energizer.

(II) Narrator: Mentor, pause and ask the participants to share what they learned in the last session. Be sure to clarify any confusing issues.

Narrator: We will begin today's session by doing a very interesting activity. Are you ready to participate in the activity?

Narrator: In this activity, we will do a drawing to help us think about our lives so far, and where we will go in the future. We will draw some of the things or people, which/ who have helped us, and those which/ who can help us to achieve our goals. We are going to start by looking at our own lives so far. We are going to think of our lives as a road that we travel along. Sometimes the road is rough; sometimes it is smooth.

(II) Narrator: Now, I would like you to open a blank page on your exercise book. Mentor Pause and give the girls time to open the blank page.

(II) Narrator: Now, draw yourself in the middle of the page. Then draw a road from bottom corner to the drawing of yourself, and then continue from there to a top corner. Mentor pause and draw your own road on a blackboard or flipchart paper for all participants to see a demonstration of the activity then give the participants about 5 minutes to draw theirs.

(II) Narrator: This is the road of your life. In the bottom corner, where the road starts, this is where you were born. Draw a picture of yourself as a tiny baby in the bottom corner. Mentor, pause and give the participants about 5 minutes to draw. 
II Narrator: Now thinking about the road you have travelled between being born and now, what are three most important things that have happened in your life so far (good or bad things which have happened)? Now draw something on your first part of their road to show those three events. Mentor, pause and show the participants on your road where they should draw. Mentor, please note that It is better NOT to make particular suggestions about what to draw, as participants are likely to then draw what has been suggested. Now, pause and give participants 5 minutes to draw.

(II) Narrator: Many of you have faced big challenges in your lives, but that you have continued along your roads. What are some things that have helped you along your road so far? [e.g. people, places, something within yourself]. Now, draw anything that has helped you on the first part of the road. Mentor, pause, explain and allow the participants 5 minutes to draw.

(II) Narrator: Do you have any questions or anything you would like to share with the group so far? Mentor, pause, listen and respond to the questions.

Narrator: Now we are going to think about the future. That is;

1. Where is your road taking you?

2. Where do you want to get to?

3. Think of yourself in 5,10 or 15 years' time, where will you be?

(II) Narrator: Now draw three things you want to achieve in the future (where you will be in 5, 10, or 15 years) on the next part of your road (the part between yourself now and the top of the paper). Mentor pause, explain and give the participants 5 minutes to draw.

(II) Narrator: Which things do you think will help you to achieve your goals? Now draw beside the road anything you think will help you. For example, it could be people, places, or things within you. Mentor pause, explain and give the participants 5 minutes to draw.

II Narrator: Those of you, who wish to, can stick their roads on the wall. But if others do not want to, that's fine. The road drawing is for you to keep. Mentor, remind the group that everybody has a different drawing style, so the purpose of the activity is not to compare drawing ability, but to understand the events and the helpers in each other's lives. Mentor, pause and allow participants a few minutes to hang their drawings.

Narrator: Mentor, pause and encourage the group to walk around and look at each other's drawings. Ask if one or two people will volunteer to describe their drawings to the group. 
(II) Narrator: Thank you girls for participating in today's session, hope you had fun. As we come to the end, please feel free to ask your mentor any questions and or clarifications. Mentor, please pause and respond.

Narrator: This was a very interesting session. Thank you for your active participation. See you next week! 


\section{Session 5: Goal Setting and Achieving 6}

Narrator: Hello, girls, welcome to today's session. In this session, we will learn about goals and practice developing goals.

Narrator: Mentor, for this session you will need a blackboard and chalk OR flipchart markers and a football which can be made out of plastic bags and string or ball up a piece of flipchart paper and wrap with a masking tape.

Narrator: The session will take about 1 hour and 30 minutes.

II Narrator: Mentor, pause and ask the participants to share what they learned in the last session. Be sure to clarify any confusing issues.

(II) Narrator: Before, we begin the session, let us have a volunteer to lead us in an energizer. We. Mentor, pause an invite one of the participants to lead the rest in an energizer.

Narrator: A goal something that you hope to achieve, especially when much time and effort will be needed.

(II) Narrator: To better understand the term goal, we will participate in a very interesting football game. Mentor, drop the football on the floor and let the participants play a quick game of football. Pause and give the participants about 5 minutes to play the game.

Narrator: In football, a goal is when you score to benefit your team. It is something you struggle to do throughout the entire game you and your team try to score as many goals as you can in one game. Now let's pretend we have front row seats for everyone in the room to watch two teams play one another in the World Cup. When you arrive in the stadium, where the games are being held, you notice that there is something strange about the field. The players are kicking the ball around, but nothing is happening. There are no goals. Without goals, the game does not have a purpose. Same in life: if you have no goals, you are just on the field aimlessly kicking the ball around.

\footnotetext{
6 Peace Corps. 2001. Camp GLOW (Girls Leading Our World): Handbook for Volunteers; Kenya Adolescent Reproductive Health Project (KARHP), PATH, Population Council. 2005. Tuko Pamoja: Adolescent Reproductive Health and Life Skills Curriculum.
} 
Narrator: In order to develop goals, one should have;

1. Mission Statement: A brief sentence explaining what you want to accomplish (E.g. to join High school)

2. WHAT: Be specific; explain the mission statement more here (E.g. To join a National School)

3. WHO: The people who will help you towards your goal (E.g. parents, teachers, and headmaster)

4. WHERE: A place, anywhere in the world (E.g. Join Alliance Girls, Statehouse Girls or Moi Girls)

5. WHEN: Set up a timeline and a specific date

(E.g. Pass class eight in 1-3 years (specify year depending on age) and join the National school)

6. HOW: Make lists of ideas to achieve a goal - explain what you need to do to achieve your goal (Study hard and improve my grades; talk to my teachers to support me to improve my grades; contact friends and relatives who are in National schools or have passed through national schools for advice; look in the newspaper and on the internet for information and, possible banks or organizations that provide education scholarships.

7. WHY: Should refer back to the mission statement (E.g. because student in a National school.)

Narrator: Goals are very important in life, just as in politics. When setting a goal you will miss a few shots. Sophia Abdi Nur is a famous female politician and she has not given up in life just because she did not manage to get an elected post in the March 2013 National General elections. She is not considered a failure. Expect to face challenges as you work towards your goals, which will make you successful rather than be considered a failure. 
Narrator: Life has 4 major phases. I will now explain the phases. Please pay attention;

Phase 1 - The Good Times. The period when everything is perfect. Life is beautiful.

$>$ Phase 2 - Problems Arise. The period when things fail. In this dark time, people tend to quit, give up. Seems like no answer in sight.

Phase 3 - Problems to solutions. When you are determined to follow your goal, know that to each problem there is a solution. This requires creativity and being open to new ideas.

$>$ Phase 4 - Growth. Once you have gone through the phases, you have grown and you are excited and ready for more. The circle starts all over again.

(II) Narrator: Mentor, pause and divide the participants into 5 small groups (Ask them to count number $1-5$ then group all number ones together, twos together, etc.)

(II) Narrator: Girls, in your small groups, you will write (or draw) out your own goals Follow the outline of the 1) Mission Statement, 2) What, 3) Who, 4) Where, 4) When, 5) How, and 6) Why like we discussed before. Remember dreaming is FREE and does not cost a thing. So in this exercise, try to dream big, crazy, and be open to new things. Anything is possible if you really want to achieve it! Mentor, pause, explain the exercise and allow the participants 10 minutes for the exercise.

(II) Narrator: Now that you have finished the exercise, the mentor will pause and have the small groups share with the larger groups. Mentor, please pause.

(II) Narrator: Thank you for participating in the exercise. Mentor, pause and distribute pieces of paper to all participants.

(II) Narrator: Now I would like you to think of some things that you cannot do. Maybe you feel you cannot travel to the other side of the country to visit your aunt, or go to university to be a doctor, or pass class eight exams. Write (or draw) these things on your piece of paper. Try to think of at least three things. Mentor, pause and allow the girls 5 minutes for this exercise.

Narrator: I hope you are done with the exercise. We are gathered here today to say goodbye to someone who has been around for a long time. We are going to have a funeral for the things that we think we cannot do. It is important to believe in yourself- with strong self-esteem and well-planned goals; you can achieve anything you want. This is an "I can't" funeral because you can do these things you think you can't do. Don't allow others to tell you that you can't do something. 
(II) Narrator: Now, I would like you to tear their "I can't" papers into small pieces and say loudly; You can do anything you set your minds to! Mentor, pause for 2 minutes for this exercise.

(II) Narrator: Hope you enjoyed today's session. Before we call it a day, please ask the mentor any questions or clarifications. Mentor, pause and respond.

Narrator: Goodbye girls and see you in the next session. Inshallah! 


\section{Session 6: My Relationships 7}

Narrator: Hello, girls, welcome to today's session. In this session, we are going to talk about the different types of relationships in our lives.

Narrator: Mentor, for this session you will need a blackboard and chalk OR flipchart markers.

Narrator: The session will take about 1 hour and 30 minutes.

II Narrator: Mentor, pause and ask the participants to share what they learned in the last session. Be sure to clarify any confusing issues.

(II) Narrator: Before, we begin the session, let us have a volunteer to lead us in an energizer. Mentor, pause and invite a participant to lead the rest in an energizer.

Narrator: This session will help you identify the different types of relationships that you have with people.

II Narrator: Can you please write on your note books a list of relationships and connections that you have with other people. Mentor, pause for about 5 minutes for this activity.

(II) Narrator: Mentor, pause and invite a few participants to share their lists voluntarily. Note on the blackboard or flipchart the different kinds of relationships they mention, such as those with relatives, friends, or neighbors.

(II) Narrator: Mentor, pause and draw a diagram of four circles; that is from small to large circles - on the flip chart or blackboard.

\footnotetext{
7 International Sexuality and HIV Curriculum Working Group. 2009. It's All One Curriculum: Guidelines and Activities for a Unified Approach to Sexuality, Gender, HIV and Human Rights Education. Edited by Nicole Haberland and Deborah Rogow; Kenya Adolescent Reproductive Health Project (KARHP), PATH, Population Council. 2005. Tuko Pamoja: Adolescent Reproductive Health and Life Skills Curriculum.
} 
Narrator: Girls, now, I would like you to open a blank piece of paper and;

1. Draw a series of four circles, from small to large, like the ones the mentor has drawn. Mentor pause and allow the girls to draw/ write.

2. In the smallest circle, write your name (or draw a picture of yourself). Mentor pause and allow the girls to draw/ write.

3. Think about the different people in your life. Just outside that small circle, write the names (or draw simple pictures) of those who are closest to you. Mentor pause and allow the girls to draw/ write.

4. In the next circle draw the people you are close to or see almost every day. Mentor pause and allow the girls to draw/ write.

5. In the two outer circles, put the names (or pictures) of those who are not as close. Mentor pause and allow the girls to draw/ write.

(II) Narrator: Mentor pause and divide the participants into groups of four by asking them to count 1-4 then group those with the same numbers together.

(II) Narrator: Girls, explain your drawings to the members of your group. Mentor pause for 10 minutes for this activity.

Narrator: I would now like to ask you a few questions. Please pay attention;

1. Did everyone in your group list the same kinds of relationships or were there differences? Mentor pause and listen to the responses.

2. Did everyone place their family members, friends, neighbors, teachers, religious leaders, or others in the same circle or in different circles? Mentor pause and listen to the responses.

3. What are some words that describe what you value in the people you feel closest to? [e.g. honest, respectful, sharing, caring, trusting, fun, safe, understanding, reliable, interesting, loving]. Mentor pause and listen to the responses.

Narrator: I am going to read some statements that ask you to think about what you have on your page. Think about these things quietly in your heads. Thinking about them will help you explore the qualities that you value most in your relationships. Are you ready?

(II) Narrator: Think about one person on your page whom you would like to have moved closer toward the inner circle. Pick one word that most describes what you value in that person. Mentor pause.

(II) Narrator: Now think about one or two of the words that you think people would say describe you. Mentor pause. 
II Narrator: Finally, think about what kind of friend you are to others, not just how other people are friends to you. Think about which qualities you could develop to become and even better friend? Mentor pause.

II Narrator: Now you have thought about what qualities you value in relationships, choose one quality you value highly - either in yourself or in others - and celebrate it by writing it on your paper (or drawing what it represents) with decorative letters or in a creative style. As you write (or draw), think about what the word means to you. Mentor, pause and explain the activity.

(II) Narrator: We have now come to the end of this session on relationships. Hope it was fun. Your mentor is now going to pause and allow you to ask questions and seek clarifications on issues that were not clear. Mentor, pause and respond.

Narrator: Thank you for participating in today's session. See you next week. 
Session 1 - Hand Washing and Water Storage ${ }^{8}$

Narrator: Hello, girls, welcome to today's session. In this session, we will learn the importance of washing their hands, how to do it, and how to improve the quality of water storage

Narrator: Mentor, for this session you will need a blackboard and chalk OR flipchart markers, tape or tacks, soap, soil, water and 3 basins for hand washing (one for clean water, one for dirty water, one pitcher to pour water)

Narrator: The session will take about 1 hour and 20 minutes.

(II) Narrator: Mentor, pause and ask the participants to share what they learned in the last session. Be sure to clarify any confusing issues.

(II) Narrator: Before, we begin the session, let us have a volunteer to lead us in an energizer. We. Mentor, pause an invite one of the participants to lead the rest in an energizer.

Narrator: Hand washing is one of the most effective means of preventing diarrheal diseases, along with safe stool disposal and safe and adequate household water supply. Diarrheal diseases and respiratory infections are two of the main reasons for childhood illness, and they are both spread by germs. Germs are what make us sick. Hand washing with soap is one of the best ways to get rid of the germs and to prevent the spread of these diseases

(II) Narrator: Girls I would now like to ask you a few questions about hand washing. Please pay attention. The first question is; where can you get access to water and soap to wash your hands? Mentor pause and listen to the feedback.

(II) Narrator: The second question is; what are some of the challenges to regular hand washing? Mentor pause and listen to the feedback.

(II) Narrator: The final question is; when is it important to wash your hand? Mentor pause and listen to the feedback.

8 The Handwashing Handbook: A guide for developing a hygiene promotion program to increase handwashing with soap. http://esa.un.org/iys/docs/san_lib_docs/Handwashing_Handbook.pdf 
Narrator: Well done girls! As you have mentioned, it is important to wash your hands before handling, preparing, or eating food; before feeding someone or giving medicines; and wash hands often during food preparation.

Narrator: It is also important to wash your hands after going to the toilet, cleaning a person who has defecated, blowing your nose, coughing, sneezing, or handling an animal or animal waste, and both before and after tending to someone who is sick.

Narrator: There are five simple steps to washing your hands properly:

1. Wet your hands with clean, running water (warm or cold), turn off the tap, and apply soap.

2. Lather your hands by rubbing them together with the soap. Be sure to lather the backs of your hands, between your fingers, and under your nails.

3. Scrub your hands for at least 20 seconds. Need a timer? Hum the "Happy Birthday" song from beginning to end twice.

4. Rinse hands well under clean water.

5. Dry hands using a clean towel or air dry them.

(II) Narrator: Mentor, please pause and set out the hand washing supplies and demonstrate. Ask for one to two volunteers to come. Put some soil on their hands and see if they are able to get it all off by proper washing. Make sure you show them the dirty water after the girls have washed their hands.

D Narrator: If you use the water that someone else used for washing their hands, the germs in that water and will get back on your hands. You need to have a clean source for the water to pour on your hands in order to get the germs off.

II Narrator: Think about the drinking water in your own homes. Can I have 2-3 volunteers describe where the water is kept for drinking? Is the drinking water treated in any way? Mentor, pause and listen to the responses.

Narrator: In addition to washing your hands, germs can get into the water that we use for drinking and cooking and may make us sick. As we come to the end of this session, please listen to a few key points to keep in mind about water safety:

1. Water in the house that is used for drinking should be separated from other household water

2. We need to make an extra effort to ensure that the water used for drinking is clean so we won't get sick. That can be done through: 
3. Chlorine tablets/water guard that you can get at the shop and put in the drinking water before you drink it

4. Boiling the water

5. Store treated water in an appropriate container preferably in a container/jerrican that has a lid or a narrow jar.

6. If the container does not have a tap, pour the water into a clean jug to serve or use a cup to distribute water.

7. Hang the jug on the wall to avoid contamination.

8. Do not touch the inside of the container with hands.

9. Using filtration systems that may be available

(II) Narrator: Mentor, please pause and give the participants time to ask questions. Be sure to clarify any confusing issues.

Narrator: Thank you very much for participating in today's session. Hope you had fun! See you next week. 


\section{Session 2 - Hygiene with Latrines and Food}

Narrator: Hello, girls, welcome to today's session. In this session, we will learn the importance of hygiene after urinating and defecating, as well as during food preparation

Narrator: Mentor, for this session you will need a blackboard and chalk OR flipchart markers.

Narrator: The session will take about 1 hour and 30 minutes.

(II) Narrator: Mentor, pause and ask the participants to share what they learned in the last session. Be sure to clarify any confusing issues.

(II) Narrator: Before, we begin the session, let us have a volunteer to lead us in an energizer. We. Mentor, pause an invite one of the participants to lead the rest in an energizer.

Narrator: Today we're going to talk about where we relieve ourselves (e.g. go to the bathroom, urinate and defecate). It might be a little bit embarrassing, but as girls it is important that we maintain good hygiene and also stay safe when we are taking care of these needs

(II) Narrator: Girls where are the different places that girls urinate and defecate in your village? Mentor, pause and listen to the responses.

(II) Narrator: Among the ones you have mentioned, which are the most common? Mentor, pause and listen to the responses.

Narrator: It is important that the latrine you use is as clean as possible. Some characteristics of a clean latrine are that:

i. Cleanable floor

ii. A cover over the pit

iii. Housing that provides privacy

iv. A hand washing station nearby (ideally located next to the latrine and/or cooking area).

(II) Narrator: What are some of the challenges that girls like yourselves face in using latrines? Mentor, pause and listen to the responses. 
(II) Narrator: As some of you have mentioned, it is not always safe to go to use the latrine at night. In that case, what do you do? Mentor, pause and listen to the responses.

Narrator: When it is not possible to go to the latrine at night, use improvised containers and make sure that they can be covered or sealed. It's best to not dispose of them at night or just throw them anywhere, but instead dispose of them properly first thing in the morning. Remember that a lot of germs and bacteria that cause diseases are present in feces, so we want to avoid the feces from overnight getting in water sources that would make you or your neighbors sick.

(II) Narrator: Now were going to talk about hygiene in the context of food. Girls, why do you think it is important food should be handled in a hygienic manner? Mentor, pause and listen to the responses.

Narrator: As we come to the end of this session, please keep the following key points related to food hygiene;

1. Keep food preparation areas clean. Wash all surfaces and equipment used to prepare or serve food with soap and water and if possible, with bleach. Protect food from insects, pests, and other animals by covering food with netting, a cloth, or keeping it in containers.

2. Separate raw and cooked food. Raw eggs, meat, milk and vegetables can easily contaminate other foods with illness-causing bacteria. Keep them away from other foods.

3. Use separate equipment and utensils such as knives and cutting boards to handle raw foods. Store foods in covered containers to avoid contact between raw and cooked foods.

4. Cook food thoroughly, especially meat, poultry, eggs, liver, and seafood. For meat and poultry, make sure juices are clear, not pink Bring soups and stews to the boiling point until the first big bubble is seen. Reheat cooked food thoroughly; bring it to a boil or heat it until it is too hot to touch. Stir while reheating.

5. Keep foods at safe temperatures. Do not leave cooked food at room temperature for more than two hours. Reheat cooked food that has been stored before reserving. Do not thaw frozen food at room temperature. Prepare fresh food for infants and young children and other people with compromised immune systems and do not store it after cooking.

6. Use safe water and raw materials. Choose fresh and nutrient-rich foods. Do not use food beyond its expiry date. Use pasteurized milk or boil milk before use. Wash raw vegetables/fruits with treated water or peel the skin before eating. 
(II) Narrator: Mentor, please pause and give the participants time to ask questions. Be sure to clarify any confusing issues. Narrator: Thank you very much for participating in today's session. Hope you had fun! See you next week. 


\section{Session 3 - Menstrual Hygiene}

Narrator: Hello girls! Welcome to today's session. We are going to learn about ways to practice good hygiene during menstruation. By the end of the session you will be able to;

1. Improve hygiene and safety during menstruation

2. Understand the importance of managing menstruation using pads or sanitary napkins

Narrator: Mentor, for this session you will need;

1. Blackboard and Chalk OR Flipchart and Markers

2. A sanitary napkin/pad to use during a demonstration

Narrator: The session will take approximately 1 hour and 50 minutes.

Narrator: but before we begin let us do an energizer, Mentor, pose the recording and ask a volunteer to lead the group in an energizer of their choice. This should take you 10 minutes.

Narrator: Thank you for participating in the energizer that was fun! Mentor, ask participants to share what they learnt during the last session. Add anything that they have left out and clarify any confusing issues. You can now pose and listen to feedback from the girls.

Narrator: Our first activity is understanding the importance of good hygiene menstruation.

Narrator: Menstruation, or a woman's monthly menses, is when blood comes out of the woman's private parts. In future sessions, we are going to talk more about why women menstruate and what happens to a girl in her community once she starts menstruating. However, today we're going to talk about the importance of hygiene during menstruation and ways that we can practice good hygiene during the monthly menses. It might be a little bit embarrassing, but as girls it is important that we maintain good hygiene and also stay safe when we are taking care of these needs.

Narrator: Girls, why do you think it is important to practice good hygiene during menstruation? Mentor, pose and listen to the girls' feedback.

Narrator: From your discussion, you will note that some of the importance of practicing good hygiene during menstruation are; to prevent infections, to prevent bad smells, to prevent accidents/soiling clothing. 
Narrator: The second question is what ways can you practice good hygiene during menstruation? Mentor, pose and listen to the girls' feedback.

Narrator: From your discussion, you will note that some of the ways that you can practice good hygiene during menstruation are: bathing regularly/properly, using sanitary towels (reusable or disposable) properly].

Narrator: Girls, what kinds of materials do women in our village use when they are on their monthly menses and where and how are the materials washed? Mentor, pose and listen to the girls' feedback.

Narrator: There are typically two main ways of managing the blood flow that comes with monthly menses. One is using reusable pads, or clothes/rags, and another is disposable. Using clothes or rags are a very common way of managing menses. Girls and women put these materials inside their underwear/panties to absorb the blood. There are also clothes that are in the shape of a sanitary towel that can be fastened onto one's underwear/panties. All of these should be cleaned daily. It is important to use soap and hot water when washing the clothes/rage/reusable sanitary towels and then hang them up to dry. Do not use them again until they are completely dry or else they could lead to infection.

Narrator: Mentor, you can now pose the recording ask a volunteer to lead the group in an energizer. This should take less than 10 minutes.

Narrator: Girls, disposable pads are also a good way to manage menstruation, if changed often. Disposable means that you use them once, throw it away and never use again. Pads are rectangles of absorbent material, the most common being cotton, that you stick to the inside of your underwear. Some have extra material on the sides that fold over the edges of your underwear to better hold the pad in place and prevent leakage. Sometimes, pads are called sanitary pads or sanitary napkins.

Narrator: Now, we are going to do a demonstration on how to correctly use and dispose pad or sanitary towel. Mentor, pose and do the demonstration.

Narrator: From the demonstration, the mentor explained that, it is important to change pads every 2-6 hours, or more often depending on how heavy the flow is. The mentor also explained that you should dispose the pad by;

1. Wrapping it to make a package so it won't contaminate anything and put it in a bin so it can be burned later. 
2. If there is no other option, drop it straight in the pit latrine as long as it is not a water seal pour flush pan as this could easily become blocked. What is important is that it is somewhere where it won't be able to contaminate any food or water source.

Narrator: There is nothing dirty about menstrual blood, and it is not different than any other blood in your body. It is important to maintain hygiene, if you don't change your pad often, or use damp or wet clothes to absorb the blood, it can cause bacteria and moisture to build up, which can cause yeast infections, skin irritations, and odors. As always, it is also important to wash your hands with soap and water before and after changing your pad.

Narrator: Girls, another question for you, what are some of the challenges you face in practicing these hygiene techniques during menstruation and how can you overcome them? Mentor, pose and listen to the girls' feedback.

Narrator: Some of the challenges you may face in practicing good hygiene during menstruation are; lack of access to disposable pads, lack of privacy to change pads, lack of water to wash disposable pads, lack of privacy to wash/hang disposable pads, etc. Remember, menstruation is a normal thing that happens to every woman. You can talk to older girls in your community or adult females about where to obtain items to help manage your menstruation. It is important that whether you use cloths or disposable pads that you ensure they are clean and dry. Using wet or dirty cloths could cause odor and infection.

Narrator: Girls, do you have any questions? The mentor will now pose and respond to your questions.

Narrator: Thank you for your questions. It is important remember to maintain daily hygiene during menstruation by doing the following;

1. Taking a bath or shower at least once a day.

2. Using clean undergarments and change them regularly.

3. Changing pads, whether made from cloth or disposable, regularly.

4. Washing the genital area with plain water (no soap) after each use of toilet and even after urination.

5. Keeping the area between the legs dry, otherwise you may experience skin irritation or rash.

6. Finally, it is very important to remember that the vagina has its own self-cleaning mechanism and an external cleaning agent like deodorant or soap should not be used inside it.

Narrator: If there is little water, try to wash daily using 2 small containers of water. Use one with soap and a clean sponge or cloth to rub the soapy water over your body. Use the water from the other to wash the soap off. 
You may notice a vaginal odor during your periods but it is unlikely to be noticed by anyone else if you are washing yourself and changing your underwear regularly. Clear or slightly yellow or milky mucus coming from the vagina is normal vaginal discharge. However, a change in the color or smell of the discharge, a strong vaginal smell unconnected to periods, burning, itchiness or pain can be signs of infection. If this happens, visit a clinic.

Narrator: We are almost coming to the end of the session, but before we finish, I would like to ask you a few questions.

1. Why do you think it is important to maintain hygiene during menstruation? Mentor pose for about 10 minutes, listen to the feedback and clarify if need be.

2. What are some of the challenges for girls in maintaining hygiene during menstruation? Mentor pose for about 10 minutes, listen to the feedback and clarify if need be

3. What are specific ways you can practice hygiene during menstruation? Mentor pose for about 10 minutes, listen to the feedback and clarify if need be.

Narrator: We have now come to the end of today's session. Thank you very much for your active participation. See you next week, same time and the same place. Goodbye! 


\section{NUTRITION}

\section{Session 1: Nutrition Needs for Adolescent Girls.}

Narrator: Hello girls! Today we will talk about nutrition and importance of good health.

Narrator: Mentor, for this session you will need a blackboard and chalk OR flipchart and markers.

Narrator: The session will take about 1 hour and 30 minutes.

II Narrator: We will begin today's session with an energizer from a volunteer. Mentor, pause and request for a volunteer to lead the energizer.

(II) Narrator: I hope the energizer was fun! Mentor, ask participants to share what they learnt during the last session. Remember to add anything that they have left out and clarify any confusing issues. You can now pause, listen and provide feedback.

Narrator: In this session, you learn about food and nutrition and how to make healthy food choices. This is because food and nutrition are important to our health. If we have good nutrition we can grow strong and stay healthy for the rest of our lives.

(II) Narrator: I will begin by asking you a question. What did you eat for breakfast (or lunch) and why did you eat that food you have mentioned? Mentor, pause and listen to the responses.

Narrator: What we eat affects every part of our lives. It can make us feel good or sick, it can help us grow, and it can give us energy to help keep us healthy.

(II) Narrator: We are now going to learn about the role of food in the body. Girls, what does nutrition mean? Mentor, pause and listen to the responses.

Narrator: Nutrition is what we get from food. What we eat or drink is broken down into tiny pieces called nutrients. Nutrients are food elements that the body needs. The nutrients give our bodies' energy and other benefits so that we can walk, run, work, play, grow, and fight sickness. 
To have good nutrition and remain healthy we must eat a variety of foods each day

Narrator: Foods are grouped into six main food groups;

$\checkmark$ Cereals and tubers examples include; maize, sweet potatoes, arrow roots.

$\checkmark$ Fruits

$\checkmark$ Vegetables

$\checkmark$ Meat and poultry. For example; chicken dry beans, fish eggs and nuts,

$\checkmark$ Milk, yogurt, ghee

$\checkmark$ Fats, oils and sweets

Narrator: To meet the nutrient needs important for good health, you need to eat a variety of foods from each of the different food groups daily. It is important to enjoy a variety of foods within each food group because different foods have different key nutrients called vitamins, minerals, proteins and carbohydrates; that the body needs to stay strong and healthy. The body uses these nutrients to build our muscles, bones, blood, hair, nails, cells, tissues and many more parts and keep them strong and healthy.

Narrator: Mentor, pause and conduct an energizer.

Narrator: Welcome back! We will now learn ways of making balanced meals with the right kinds of food eaten together. Food can be categorized as Staple (main food), Go, Grow and Glow.

Narrator: STAPLE foods include cereals and grains (wheat, maize, rice, millet and sorghum), starchy roots (potatoes, cassava) and starchy fruits (bananas). These foods provide the body with energy.

(II) Narrator: Girls, can you name other STAPLE foods that are locally available? Mentor, pause and lead the discussion.

Narrator: GO foods include oils, nuts, oil seeds, fatty meat, and, sugar, honey, and sugar cane. These foods help the body to have energy to run, play, work, think and generally to keep the body in good working condition.

(II) Narrator: Can you name other GO foods that are locally available? Mentor, pause and lead the discussion.

Narrator: GROW foods are foods high protein foods. These include legumes for example, peas, beans, oil seeds e.g. groundnuts and food that come from animals e.g. meat, milk, chicken, fish, eggs and liver. When eaten with staple foods, these foods help the body to grow well and stay healthy. 
(II) Narrator: Can you name other GROW foods that are locally available? Mentor, pause and lead the discussion.

Narrator: GLOW foods are rich in vitamins and minerals. These foods include dark green leafy vegetables such as spinach, kunde, sukuma wiki; tomatoes and carrots and fruits like mangoes, oranges, guavas. Also included are chicken, eggs, meat, fish, milk and liver. All these foods are excellent sources of vitamins and important elements that are used by the body. Glow foods keep us healthy and help the hair, eyes and skin to look shiny or to "glow".

II Narrator: Can you name other GLOW foods that are locally available? Mentor, pause and lead the discussion.

(II) Narrator: We shall now talk about meal planning using the staple, go, grow and glow guiding principle. Girls, why is it so important to eat different kinds of foods from each of the food groups? Mentor pause and listen to the feedback.

Narrator: It is important to enjoy foods from each of the food groups because different foods provide us with different amounts of key nutrients. It is not necessary to eat from each food group at EVERY meal but make sure that you eat from ALL food groups by the end of the day.

(II) Narrator: What do you think might happen to a girl who eats only two kinds of food at every meal for example ugali and nyrinyri or rice and meat? Mentor pause and discuss the responses.

(II) Narrator: How can you be sure that you are getting the nutrients needed? Mentor, pause and discuss the responses.

Narrator: If we eat a variety of foods from all the food groups, we will get a mixture of nutrients required by the body for growth and strength. It is important to eat a variety of foods from each of the food groups in order to GO, GROW and GLOW!

II Narrator: We have now come to the end of the session. Before we conclude, please ask the mentor questions or clarifications. Mentor, pause and respond to the questions.

Narrator: I hope you enjoyed today's session. See you next week! Goodbye. 


\section{Session 2: Anemia in Adolescent Girls}

Narrator: Hello, today we will talk about signs, causes and dangers of anemia in adolescent girls.

Narrator: Mentor, for this session you will need a blackboard and chalk OR flipchart markers.

Narrator: The session will take about 1 hour and 30 minutes.

III Narrator: Mentor, pause and ask the participants to share what they learned in the last session. Be sure to clarify any confusing issues.

(II) Narrator: Before, we begin the session, let us have a volunteer to lead us in an energizer. We. Mentor, pause an invite one of the participants to lead the rest in an energizer.

Narrator: Good eating habits can help us keep our bodies and minds healthy and strong. Other ways healthy eating can help us include keeping us alert and strong by helping our bodies fight sickness and disease. There are lots of healthy foods, unhealthy foods, and foods where we are not sure if they are health or unhealthy.

(II) Narrator: Mentor, pause and write the words healthy, unhealthy and not sure on 3 different pieces of papers and stick them in three different places on the wall.

Narrator: Thank you mentor for sticking the words. Girls, I would not like to read out some foods then you will stand up and move to the area where the food belongs. That is; health, unhealthy or not sure corner.

(II) Narrator: Are you ready? Soda. Mentor please pause and allow the participants to move.

(II) Narrator: Soda is unhealthy. What about rice? Mentor please pause and allow the participants to move.

(II) Narrator: Rice is healthy. Milk? Mentor please pause and allow the participants to move.

(II) Narrator: Milk is healthy. What about pasta? Mentor please pause and allow the participants to move.

II Narrator: Pasta is healthy if eaten in small amounts. Sugar? Mentor please pause and allow the participants to move. 
(II) Narrator: Sugar is healthy if taken in small amounts. Biscuits? Mentor please pause and allow the participants to move.

(II) Narrator: Biscuits is unhealthy. Oil? Mentor please pause and allow the participants to move.

(II) Narrator: Oil is healthy if taken in small amounts. Sweets? Mentor please pause and allow the participants to move.

(II) Narrator: Sweets are unhealthy. Oranges? Mentor please pause and allow the participants to move.

(II) Narrator: Oranges are healthy. Ugali? Mentor please pause and allow the participants to move.

II Narrator: Ugali is healthy if consumed in small amounts. Nyirnyir? Mentor please pause and allow the participants to move.

(II) Narrator: Nyirnyir is healthy. Lastly sukumawiki? Mentor please pause and allow the participants to move.

Narrator: Sukumawiki is healthy. Thank you for participating in the activity. Hope it was fun!

Narrator: Different foods affect our bodies differently. If you put fresh fruits and vegetables, whole grains and nuts, or food filled with lots of vitamins and nutrients into your body, your body will grow and feel strong. If you eat more food that is not healthy as compared to food that is healthy your body will not like it and you will have less energy, feel less well and get sick easier.

II Narrator: Are the foods on the "healthy" section found in our community? Mentor pause and listen to the responses.

Narrator: As you can see, there are many healthy foods in our community. This means that it is possible to eat healthy food and live a healthy life. All we need to do is stop a while and think about what we eat to make the right food choices.

Narrator: We are now going to do an activity that will help us to learn anemia which is a health problem that affects many people, especially adolescents' girls

(II) Narrator: Does anyone know what anemia means? Mentor, pause and listen to the feedback.

Narrator: Anemia is a health condition that occurs when the blood does not have enough of one very important nutrient we get from food called iron. When you don't have enough iron in your blood, you are anemic. 
Narrator: Adolescent girls can become anemic because they don't eat enough of the right kinds of food and because of their periods. When girls are on their periods, the amount of iron in their blood can drop through blood loss.

Narrator: When you are anemic and have too little iron in your blood, you can feel very weak and tired. You can also feel dizzy from time-to-time. You may also have pale palms, feel breathless, experience headaches and may be too weak to do physical work.

Narrator: In order to prevent anaemia we have to eat food with enough iron.You can get enough iron in your blood by eating good food with lots of iron such as fish, chicken, liver, eggs, Soya, beans and groundnuts, dark green leafy vegetables (spinach, sukumawiki)

Narrator: It is important to eat foods that have lots of iron in them at every meal. Eating plenty of dark green leafy vegetables in addition to eating fruits after meals can give you enough iron to keep you strong and healthy.

(II) Narrator: We have now come to the end of today's session. The mentor will now pause the recording and allow you to ask questions and clarifications. Mentor, please pause and respond to questions.

Narrator: Thank you girls for participating in the session. Hope you learnt something useful. See you next week. Inshallah! 


\section{Life Skills}

\section{Session 1 - Self-Esteem}

Narrator: Hi girls! Today we will learn about self-esteem and self-image. In this session, we will be able to identify qualities that we admire most about ourselves and areas we would like to improve.

Narrator: Mentor, for this session you will need;

1. Blackboard and chalk OR flipchart and markers

2. Paper and pens/pencils for each participant

3. Masking Tape, pins, paper clips for each participant

Narrator: The session will take about 1 hour and 30 minutes.

(II) Narrator: Girls, we will begin today's session with an interesting energizer called "I like". Mentor, ask the girls to sit in a circle and say what they like about the person on their right. Give the group two minutes to think. Mentor, you can now pause and conduct the energizer.

(II) Narrator: I hope the energizer was fun! Mentor, ask participants to share what they learnt during the last session. Remember to add anything that they have left out and clarify any confusing issues. You can now pause and listen to feedback their girls.

(II) Narrator: Thank you girls for sharing what you learnt last time! For this session, we will begin with an activity called "A pat on the back." Mentor pause and give each girl a piece of paper and ask them to write their name at the top of the paper and stick the paper on their back.

Narrator: I know that we all have some positive things that we would like to say to each other, but sometimes we forget to tell each other the good things. The exercise we are about to do will give us an opportunity to share positive things about each other and have some fun at the same time.

(II) Narrator: Now think about the different girls in our safe space. What positive words would you use to describe each person? What happy message would you like to give to different people in the room? Mentor Pause and allow the girls to think for 2 minutes. 
(II) Narrator: Girls, now we are going to write those nice things you have thought about, When the Mentor says, "Go!" you should move around and write one (or two) word(s) on each other's papers. Remember we are only writing/talking about the positive things and not negative

Mentor, pause and tell the girls to 'Go'. This exercise should take 5 minutes.

(II) Narrator: I hope that was fun! You can now remove the papers from your back and read all the positive things that your fellow participants think about you. Mentor, pause and allow the girls to look at their papers for 2 minutes.

Narrator: We are now going to do another interesting activity called 'Who am I." Mentor, please make sure each girl has a notebook (or piece of paper) and pencil.

(II) Narrator: Girls, when you look at yourself, what are some of the things that describe you? How do you see yourself? Now, write 10 sentences that start with the words, "I am..." or draw a picture that includes 10 things to describe themselves. An examples might be: "I am an intelligent young woman." Or "I am a really good friend to others." This exercise is for personal use, only those who want to share will do so at a later stage. Mentor, pause and allow the girls 5 minutes to write/ draw.

(II) Narrator: I hope you have written / drawn things that describe you. Now, please tick the things you like about yourself and put a question mark next to the things you want to change. Mentor, pause and give the girls 2 minutes.

II Narrator: Girls, when you look at your list/ drawing, would you say that you feel good about yourself in general, or are there many things you feel you need to improve on? Mentor, pause and give those who might want to share to do so.

(II) Narrator: In this last activity, we will talk about self-esteem and try to understand where it comes from. Mentor, pause for 2 minutes and ask the participants to share their understanding of the word self-esteem. List the answers on the flipchart or blackboard.

Narrator: From your discussion with the mentor, you have noted that the word self-esteem means [How you see yourself, believing that you are worth a lot, personal strength, etc.]

Narrator: Having good self-esteem is an important part of building good decision-making, communication, and thinking skills.

(II) Narrator: Girls, where do you think self-esteem comes from? Mentor, pause and write the girl's feedback on a flipchart or blackboard. 
2 Narrator: Self- esteem comes from how your parents raise you or treat you, belief in God image of girls or boys in the community, treatment by brothers, sisters, other family members, personal reflection on our lives, among other sources.

(II) Narrator: We are almost coming to the end of today's session but before we do that, please stand up one by one and read out all the nice things your friends wrote about you in the "A Pat On the Back" activity. You will begin by saying "My name is.... then read out all the things that were written on your piece of paper. Mentor, pause and explain the activity.

II Narrator: We have now come to the end of today's session. Do you have any questions for your mentor? Mentor, pause and respond to any questions.

Narrator: Thank you very much for your active participation in today's session. See you next week. Bye. 


\section{Session 2: Passive, Assertive, Aggressive ${ }^{9}$}

Narrator: Hi girls! Today we will learn about passive, aggressive and assertive behaviors. In this session, we will learn about attacking and avoiding behaviors, and perform role-plays to practice identifying passive, assertive and aggressive behaviors.

Narrator: Mentor, for this session you will need a blackboard and chalk OR flipchart and markers.

Narrator: The session will take about 1 hour and 30 minutes.

(II) Narrator: We will begin today's session with an energizer of about 5 minutes. Mentor, pause and ask a volunteer to lead the group in an energizer.

(II) Narrator: I hope you enjoyed the energizer! Mentor, pause and ask the girls to share what they learnt during the last session. Please remember to clarify any confusing issues.

Narrator: We will begin today's session by differentiating assertive, passive and aggressive behavior. For you go understand the three words, we will begin by discussing our understanding of the words attacking and avoiding.

(II) Narrator: Girls, what are some of the attacking behaviors that you know? Mentor, pause and record the girl's feedback on the blackboard or flip chart

(II) Narrator: Thank you for your responses. Can we now give examples of "avoiding" behaviors? Mentor, pause and record the girl's feedback on the blackboard or flip chart.

Narrator: Some examples of attacking behaviors are:

Nagging, Shouting, Persisting (I am right!), Revenge (I'll get you back, Warning (If you don't...) Interrupting, Exploding, Sarcastic, Insulting,

Narrator: Some examples of avoiding behaviors are:

\footnotetext{
9 Peace Corps. 2001. Information Collection and Exchange Publication: Life Skills Manual; Kenya Adolescent Reproductive Health Project (KARHP), PATH, Population Council. 2005. Tuko Pamoja: Adolescent Reproductive Health and Life Skills Curriculum.
} 
Withdrawal, Sulking in silence, Taking it out on the wrong person, Saying that you are being unfairly treated, Talking behind someone's back, Feeling ill, Being polite but feeling angry, Feeling low and depressed, Not wanting to hurt the other person, Trying to forget about the problem.

Narrator: In this session we are going to talk in depth about "attacking" and "avoiding" behaviors. "Attacking" behavior, is when someone explodes or interrupts and persists. This is type of behavior is also called "aggressive" behavior. On the other hand examples of "avoiding" are behaviors like sulking in silence or trying to forget about something. This type of behavior is also called "passive"

(II) Narrator: Which type of behavior is better? Mentor, pause and record the responses on a flip chart or blackboard.

(II) Narrator: Are either of them the best type of behavior? Mentor, pause and record the responses on a flip chart or blackboard.

(II) Narrator: Is there another way to act? Mentor, pause and record the responses on a flip chart or blackboard.

II Narrator: What would be a better approach to interacting with each other? Mentor, pause and record the responses on a flip chart or blackboard.

Narrator: The best way to interact with one another is by being assertive. "Assertive" behavior means [delivering a message by honestly expressing one's thoughts and feelings, being direct and clear without putting down the rights of others; showing mutual respect]

Narrator: To be "assertive", it is not necessary for someone to be in the powerful or powerless position-in other words, it is not necessary to attack or avoid. Instead, it is possible to reach a balance between attacking and avoiding behaviors. We call this type of behavior "assertive."

(II) Narrator: Is it okay for a girl in your community to be firm about a decision and stand up for their rights, when they feel violated? For example can a girl can stand up and say no to issues which she considers not right e.g. marrying her off without her consent? Or can a girl ask her parents to enroll her to school if she is not in school? Mentor pause and discuss the responses by asking the girls to clarify reasons for their responses. For example if a girl says no she cannot change a decision regarding her marriage why does she think it's not possible, and for those who say yes how can they influence the decision, what ways will they use to influence the decision of not getting married early. 
Narrator: I would now like to tell you a very interesting story. So listen carefully because I will ask you some questions related to the story.

\section{Abishiro's Story}

Abshiro and Genya are friends and go to the same school. One day Genya asked Abshiro to lend her her English text book to finish her homework as Genya did not have a copy of the book, and her desk mate in school had gone with it. Abshiro gave Genya the book but upon returning it, it had missing pages. Abshiro was very annoyed and shouted at Genya and promised she would never lend her a book anymore, and even told her that they would never be friends again. Genya looked down and walked away without saying anything to Abshiro.

(II) Narrator: Was Abshiro's behavior passive, assertive, or aggressive? Mentor. Pause and listen to the responses

Narrator: Very good! Abshiro's behavior was aggressive. Aggressive behavior means:

$\checkmark$ Expressing your feelings, opinions, or desires in a way that threatens or punishes the other person

$\checkmark$ Standing up for your own rights with no thought for the other person

$\checkmark$ Putting yourself first at the expense of others

$\checkmark$ Overpowering others

$\checkmark$ Reaching your own goals, but at the sake of others

$\checkmark$ Dominating behaviors - for example: shouting, demanding, not listening to others; saying others are wrong; leaning forward; looking down on others; wagging or pointing finger at others; threatening; or fighting

(II) Narrator: What did Abshiro say or do to make you decide she was aggressive? Mentor. Pause and listen to the responses.

Narrator: Very good! Abshiro shouted at Genya and told her that they would never be friends with her again. She also told Genya that she will never lend her a book again

Narrator: I am now going to tell you the second story so listen carefully. 


\section{Ebla's Story}

Ebla likes playing with her friends a few meters away from home. Usually on her way back home, a certain older boy from school called Yussuf tries to call her aside. She does not like it because this means something else when they are seen together. One day after playing she calls her friend Amina and instructs her to accompany her home. On their way, Yussuf stops them and Ebla explains to him that it is wrong and that she does not like his behavior. Yussuf apologizes and Amina pats Ebla on her back impressed by her courage.

(II) Narrator: Was Ebla's behavior passive, assertive, or aggressive? Mentor. Pause and listen to the responses.

Narrator: Very good! Ebla's behavior was assertive. Assertive behavior means:

$\checkmark$ Telling someone exactly what you want in a way that does not seem rude or threatening to them

$\checkmark$ Standing up for your own rights without putting down the rights of others

$\checkmark$ Respecting yourself as well as the other person

$\checkmark$ Listening and talking

$\checkmark$ Expressing positive and negative feelings

$\checkmark$ Being confident, but not "pushy"

$\checkmark$ Staying balanced—knowing what you want to say; saying "I feel" not "I think"; being specific; using "I" statements; talking face-toface with the person; no whining or mocking; using body language that shows you are standing your ground, and staying centered

(II) Narrator: What did Elba do/ say to make you decide she was assertive? Mentor, pause and listen to the responses.

Narrator: Elba was assertive because she spoke in calm, firm voice, discussed her needs; made her feelings clear, checked to see if Yusuf was comfortable with her statements

(II) Narrator: Girls, we are almost coming to the end of today's session but before we wind-up please ask your mentor any questions or clarifications. Mentor, pause and respond.

Narrator: Thank you for your active participant in today's session. See you next week. Inshallah! 


\section{Session 3: Reasons to Delay Marriage 10}

Narrator: Hello and welcome to today's session! In this session, we will discuss some of the reasons why it is important to delay marriage.

Narrator: Mentor, for this session you will need a blackboard and chalk OR flipchart and markers

Narrator: The session will take about 1 hour and 30 minutes.

(II) Narrator: We will begin today's session with an energizer of about 5 minutes. Mentor, pause and ask a volunteer to lead the group in an energizer.

(II) Narrator: I hope you enjoyed the energizer! Mentor, pause and ask the girls to share what they learnt during the last session. Please remember to clarify any confusing issues.

Narrator: Today we will talk about marriage of girls in our community including the time when they get married. We know that getting married is very important, but there can be some benefits if girls wait just a little bit longer to get married, so that they can grow a bit more and finish school.

Narrator: I will begin the session by narrating to you a story. Listen carefully because I will ask questions at the end of the story

10 Peace Corps. 2001. Information Collection and Exchange Publication: Life Skills Manual; World Health Organization. 1994. School Health Education to prevent AIDS and STD: A Resource Package for Curriculum Planners; Kenya Adolescent Reproductive Health Project (KARHP), PATH, Population Council. 2005. Tuko Pamoja: Adolescent Reproductive Health and Life Skills Curriculum. 


\section{Hassan's Story}

Hassan is 21 years old and helps his uncle in his shop. His parents are hard-working and hold traditional values. They believe that young people should not have sex before marriage. Hassan is quite shy but would like to have a young wife because most of his friends are already married.

Isniino is 14 but appears and acts older. Her sister got married when she was 14 so she dropped out of school during class seven and has been wishing she can go back to school as her friends who finished primary school, have now moved to secondary school. Isniino has not known Hassan for very long, but she thinks he would make a good husband. She is also in her final year of primary school and wishes to complete primary and secondary school before getting married. She is afraid, however, that she might lose Hassan if she refuses to marry him.

She confides to her educated aunt, who is a secondary school teacher, and her aunt advices her to concentrate on her education. Isniino followed her auntie's advice and she is now proceeding to Wajir Secondary School; after scoring good marks in her KCPE. She is grateful to her auntie for advising her in good time.

Narrator: Mentor, draw two columns on the backboard or flipchart and write "Reasons for Getting Married Right Away" on one column and "Reasons for Waiting to Get Married." On the other column.

(II) Narrator: I promised to ask you questions after the story. The first question is what were some reasons for getting married in the story? Mentor, pause and listen and record responses on the "Reasons for Getting Married Right Away" column.

Narrator: Some of the reasons for getting married in the story are: To prevent their relationship from ending, because everyone else is married, because it felt right, because one partner convinces the other that there will be no problems, if both are comfortable with the decision, it is expected by society that by age 14 one can get married]

(II) Narrator: What were some reasons to delay marriage in the story? Mentor, pause and listen and record responses on the "Reasons for Waiting to Get Married." column.

Narrator: The reasons from the story are; education aspirations- the need to complete school, allow the relationship to grow more first, other forms of affection are possible, religious values do not approve of sex before marriage, do not feel ready, are too young

(II) Narrator: What are some of the reasons why girls in your community get married? Mentor, pause and listen to the responses. 
(II) Narrator: Now we will come up with a working list that you all agree on as the top 10 reasons to delay marriage. Mentor, pause, listen and record the responses on a flipchart or blackboard.

Narrator: From your discussion with the mentor, you have also listen the following as reasons to delay marriage;

1. Future aspirations for getting meaningful employment and fend for one self and family.

2. Waiting to have children, which is an obligation for a married woman, until the girls are a bit older and more physically and mentally mature.

3. The family will be proud when one completes school and has a job.

4. Fear of violence - in a marriage situation, there is the possibility of being forced to have sexual intercourse, despite the girl not being ready

5. Friendship - Allow time for the friendship to develop and grow your career through education and training.

6. Better health outcomes for the girl since her body will mature with time

7. Allows for personal development and enjoyment of human rights.

8. Not ready - you feel too young or just not ready.

9. Waiting for the right person - you want the person to wait for you' until you finish education and get a job before you get married.

10. Wait until when you have completed education and started your career

(II) Narrator: We have come to the end of today's session. You can now ask the mentor any questions. Mentor, pause and respond to questions and or clarify confusing issues.

Narrator: Thank you for participating in today's session. See you next week.

Session 4: Drugs, and Other Mind Altering Substances ${ }^{11}$

Narrator: Hello, today we will talk about drugs and other mind altering substances.

Narrator: Mentor, for this session you will need a blackboard and chalk OR flipchart markers.

${ }^{11}$ RAPIDS/Consortium in Zambia. RAPIDS Youth Life skills Training Manual. Prepared by Motivational Centre for Africa's Transformation (MoCAT) for AFRICARE. 
Narrator: The session will take about 1 hour and 30 minutes.

II Narrator: Mentor, pause and ask the participants to share what they learned in the last session. Be sure to clarify any confusing issues.

(II) Narrator: Before, we begin the session, let us have a volunteer to lead us in an energizer. We. Mentor, pause an invite one of the participants to lead the rest in an energizer.

Narrator: The term "drug" generally includes medicines, substances used for the treatment or prevention of disease. Drugs of this type are generally easily available, though some may require a prescription. 'Mind altering substances' are also drugs, but they are used to achieve altered states of consciousness. Both can harm the body; both can be abused.

Narrator: Drugs used for the treatment or prevention of disease are called medicine. But even medicine can be harmful if used excessively or improperly. When we are sick, medicinal drugs may be given in prescribed doses to cure our illness. Medicinal drugs are legal, meaning they are permitted by law, in certain doses. Some non-medicinal drugs are legal, like tobacco or alcohol.

Narrator: Many drugs are illegal, meaning they are not permitted by the law and someone can get in trouble for using them. These drugs usually have extreme effects on the mind and body. Some examples of illegal drugs in Kenya include: cocaine, heroin, mandrax, opium, and cannabis commonly known as Bhangi.

Narrator: The "use" and "abuse" of drugs and alcohol are not the same. Use of drugs may come before abuse of drugs and does not necessarily lead to abuse. Drug abuse is not defined by frequency of drug use alone but also considers the age of the drug user, physiological responses, levels of dependency, attitudes about substance use, and the effects that the drug uses has on other areas of the user's life.

(II) Narrator: Girls, what are some examples of different types of medicine that can be abused? Mentor, pause and listen to the responses.

Narrator: As you have mentioned, some of the drugs that can easily be abused include; Cortem which can be used for treating malaria, but if deliberately taken in high doses, it can terminate an unwanted pregnancy, which is regarded as an abuse of that drug, also Panadol may be ideal for aches and pains, but can be abused if taken for any and every slight discomfort. 
Narrator: Drugs used to create an altered state of consciousness are called mind-altering substances. Drugs that speed a person up are called "stimulants", e.g. tobacco, cocaine. Drugs that slow a person down are called "depressants," e.g. alcohol, sleeping pills. Drugs that change the way a person feels, sees and hears are called "hallucinogens", e.g. Mandrax, bhangi. There is still another category of substances used neither medicinally nor recreationally but to alter the body's functioning nonetheless. These would include drugs like diet pills. Tobacco and alcohol are among the most widely used "recreational" drugs.

Narrator: I would now like to ask you a few questions related to drugs. Are you ready?

(II) Narrator: The first question is, what are some examples of drugs that you know. Mentor, pause and listen to the responses.

(II) Narrator: What are the possible effects of the drugs you have mentioned? Mentor, pause and listen to the responses.

(II) Narrator: How do the drugs you have mentioned look like? Mentor, pause and listen to the feedback.

(II) Narrator: How are those drugs used? Mentor, pause and listen to the feedback. 
Narrator: Thank you very much for your feedback! I am now going to mentioned some commonly abused drugs and their side effects. Please listen attentively;

\begin{tabular}{|c|c|}
\hline $\begin{array}{l}\text { 1. Nicotine (the substance in } \\
\text { cigarettes) } \\
\text { A highly addictive stimulant }\end{array}$ & $\begin{array}{l}\text { Increases heart rate constricts blood vessels causing } \\
\text { the heart to work harder }\end{array}$ \\
\hline $\begin{array}{l}\text { 2. Alcohol } \\
\text { Addictive depressant }\end{array}$ & $\begin{array}{l}\text { Drunkenness loss of coordination personality } \\
\text { changes interferes with learning and memory } \\
\text { increase in accidents increase in destructive acts }\end{array}$ \\
\hline $\begin{array}{l}\text { 3. Marijuana } \\
\text { Hallucinogen, stimulant, and } \\
\text { depressant (all) }\end{array}$ & $\begin{array}{l}\text { Altered perception slowed reflexes poor memory } \\
\text { short attention span. }\end{array}$ \\
\hline $\begin{array}{l}\text { 4. Inhalants } \\
\text { Jenkem, gasoline mind altering } \\
\text { substance }\end{array}$ & May cause serious, permanent damages to liver. \\
\hline $\begin{array}{l}\text { 5. Miraa/Khat } \\
\text { Khat is a drug that creates } \\
\text { "dependence" in people, } \\
\text { meaning it produces a } \\
\text { continuing desire to keep } \\
\text { using it }\end{array}$ & $\begin{array}{l}\text { Mood changes, increased alertness, excessive } \\
\text { talkativeness, hyperactivity, excitement, } \\
\text { aggressiveness, anxiety, paranoia. Trouble } \\
\text { sleeping(insomnia), loss of energy (malaise), and } \\
\text { lack of concentration }\end{array}$ \\
\hline
\end{tabular}

(II) Narrator: Girls, what does the term "addiction" mean? Mentor, pause and listen to the feedback.

Narrator: Correct, addiction is the condition of being dependent on a substance, thing, or activity.

Drug addiction occurs when the normal functions of the body are altered in such a way that the body begins to require the drug to function. Addiction can be psychological or physical, depending on the drug. The person who is addicted cannot function normally without the drugs of addiction. Many people cannot function without the stimulant caffeine found in coffee, tea and an assortment of softies. Some cannot socialize without alcohol or bhang. Without the drugs, the addict feels poorly, is anxious and restless and may even neglect him or herself. Drug addiction is a serious problem requiring professional help to break the habit.

(II) Narrator: What are some of the serious consequences that can result from drug use? Mentor, pause and listen to the feedback. 
Narrator: Some of the serious consequences are;

1. young people's normal growth and development is often stopped,

2. drug abuse and addictive behaviors interfere with the establishment of healthy relationships,

3. drug use impairs judgment in critical areas,

4. accidents, missed opportunities unintended pregnancies, academic failure and STI infections are more likely when you can't think straight, and

5. drug addiction and alcoholism also diverts needed financial resources from more constructive endeavors]

(II) Narrator: We are almost coming to the end of the session. Mentor, please pause and allow the girls time to ask questions. Be sure to clarify any confusing issues.

Narrator: Thank you for participating in today's session. I hope you have learnt something useful! See you next week. 


\section{Session 5: Peer Pressure 12}

Narrator: Hello girls! Welcome to today's session. We are going to learn what peer pressure is and explore ways of resisting peer pressure. By the end of the session you will be able to;

- Describe common situations faced by young people

- List several strategies for dealing with peer pressure

- Identify the strategies they are most comfortable with

Narrator: Mentor, for this session you will need; various props for the role-plays such as

- empty bottles,

- radios with tape players,

- cloth or clothes, and others

- Training aid "Peer Pressure Scenario Cards"

(II) Narrator: The session will take approximately 1 hour and 25 minutes. But before we begin let us do an energizer, Mentor, pause the recording and ask a volunteer to lead the group in an energizer of their choice. This should take you 10 minutes.

(II) Narrator: Thank you for participating in the energizer that was fun! Mentor, ask participants to share what they learnt during the last session. Add anything that they have left out and clarify any confusing issues. You can now pause and listen to feedback from the girls.

Narrator: Peer Pressure is Influence on another person's decisions to control them into following certain behaviors or beliefs of people in their group.

(II) Narrator: We are now going to work in 3 small groups. I will then read out a story for each group and the mentor will help you create a role play showing how the situation can be handled assertively. You will then create a role-play showing the situation and how the young person resists peer pressure, and finally perform it for the larger group. Mentor, now pause for 5 minutes and divide the girls into 3 small groups.

\footnotetext{
12Peace Corps. 2001. Information Collection and Exchange Publication: Life Skills Manual; Kenya Adolescent Reproductive Health Project (KARHP), PATH, Population Council. 2005. Tuko Pamoja: Adolescent Reproductive Health and Life Skills Curriculum.
} 
Narrator: We are now in our small groups, I am now going to read out the scenario for each group starting with group 1

Group 1. A group of girls are sitting together and talking about the latest hijabs that they saw during their cousin's wedding. They start making fun of one of the girls who has not been able to buy any new clothes lately. The girls say that she doesn't have the money. The other girls tell her that she should ask for money from Hassan, her neighbor who is 10 years older than she is. The girl says that she knows he would give the money, but then he would eventually expect her to have relations with him.

Create a role-play showing how this girl could handle this situation assertively.

Group 2. A group of primary school girls are leaving school in the evening. Then one of the girls tells the others to pass by her older brother's shop at the market for drinking water. When they get to the shop the girl not only gives them water but she also introduces miraa and shows the girls how to chew the miraa. She influences some girls to spend time with her chewing miraa but others refuse and head home.

Create a role-play showing how the friends who do not agree could handle this situation.

Group 3. A group of friends have gone to fetch water, they finish fetching water and start discussing school work, one of them is very bored with the school discussion and decides to influence the other girls to walk her to her cousin's place where there are wedding preparations so that they can steal some henna, after they finish fetching water. Some of the friends agree-excited to do something on this boring day! As the group walks to the cousin's place, one of them is not comfortable with the idea and suggests that they go to her place and review some exam questions together. To convince her friends not to steal, she explains to them the dangers of stealing. She also explains how exciting and fun it will be for all the friends to study together and learn from one another.

Narrator: Thank you for participating, now let us talk about the role plays.

1. Was the role-play realistic? Mentor pause and listen to the girls views.

2. Would the resistance demonstrated actually work in the situation? Mentor pause and listen to the girls views.

3. Is this a common situation in our communities? Mentor pause and listen to the girls views. 
Narrator: Girls thank you for sharing. we have learnt how we can overcome peer pressure.

Narrator: Girls in our second activity, we are going to continue discussing about Peer pressure. Mentor now Facilitate a discussion by getting feedback for the following questions. Pause after each question.

\section{Q 1: What is peer pressure? Mentor pause and listen to girl's feedback.}

Narrator: we have heard peer pressure is social pressure by members of one's peer group to take a certain action, adopt certain values, or otherwise conform in order to be accepted. Now the next question

\section{Q 2: What types of peer pressure do you face? Mentor pause and listen to girl's feedback}

Narrator: we have heard that some of the peer pressure you may face are E.g. pressure to wear certain clothes, pressure to like certain things, pressure to do certain things, pressure to try taking drugs, pressure to get married, etc. The next question.

\section{Q 2: Where does peer pressure come from? Mentor pause and listen to girl's feedback}

Narrator: we have heard peer pressure may be present at school, home, or in the community. The next question

\section{Q3: Why does peer pressure arise? Mentor pause and listen to girl's feedback}

Narrator: We have heard someone may tell you what to do, sometimes you think it in your own head - feeling different from the group, sometimes it happens naturally if you and your peers normally do certain activities or have certain habits. The next question.

\section{Q 4: How can one avoid or manage peer pressure? Mentor pause and listen to girl's feedback}

Narrator: We have heard that one can avoid or manage peer pressure by hanging out with people who have the same interests as you, say 'no' using assertive techniques, stand-up for someone to help them feel it is okay to do what they choose, try not to judge others. The last question

Where can someone go for help if they face too much peer pressure? Mentor pause and listen to girl's feedback 
Narrator: We have heard that one can go to e.g. older siblings, close friends, parents, teachers, community leaders, mentors, etc.

Narrator: That brings us to the end of our session today. Thank you for your active participation and see you next week same place, same time. Good bye. 


\section{Session 6: Making Good Decisions ${ }^{13}$}

Narrator: Hello, today we will discuss the steps involved in making good decisions, and learn the importance of considering the consequences of each decision they make.

Narrator: Mentor, for this session you will need a blackboard and chalk OR flipchart markers.

Narrator: The session will take about 1 hour and 30 minutes.

(II) Narrator: Mentor, pause and ask the participants to share what they learned in the last session. Be sure to clarify any confusing issues.

(II) Narrator: Before, we begin the session, let us have a volunteer to lead us in an energizer. We. Mentor, pause an invite one of the participants to lead the rest in an energizer.

(II) Narrator: Now I want you to think about this day, from when you woke up to right now. What is one decision you have made today? Mentor, pause and allow the participants a few minutes think and share amongst themselves.

(II) Narrator: Turn to the person next to you and explain about a time when you have made a difficult decision. Make sure you tell the person what the decision was and what happened as a result of it. Mentor, pause for a few minutes and allow the girls to share.

Narrator: Some examples of difficult decisions that you might have mentioned are; to skip school when asked to do household chores, to ask her mother for extra time for studying, among others.

\footnotetext{
13 Johns Hopkins Bloomberg School of Public Health/Center for Communication Programs. 2011. Go Girls! Community-based Life Skills for Girls: A Training Manual. Baltimore, Maryland. Developed under the terms of USAID Contract No. GHH-1-00-07-00032-00, Project SEARCH, Task Order 01; Peace Corps. 2001. Information Collection and Exchange Publication: Life Skills Manual; UNICEF Harare. 1995. Think About It! An AIDS Action Programme for Schools; Kenya Adolescent Reproductive Health Project (KARHP), PATH, Population Council (2005). Tuko Pamoja: Adolescent Reproductive Health and Life Skills Curriculum
} 
Narrator: In order to make good decisions, it is important to follow four steps. The steps are:

1. Stop and think.

2. Consider the consequences of your decision. (Consequences are good or bad things that can result from your decisions or actions.)

3. Know the facts.

4. Execute your decision.

(II) Narrator: Now, talk to the person sitting next to you again and see if they went through these four steps when making their decision they talked about. If they did not, discuss how these four steps could have been helpful? Mentor, pause and allow participants to share with their partners.

(II) Narrator: The next activity is a "decision points" game and is an opportunity for you to practice making decisions. I am going to tell you a story about Ali and Zamzam. Whenever I stop the story, you should clap your hands twice (CLAP, CLAP). Clapping means Zamzam and Ali need to stop and make a decision. You will work together to make a decision for Zamzam and Ali. Mentor, pause and explain the activity.

(II) Narrator: Here goes the story. Are you ready? A young man named Ali, herd's camels and occasionally moves to where Zamzam herds goats and asks her to accompany him to a water pan where she can quench her thirst. Mentor, pause and allow the girls to clap two times.

(II) Narrator: Girls, what could happen if Zamzam went to the water pan with Ali? Mentor, pause and listen to the feedlback.

II Narrator: What can happen if she doesn't accompany Ali? Mentor, pause and listen to the feedback.

(II) Narrator: What does Zamzam know about Ali? Mentor, pause and listen to the feedback.

(II) Narrator: What does she know about others who have accepted things from strangers like Ali? Mentor, pause and listen to the feedback.

II Narrator: Please pay attention and listen to the second part of the story......When Zamzam agrees to accompany Ali to the water pan, Ali diverts to a different direction towards the forest away from where Zamzam was herding goats. A struggle ensues between Zamzam and Ali, as he tries to rape her. Mentor, pause and allow the girls to clap two times 
(II) Narrator: How could she get home safely? Mentor, pause and listen to the feedback.

II Narrator: What could happen if she ran away screaming? Mentor, pause and listen to the feedback.

II Narrator: What could happen if she contacts a friend or family member? Mentor, pause and listen to the feedback.

(II) Narrator: What are her other options? Mentor, pause and listen to the feedback.

(II) Narrator: Can she ask someone else? Or call a person for help? Mentor, pause and listen to the feedback.

Narrator: What were the decision points within this story?

Narrator: Good. The decision points include when Ali asks Zamzam if she wants water, when Zamzam sees they are going on a different path.

(II) Narrator: What were the consequences of Zamzam's decisions? Mentor, pause and listen to the feedback.

Narrator: The consequences of Zamzams decisions included; her decision to go with Ali led to her being picked to go to the forest, which led to him raping her, which led to her wanting to get home and not knowing how.

(II) Narrator: Would you have made similar decisions if you were in the same situation? Mentor, pause and listen to the feedback.

(II) Narrator: If yes, why and if not, why? Mentor, pause and listen to the feedback.

Narrator: Now that we are coming to the end of the session, the mentor will pause and allow you to ask questions. Mentor, please pause and respond.

Narrator: I hope you have gained some valuable skills on decision making. See you next time. 


\section{Session 7: How to Communicate with Adults 14}

Narrator: Hello, girls, welcome to today's session. In this session, we will practice skills for dealing with situations that you may disagree with an adult or wish to ask for something from an adult

Narrator: Mentor, for this session you will need a blackboard and chalk OR flipchart markers.

Narrator: The session will take about 1 hour and 20 minutes.

(II) Narrator: Mentor, pause and ask the participants to share what they learned in the last session. Be sure to clarify any confusing issues.

(II) Narrator: Before, we begin the session, let us have a volunteer to lead us in an energizer. We. Mentor, pause an invite one of the participants to lead the rest in an energizer.

(II) Narrator: Girls, what are some different ways to communicate? Mentor, pause and listen to the feedback.

Narrator: Very good. Some of the different ways you might have mentioned are; smiling, talking, laughing, waving, talking with hands, writing, singing, among others.

Narrator: Communication is the process of sending and receiving information or thoughts through words, actions, or signs. Much of communication is nonverbal. Nonverbal communication is used to express a variety of emotions. For example, someone can communicate agreement by nodding.

(II) Narrator: Can someone show me a non-verbal way of communicating that you are happy? Mentor, pause and give a volunteer to show the action.

(II) Narrator: Can someone show me a non-verbal way of communicating to someone that you are interested in what they are saying? Mentor, pause and give a volunteer to show the action.

\footnotetext{
14 Johns Hopkins Bloomberg School of Public Health/Center for Communication Programs. 2011. Go Girls! Community-based Life Skills for Girls: A Training Manual. Baltimore, Maryland. Developed under the terms of USAID Contract No. GHH-1-00-07-00032-00, Project SEARCH, Task Order 01; Kenya Adolescent Reproductive Health Project (KARHP), PATH, Population Council. 2005. Tuko Pamoja: Adolescent Reproductive Health and Life Skills Curriculum.
} 
(II) Narrator: Can someone shoe me a non-verbal way of communicating anger or frustration? Mentor, pause and give a volunteer to show the action.

Narrator: Our parents are some of the people that we communicate with the most, and we know that you might not always agree with your parents. However, when you talk to them it must be done in such a way that is positive and respectful. It is also possible to share your point of view with them, even if it is different.

Narrator: In addition to the strong communication skills learned in previous sessions - including assertiveness, there are specific skills that youth can use to improve communication with parents/guardians. These are called the "Convincing" skills. Convening skills can be applied by;

1. Being prepared. That is knowing what you are asking for and thinking through the consequences of your request.

2. Picking the right time: That is when the situation at home is relaxed.

3. Being calm. That is presenting your topic calmly and with facts.

4. Listening to what your parents or guardians have to say. Which is considering their point of view and whether they might be right. Remember that parents generally have your best interest at heart.

Narrator: Now, am going to read out some scenarios. For each scenario, we will have a discussion on how the people in the scenario could use "convincing" skills. Are you ready?

(II) Narrator: Scenario 1: Amina wants to ask her parent or guardian to help her go back to school. How can Amina use convincing? Mentor, pause and lead the discussion.

(II) Narrator: Scenario 2: Halima's father has been pressuring her to perform well in her studies. How can Halima use convincing? Mentor, pause and lead the discussion.

(II) Narrator: Scenario 3: Zamzam wants to ask her mother accompany her for general health testing at the nearest health facility. How can Halima use convincing? Mentor, pause and lead the discussion.

Narrator: Using convincing skills can help you communicate with adults so that they can better understand your point of view. Often they lead to outcomes, which are satisfactory for both you and the adult. In the end, we want a situation that is good for both the parents and the girls.

(II) Narrator: I am now going to ask you a few question regarding how to handle disagreements. The first question is; how do you usually communicate with adults? Mentor, pause and lead the discussion. 
(II) Narrator: The next question is; how has the way you communicate with adults changed over time? Mentor, pause and lead the discussion.

II Narrator: The third question is, what are some disagreements you have had with your parent/guardian in the past six months? Mentor, pause and lead the discussion.

(II) Narrator: The last question is, what are the Somali cultural expectations of a woman regarding disagreements? For example, If the disagreement does not entail physical harm or abuse, is a girl encouraged to listen and respect the views of the adult? Mentor, pause and lead the discussion.

(II) Narrator: We are now going to practice how to handle disagreements. In each scenario, one person is the adolescent and the other is the parent. Together, you will make a role-play about the disagreement. Mentor, pause and pair up the participants into twos.

Narrator: I hope you are all in pairs. The first 10 pairs, please listen to your scenario; Your parent/guardian told you not to spend time with a certain older girl in the village who is known to chew miraa. Your older sister saw you with the girl and reported it to your parent/guardian. How would you handle this disagreement?

Narrator: Second 10 pairs, please listen to your scenario; Your mother wants you to wake up early in the morning to help with the household chores but you want to sleep in. How would you handle this disagreement?

Narrator: Last 10 pairs, your father/guardian saw you fighting with other girls after school. How would you handle this disagreement?

(II) Narrator: Mentor, pause and invite three groups to volunteer to perform their role paly for the rest of the participants. Make sure that the rest of the participants clap after every role play.

Narrator: Thank you for the wonderful role plays. We are now going to discuss a few questions regarding the role plays.

II Narrator: What helped the adults in the role plays you have watched understand the adolescent? Mentor, pause and lead the discussion. 
(II) Narrator: What didn't help/made it harder for the adults in the role plays to understand the adolescent? Mentor, pause and lead the discussion.

(II) Narrator: How could the situation be improved? Mentor, pause and lead the discussion.

(II) Narrator: What could the adolescent and the adult do to understand each other better? Mentor, pause and lead the discussion.

(II) Narrator: Mentor, please pause and give the participants time to ask questions. Be sure to clarify any confusing issues.

Narrator: Thank you very much for participating in today's session. Hope you had fun! See you next week. 


\section{Session 8: Managing Stress and Anger 15}

Narrator: Hello, girls, welcome to today's session. In this session, we will learn about stress, symptoms of stress, and tips for managing anger and resolving conflict.

Narrator: Mentor, for this session you will need a blackboard and chalk OR flipchart markers.

Narrator: The session will take about 1 hour and 20 minutes.

(II) Narrator: Mentor, pause and ask the participants to share what they learned in the last session. Be sure to clarify any confusing issues.

(II) Narrator: Before, we begin the session, let us have a volunteer to lead us in an energizer. We. Mentor, pause an invite one of the participants to lead the rest in an energizer

(II) Narrator: Girls, what is your understanding of the word "stress"? Mentor, pause and listen to the feedback.

Narrator: Well done! Stress is a state of mental or emotional strain or tension resulting from adverse or demanding circumstances.

(II) Narrator: How would you know if someone was stressed? Mentor, pause and listen to the feedback.

Narrator: Stress can be defined as the body's reaction to a change that requires a physical, mental or emotional adjustment or response. It is commonly experienced as a feeling of tension, anxiety or pressure.

\footnotetext{
15 Kenya Adolescent Reproductive Health Project (KARHP), PATH, Population Council. 2005. Tuko Pamoja: Adolescent Reproductive Health and Life Skills Curriculum; USAID. 2006. Doorways I: Student Training Manual on School-Related Gender-Based Violence Prevention and Response.
} 
Narrator: When you are under stress you may experience the following feelings;

1. Anxiety

2. Irritability

3. Fear

4. Moodiness

5. Embarrassment

Narrator: You might also experience the following thoughts;

1. Self-criticism

2. Difficulty concentrating or making decisions

3. Forgetfulness or mental

4. disorganization

5. Preoccupation with the future

6. Repetitive thoughts

7. Fear of failure

Narrator: Some of the behaviors you might experience are;

1. Stuttering

2. Difficulty speaking

3. Crying

4. Acting impulsively

5. Nervous laughter

6. Yelling at friends/family

7. Grinding teeth

8. Jaw clenching

9. More prone to accidents

10. Increased or decreased appetite

Narrator: And finally, you might experience physical symptoms such as;

1. Tight muscles

2. Cold or sweaty hands

3. Headaches 
4. Back or neck problems

5. Sleep disturbances

6. Stomach aches

7. More colds \& infections

8. Fatigue

9. Rapid breathing

10. Pounding heart

11. Shaking hands

12. Dry mouth

(II) Narrator: Girls, when was a time when you were under stress? Mentor, pause and listen to the feedback.

(II) Narrator: Thank you for sharing your experiences. Now, I would like us to do a group activity. Mentor, pause and divide participants into groups of four or five.

(II) Narrator: In your groups, I would like you to discuss different techniques that can be used to help manage stress for a few minutes. Then we will return to the large group and a representative from each of the smaller group will share the stress management techniques you discussed. Mentor, pause and allocate this activity 10 minutes.

(II) Narrator: Mentor, call out the groups one by one to present to the larger group. Mentor, as each group presents, please remember to write a list of the techniques they mention for managing stress on the blackboard or flipchart. Mentor, you can now pause and lead the activity.

Narrator: Thank you for participating in the group activity! Some of the stress management techniques you might have mentioned are;

1. Take a Deep Breath! Stress often causes us to breathe shallowly, and this almost always causes more stress! Try taking a minute to slow down and breathe deeply

2. Talk It Out: Keeping feelings inside can increase stress. Sharing your feelings with a friend, family member, teacher, or church leader can help you see your problem in a new way. Even if it is slightly embarrassing, asking for help soon after a problem occurs may help you avoid serious problems later. Writing down thoughts and feelings can also help clarify the situation and give you a new perspective. 
3. Take a "Minute" Vacation: You cannot always run away, but you can dream. Take a moment to close your eyes and imagine a place where you feel relaxed and comfortable. Notice all the details of your chosen place, including pleasant sounds, smells and temperature.

4. Pay Attention to Physical Comfort: Be as physically comfortable as the situation will allow. Wear comfortable clothing. If it's too hot, go somewhere where it's not. If your chair is uncomfortable, move. Do not wait until your discomfort turns into a real problem.

5. Get Physical: When you feel nervous, angry or upset, release the pressure through exercise or physical activity. Try to find something you enjoy and make regular time for it. This can be anything from playing a game with friends to doing some regular physical work that you like doing. Running, walking or dancing can be done anywhere. Working in the garden, cleaning, or playing with younger children can relieve stress, relax you, and energize you! Remember, your body and mind work together.

6. Take Care of Your Body: Healthy eating and adequate sleep fuels your mind as well as your body. Avoid eating too much caffeine and sugar. Well-nourished bodies are better able to cope with stress, so eat well.

7. Laugh: Maintain your sense of humor, including the ability to laugh at yourself. Share jokes and funny stories with your friends. Laughter is good for you!

8. Manage Your Time: Plan ahead. Make a realistic schedule for yourself and include time for stress reduction. Trying to take care of everything at once can seem overwhelming. Instead, make a list of what you have to do, then do one thing at a time, checking them off as they're completed. Do the most important or unpleasant ones first, and then the rest of your day will be less stressful. Recognize when you are most stressed and allow yourself some reasonable breaks, like taking a walk or otherwise changing your scenery.

Narrator: We are now going to talk about dealing with anger. Anger is a completely normal, usually healthy, human emotion that ranges from mild irritation to intense rage. When it gets out of control and turns destructive, it can lead to problems. Like other emotions, it causes physical changes. When you get angry, your heart rate, blood pressure, and energy hormone levels go up. You could be angry at a specific person or event. Worrying about personal problems or remembering traumatic events can also cause you to feel angry.

Narrator: Anger is a natural, adaptive response to threats and inspires powerful, often aggressive, feelings and behaviors, which allow us to defend ourselves when attacked. A certain amount of anger is necessary for survival. We cannot, however, physically attack every person or object that irritates or annoys us; laws, social norms, and common sense place limits on how far our anger can take us.

(II) Narrator: Girls, what are some inappropriate expressions of anger? Mentor, pause and lead the discussion. 
Narrator: Very good! Some of the inappropriate expressions of anger that you might have mentioned are; yelling, hitting, humiliating someone, name-calling, damaging property, throwing things, or refusing to help someone in need

(II) Narrator: Now, what are some appropriate expressions of anger? Mentor, pause and lead the discussion.

Narrator: Very good! Some of the appropriate expression of anger include; calmly expressing an opinion, leaving the situation, or counting to ten before reacting.

Narrator: Anger can be managed. The goal of anger management is to reduce both your emotional feelings and the physical responses that anger causes. You cannot get rid of, or avoid, the things or the people that make you angry, nor can you change them, but you can learn to control your reactions.

(II) Narrator: What are some ways to manage anger? Mentor, pause and lead the discussion.

Narrator: Some of the ways to manage anger that you might have mentioned are;

1. Ask yourself if this will matter ten years from now? Chances are, you will see things from a calmer perspective.

2. Tell yourself, "it's frustrating, and it's understandable that I'm upset about it, but it's not the end of the world and getting angry is not going to fix anything.

3. Have you ever done the same thing to someone else, even if by accident? Do you get angry at yourself? Ask yourself if the person did it on purpose. In many cases, you will see that they were just careless or in a rush, and really did not mean you any harm.

4. Remind yourself that getting angry is not going to fix anything, and that it won't make you feel better (and may actually make you feel worse).

5. Try counting to ten before saying anything. This may not address the anger directly, but it can minimize the damage you will do while angry. Or try counting to ten with a deep slow breath in between each number. Deep breathing helps people relax.

6. Imagine a relaxing experience. Close your eyes, and travel there in your mind. Make it your anger-free place.

7. Non-strenuous physical activities, like walking, can relax your muscles and help you feel much calmer.

8. Give yourself time and space alone. Physically move away from situations that make you angry. 
Narrator: People use a variety of both conscious and unconscious processes to deal with their angry feelings. The three main approaches are expressing, suppressing, and calming.

Narrator: Expressing your angry feelings in an assertive, not aggressive, manner is the healthiest way to express anger. To do this, you have to learn how to make clear what your needs are, and how to get them met, without hurting others. Being assertive doesn't mean being pushy or demanding; it means being respectful of yourself and others.

Narrator: Anger can be held in by not thinking about it or focusing on something positive. The task is to convert your anger into more constructive behavior. If anger is not allowed out it can cause physical and emotional harm. Anger turned inward may cause hypertension, high blood pressure, or depression. Or people can become hostile and critical, which can negatively affect their relationships with others.

Narrator: You can calm down inside. This means not only controlling your behavior, but also controlling your internal responses, taking steps to lower your heart rate, calm yourself down, and let the anger go away.

Narrator: Psychologists now say that it is dangerous to express all of your angry feelings because it can actually make you angrier and does not help resolve the situation. It is best to find out what makes you angry, and then develop ways to keep those things from making you angry. Sometimes, our anger and frustration are caused by very real, unavoidable problems in our lives. Not all anger is wrong, and often it is a healthy, natural response to difficult times. Not all problems have a solution. In these situations, try not to focus on finding the solution, but on how you handle the problem.

(II) Narrator: In this last section of today's session, we will to do roles plays about anger and stress. Mentor, pause and divide the participants into four or five.

(II) Narrator: I hope you are all in groups. Now, please listen carefully to the instructions. In your groups, brainstorm a scenario to act out about someone who is angry and/or stressed. To come up with ideas for the scenario, think of a time when you were very angry or in a stressful situation, and try to reenact it. Use the tips we discussed to deal with stress and anger to act out a 1-2-minute role-play and resolve the scenario. Mentor, pause, explain the activity and allow the groups 10 minutes to develop a role play.

(II) Narrator: Thank you for coming up with the role plays. Mentor, please pause and allocate each group about 5 minutes to present to the larger group. 
Narrator: Thank you for the wonderful role plays, I hope you enjoyed! Now, I would like to ask you a few questions about the role plays you have just watched.

(II) Narrator: What happened in the role-plays? Mentor, pause and allow the participants to give feedback on all the role plays.

(II) Narrator: How did you feel in that role? Why did you have that feeling? Mentor, pause and allow the participants to give feedback on all the role plays.

(II) Narrator: Was the problem solved in the role-play? How? Mentor, pause and allow the participants to give feedback on all the role plays.

(II) Narrator: What would you change about the role-play? Mentor, pause and allow the participants to give feedback on all the role plays.

(II) Narrator: What advice would you give the person in the role-play? Mentor, pause and allow the participants to give feedback on all the role plays.

(II) Narrator: What have you learned that can help you the next time you face a similar situation? Mentor, pause and allow the participants to give feedback on all the role plays.

(II) Narrator: Mentor, pause and allow participants to ask questions and clarify any confusing issues.

Narrator: We have now come to the end of today's session. I hope you learnt something useful. See you next week. 


\section{Session 9: Conflict Resolution and Problem Solving Skills 16}

Narrator: Hello! Today you will learn about conflict resolution. You will learn conflict resolution and problem solving skills that are essential for dealing with conflict situations.

Narrator: Mentor, for this session, you will need a blackboard and chalk OR flipchart and markers

Narrator: The session will take about 1 hour 25 minutes.

(II) Narrator: Mentor, pause and request for a volunteer to lead the group in an energizer.

(II) Narrator: I hope the energizer was fun! Mentor, ask participants to share what they learnt during the last session. Remember to add anything that they have left out and clarify any confusing issues. You can now pause and listen to feedback their girls.

Narrator: We will begin the session by an activity to help us look at some of the conflict that can occur in our families.

(II) Narrator: The mentor will divide you into 3 groups then I will give each group a task. Mentor, pause and divide participants into 3 groups. Girls, you will begin the activity once all the groups are assigned their activity. Once you are done you will present your small play to the rest.

Narrator: Group 1,act out a small play where a girl called Rahma is upset because her mother told her that she was not allowed to go and play with her friends on Saturday afternoon, even though she had already made plans with her friends. What should Rahma say to her mother?

(II) Narrator: Mentor, pause and clarify the activity. Instruct them to start preparing for the presentation.

Narrator: Group 2: act out a small play where a girl called Zeinab has a big exam at school on Friday. On Thursday afternoon, she realizes that she is not well prepared for the exam and is worried that she will not pass. Her sister wants Zeinab to help her make dinner, but Zeinab wants to study. What should Zeinab do?

\footnotetext{
16 RAPIDS/Consortium in Zambia. RAPIDS Youth Lifeskills Training Manual. Prepared by Motivational Centre for Africa's Transformation (MoCAT) for AFRICARE; International HIV/AIDS Alliance. 2008. Sexuality and Life-Skills: Participatory activities on sexual and reproductive health with young people.
} 
(II) Narrator: Mentor, pause and clarify the activity. Instruct them to start preparing for the presentation.

Narrator: Group 3: Act out a small play where a girl called Maimuna notices that her friend Zeinab is wearing a hijab that was stolen from her last week. Zeinab tells her she borrowed it from a friend to attend a wedding. How should Maimuna talk to Zeinab?

(II) Narrator: Mentor, pause and clarify the activity. Instruct them to start preparing for the presentation.

(II) Narrator: You now take 20 minutes to complete your group activity. Mentor, pause.

Narrator: You will now present and discuss your group work. Mentor, pause and lead the discussion after each question.

a. What was the relationship between the two persons? Pause for 5 minutes

b. What was the nature of the conflict? Pause for 5 minutes

c. Was the role-play realistic? Pause for 5 minutes

d. What other conflicts may arise? Pause for 5 minutes

e. Could this situation be avoided or handled differently? If so, how? Pause for 5 minutes

f. What was the impact of the conflict on the individual, family, community, etc.? Pause for 5 minutes

Narrator; Good communication during a conflict can help resolve the situation. However, there are things that interfere with 'good' communication during a conflict, such as name-calling, cursing, insulting, and accusations, etc. These are called "communication blockers."

Narrator: Other communication blockers can be interrupting, ignoring, sarcasm insulting, threatening, stereotyping (statements which label people and make them angry/resentful, judging, blaming, starting opinions as fact, expecting someone to read your mind, hitting, punching, slapping, screaming, etc.

Narrator: "Communication-blockers" can lead to violence. In fact, violence is increasing in many countries. The environments in which many young people grow up do not encourage peacemaking attitudes and behaviors. While young people need to know how to avoid conflicts and how to resolve them peaceably, it is equally important for them to know how to survive in a hostile climate. They need to practice different methods of resolving conflicts to see which ones are more effective.

Narrator: Girls, it is important to note that conflict is natural and happens in almost every relationship. Since conflict is unavoidable, we must learn to manage it. Conflict is a sign of a need for change and an opportunity for growth, new understanding, and improved 
communication. It is normal for people to disagree, but it is important to address conflict with the people involved and resolve these disagreements in a constructive and healthy way.

(II) Narrator: Mentor pause for 5 minutes and let's listen to the girls as the share some of the techniques they have learned through AGIK for resolving conflict?

Narrator: Thank you for sharing with. Now I am going to read out tips that we can apply in conflict resolution. Listen carefully.

- Respond, don't react. If you keep your emotions under control you have a better chance of hearing what the other person is trying to say.

- Listen carefully without interrupting. Ask questions and wait for and listen to answers.

- Acknowledge the other person's thoughts and feelings. You do not have to agree with the other person to acknowledge his or her feelings.

- Give respect to get respect. Treat people the way you would like to be treated if you were in the same situation.

- Communicate clearly and respectfully so your viewpoint can be understood.

- Identify points of agreement and points of disagreement. Agree wherever you can. Your underlying interests may be more alike than you imagine.

- Be open to change. Open your mind before you open your mouth.

- Look forward, not backward. Live in the present, plan the future, do not dwell on the past.

- Stay focused on the topic at hand. Don't expand an argument. If there are a number of issues, deal with them, one at a time.

- Work together. Commit to working together and listening to each other to solve conflicts.

- Conflicts don't have to end with a winner and a loser. Try to find a solution that is acceptable to both parties.

- Be creative. Generate silly options to begin thinking "outside of the box" of original positions.

- Be careful not to give in simply to avoid conflict or maintain harmony. Agreements reached too early usually do not last.

- Be specific when problem solving. Clarify terms that each person may interpret differently.

Narrator: Remember an "I" statement is a useful way to share your opinion or perspective without placing blame on someone else. For example, instead of saying, "You made me feel angry" you can say, "I feel angry." Using an "l" statement is a constructive way to convey your message without making any demands. "l" statements should be clear, concise, and free of judgment. 
(II) Narrator: Mentor pause and girls to mention some "l" statements that can help adolescents cope with or avoid a conflict?

Narrator: Thank you girls for mentioning the "l" statements, here are more examples

"That upsets me, and I would like to talk with you about it,"

"It hurts my feelings when...,"

"It upsets me when...,"

"I think we should talk about this situation.

Tell me how you feel about...

Narrator: Our next activity is to look at some peace-making rules and core values in conflict resolution.

Peacemaking Rules

1. Identify the problem

2. Focus on the problem, not the person

3. Attack the problem, not the person

4. Listen with an open mind

5. Treat the other person's feelings with respect

6. Take responsibilities for your own actions

\section{Core Values in Conflict Resolution}

1. Cooperation

2. Affirmation

3. Empowerment

4. Neutrality

5. Confidentiality

(II) Narrator: Now let us go back to our 3 groups and use the role play scenarios to practice how you would use " $I$ ' Statements," "Peacemaking Rules," and "Core Values in Conflict Resolution" to resolve conflicts. Mentor pause for 20 minutes and guide the girls in this activity. Explain further for clarity. 
(II) Narrator: We are almost coming to the end of today's session. Mentor, pause and give the girls an opportunity to ask any questions. Remember to clarify any confusing issues

Narrator: I hope you enjoyed today's session. See you next week. Bye bye! 


\section{HIV, AIDS, and STIS}

\section{Session 1: HIV and AIDS 17}

Narrator: Hello girls! Welcome to today's session. We are going to learn what HIV and AIDS are, and what behaviors do and do not put one at risk of being infected. By the end of the session you will be able to;

1. Define HIV and AIDS

2. Explain modes of transmission of HIV

3. Identify risky and non-risky behaviors

4. Describe the common symptoms of AIDS

Narrator: Mentor, for this session you will need;

1. Slips of paper (several per participant)

2. Blackboard or flipchart

(II) Narrator: The session will take approximately 1 hour and 10 minutes. But before we begin let us do an energizer, Mentor, pause the recording and ask a volunteer to lead the group in an energizer of their choice. This should take you 10 minutes.

(II) Narrator: Thank you for participating in the energizer, that was fun! Mentor, ask participants to share what they learnt during the last session. Add anything that they have left out and clarify any confusing issues. You can now pause and listen to feedback from the girls.

(II) Narrator: we are now going to look at HIV/AIDS overview. We will do this through an exercise. Mentor, pause and let the girls get two slips of paper each.

(II) Narrator: We all have two pieces of papers, write on each paper (or draw an illustration representing) something that you have heard people in your community say about HIV or AIDS (this does not have to be something you agree with). Mentor, now pause for 5 mins for all to write.

\footnotetext{
17 Kenya Adolescent Reproductive Health Project (KARHP), PATH, Population Council. 2005. Tuko Pamoja: Adolescent Reproductive Health and Life Skills Curriculum; One Love Southern Africa Campaign; Central Statistical Office (CSO) Ministry of Health (MOH) Tropical Diseases Research Centre (TDRC) University of Zambia, and Macro International Inc. "Zambia Demographic and Health Survey 2007." (2009).
} 
Narrator: Thank you for participating, mentor now Collect all the slips of paper and mix them up. Divide participants into four groups get a way of dividing them and deal out the slips of paper to the groups at random. Now each group should sort out their slips of paper into three categories: 'AGREE', 'DISAGREE' and 'DON'T KNOW'.

Write these categories on the black blackboard or flipchart. When all the groups have finished, reassemble. Have each small group to present to the main group any statement they found difficult to reach agreement on. The main group can offer opinions on the difficult statements.

(II) Narrator: From our exercise we have learnt a lot about what people in our community say about HIV. Now let us define the word HIV IAIDS. Mentor pause for 5 mins and let the girls define the word HIV/AIDS.

Narrator: Girls thank you for sharing .We have heard that HIV stands for (Human Immunodeficiency Virus)

The name indicates that it is a virus found in humans, that makes the immune system deficient (lacking in something), and therefore weakens the system. The immune system is the body's defense against disease. With a damaged immune system the body is exposed to a range of infections and diseases. The person becomes weaker and eventually develops AIDS.

Narrator: From your discussion, we have also heard that AIDS stands for ([Acquired Immune Deficiency Syndrome] Acquired means that it is passed from one person to another; it does not just develop spontaneously. It is passed from exposure to an infected person's blood, sexual fluids or breast milk. AIDS is a condition where the body's immune system is destroyed by HIV. It has no cure and eventually kills the infected person. It can be controlled with drugs, but they are costly and not widely available.

(II) Narrator: we have learnt what HIV/AIDS is, now we are going to learn how one can contract HIV/AIDS. Mentor pause and in 5 minutes let the girls share different ways one can contract HIV/AIDS.

Narrator: From your discussion, you will note that some of the ways that HIV is passed between people in three ways: 1. Sex: Penetrative unprotected sex with an HIV-infected person

2. Blood to blood: From an HIV infected person's blood to another person's blood through an opening in the body such as a cut, from a transfusion or by sharing something that cuts or pierces the skin (knife, razor, and needle). This includes sharing circumcision knives, needles, tattooing, or ear piercing, with someone who has HIV.

3. Mother to child: HIV can be passed from a mother who is HIV infected to her baby during pregnancy, at the time of birth, or through breastfeeding. 
The majority of people in Kenya are infected with HIV by having unprotected sex with someone who is HIV infected. It is important to note that a person suffering from other STIs is eight to ten times more likely to contract HIV. HIV cannot survive in air, water, or on things people touch.

Narrator: Girls, it is also important to know that HIV is different from other diseases because it does not pass through air. We cannot catch it from being in the same room as an infected person or by hugging or touching a person. We cannot catch it from an infected person coughing or sneezing on us or by drinking from the person's cup.

But we can choose to not become infected if we abstain from sex outside marriage, or remain faithful to one partner. HIV can be prevented by being in a mutually faithful relationship with an uninfected person and by never sharing needles or other equipment such as razors, circumcision knives.

(II) Narrator: Is HIV easy difficult to contract? Mentor pause for 5 mins and listen to feedback form the girls.

Narrator: thank you for sharing ,we have seen that HIV is easy to catch if one is not careful, i.e. having unprotected sex outside the union of marriage, certain factors increase the chances of catching HIV such as having STIs, being uncircumcised (for males), etc.]

Narrator: It is important to note that there is no cure for AIDS, however there are ways to treat the symptoms. Treatment means the use of a drug, injection, or intervention that can cause symptoms to become less painful or pronounced or cause them to disappear altogether. It is important for people with HIV and AIDS to eat a nutritious diet to fight infection and disease and to stay energetic, strong, and productive. Nutrition and HIV are strongly related to each other. People who are malnourished are more likely to progress faster to AIDS, because their bodies are weak and cannot fight infection.

(II) Narrator: Now let us look at Risky and Non-Risky Behaviors and Practices

You will now have a chance to assess your own risk of being infected with HIV, if you do certain things. I am going to read a list of items, and you will tell me whether each statement puts you at risk for HIV. Listen carefully. Mentor, pause after every statement and listen to the girl's views. 
Narrator: If you do this, are you at risk of being infected with HIV?

1. If you hug, kiss or massage your friend. (pause)

We have seen it is not a risk to hug, kiss or massage your friend. Now the 2nd statement

2. If you don't protect yourself when handling blood (pause)

3. We have heard it is a risk If you don't protect yourself when handling blood. Now the $3^{\text {rd }}$ statement

4. If you take drugs. (pause)

We have heard Taking drugs can lead to other risky behavior. Now the 4th statement

5. If you are bitten by mosquitoes (pause)

6. We have heard it is Not a risk (for HIV, but is a risk for malaria!). Now the $5^{\text {th }}$ statement

7. If you share a razor/knife with a person with HIV or AIDS. (pause) We have heard it is a risk if you share a razor/knife with a person with HIV or AIDS. Now the $6^{\text {th }}$ statement

8. If you only have sex with one partner. (pause) We have heard it is less risky if you are BOTH faithful, use protection and have both been tested for HIV and STIs. .Now the $7^{\text {th }}$ statement

9. If you live, work or play with a person with HIV or AIDS. (pause)

We have heard it is not risky if you live, work or play with a person with HIV or AIDS. Now the $8^{\text {th }}$ statement

10. If you have injections, or piercings. (Pause)

We have heard it is a risk you have injections, or piercings if needles are shared.

11. Getting blood transfusion (Pause)

We have heard it is a risk getting blood transfusion

12. Shaking hands with person with HIV (No Risk)

We have heard it is not risky Shaking hands with person with HIV

13. Shaking hands with person with HIV (Not a Risk)

We have heard it is not risky Shaking hands with person with HIV

Narrator: mentor now Facilitate a discussion by getting feedback for the following questions. Pause after each question

Q 1. Does knowing that some things are definitely or probably a risk worry you?

Q 2. Did you learn any new information?

Q 3. Do you have any questions about any behaviors we did not list today?

Q 4. If you were explaining information on risky or non-risky behaviors to a friend, what would you say first? 
Narrator: That brings us to the end of our session today. Thank you for your active participation. We have learnt a lot today. See you next week same place, same time. Good bye. 


\section{Session 2: Myth or Fact 18}

Narrator: Hello, girls, welcome to today's session. Today we will learn about the different myths and facts related to HIV and AIDS

Narrator: Mentor, for this session you will need a blackboard and chalk OR flipchart markers.

Narrator: The session will take about 1 hour and 20 minutes.

(II) Narrator: Mentor, pause and ask the participants to share what they learned in the last session. Be sure to clarify any confusing issues.

(II) Narrator: Before, we begin the session, let us have a volunteer to lead us in an energizer. We. Mentor, pause an invite one of the participants to lead the rest in an energizer.

Narrator: This session will blow away some of the myths and misunderstandings surrounding the topic of HIV and AIDS. As we carry out activities in this session, try to remember what we discussed and learned in the previous session about HIV and AIDS.

(II) Narrator: Mentor, pause and request the participants stand in the middle of the room. Make sure that there is enough space for them to move around.

(II) Narrator: I hope we all have enough space to move around for this activity. I am going to read a number of statements. When I call out each statement, think silently about whether the statement is a Myth or a Fact (False or True). When the mentor pauses the radio, you have to decide if the statement is a fact or a myth. If you believe the statement is a fact, you must jump up in the air and shout "Fact!" at the top of your voice. If you believe the statement is a myth, you will bend down and touch the floor, and shout "Myth!" If you cannot make up your mind, you can stay still. Remember, it is ok to guess incorrectly; the point is for everyone to learn the facts while having fun! Mentor, pause and clarify the activity.

(II) Narrator: Are you ready to participate in the activity? Okay, here you go.... The first statement is children should not be allowed to go to school if they are HIV-positive. Is it a myth or a fact? Mentor, pause and give the participants time to jump if they think it is a fact and touch the ground if they think it is a myth. Once they decide whether it is a myth or fact request two girls to explain why they think the statement is a myth or fact. Mentor, you can now cause.

18 International Labor Organization (2007). A Special Module On HIV and AIDS and Child Labor: Scream-Stop Child Labor. 
Narrator: The statement is not true, so it is a myth Children who are HIV-positive should not be treated any differently to those who are HIV-negative. Their status is not a danger to anyone else and they are entitled to live normal lives.

(II) Narrator: Now, listen to the next statement; HIV will never affect me. Mentor, pause and give the participants time to jump if they think it is a fact and touch the ground if they think it is a myth. Once they decide whether it is a myth or fact request two girls to explain why they think the statement is a myth or fact. Mentor, you can now cause.

Narrator: The statement is my HIV affects everybody. There are certain cultural and economic groups who assume they cannot HIV. This is an assumption that makes other people think they are better than others. HIV/AIDs does not discriminate it can affect the rich or poor, religious or non-religious

(II) Narrator: The third statement is; I can get HIV from touching an infected person or being in the same room as them. Mentor, pause and give the participants time to jump if they think it is a fact and touch the ground if they think it is a myth. Once they decide whether it is a myth or fact request two girls to explain why they think the statement is a myth or fact. Mentor, you can now cause.

Narrator: The statement is a myth. This is not true. Touching or hugging someone with HIV does not mean you will be infected with the virus. The virus is principally transmitted sexually through sexual intercourse and exchange of body fluids. People also think that by sharing cups, knives and forks etc. they can also be infected. This is also not true.

(II) Narrator: The next statement is; You can get HIV by sharing meals and sharing a room with someone who is infected with HIV. Mentor, pause and give the participants time to jump if they think it is a fact and touch the ground if they think it is a myth. Once they decide whether it is a myth or fact request two girls to explain why they think the statement is a myth or fact. Mentor, you can now cause.

Narrator: The statement is a myth meaning it is not true. HIV/AIDS is only transmitted through blood, and sexual contact sharing meals and also a room with someone who is infected cannot make one get infected.

(II) Narrator: The last statement is; You can share razor blades/needles with other girls during circumcision and nothing will happen. Mentor, pause and give the participants time to jump if they think it is a fact and touch the ground if they think it is a myth. Once they decide whether it is a myth or fact request two girls to explain why they think the statement is a myth or fact. Mentor, you can now cause. 
Narrator: The statement is a myth. Sharing razor blades and needles is one method of contracting HIV. It is therefore recommended for people not to share razor blades or needles regardless of what they are for.

Narrator: I hope you enjoyed the activity! We are now going to participate in role plays about HIV rumors.

(II) Narrator: Mentor, pause and divide the girls into 3 groups.

(II) Narrator: I hope we are all in groups. Group one, please listen carefully to your instructions. A group of people are sitting around discussing a rumor about how you can you can get HIV from kissing someone. In the course of the discussion, present the correct information. That is, explain why the rumor is not true. Mentor, pause and clarify.

(II) Narrator: Group 2, please listen to your instructions. A group of people are sitting around discussing a rumor about how you can tell if someone is HIV-positive by looking at them. In the course of the discussion, present the correct information. That is, explain why the rumor is not true. Mentor, pause and clarify.

(II) Narrator: Group 3. Here go your instructions; A group of people are sitting around discussing a rumor about how once you have become HIV-positive you can feel it in your body. In the course of the discussion, present the correct information. That is, explain why the rumor is not true. Mentor, pause and clarify.

(II) Narrator: Mentor, pause and allocate the groups 10 minutes to practice their role plays. Girls, please note that each role play should take a maximum of 5 minutes.

II Narrator: I hope we have all practiced our role plays. Mentor allocate each group time to present their role play. After each presentation, allow the group to make suggestions to explain why each rumor is not true. Make sure the correct information is presented. Mentor, pause and let the groups present the role plays.

(II) Narrator: I hope you had fun in today's session. Mentor, pause and allow participants to ask questions and clarify any confusing issues.

Narrator: We have now come to the end of today's session. I hope you learnt something useful. See you next week! 


\section{Reproductive Health}

\section{Session 1: My Body Is Changing - Am I Normal? 19}

Narrator: Welcome to today's session! In this session, we will learn about the changes that occur during puberty and discuss how you can help each other through this very important stage.

Narrator: Mentor, for this session you will need;

$\checkmark$ A blackboard and chalk OR flipchart and markers.

$\checkmark 4$ large pieces of blank paper and pens, pencils or markers

Narrator: The session will take about 1 hour and 30 minutes.

(II) Narrator: We will begin today's session with an energizer from a volunteer. Mentor, pause and request for a volunteer to lead the energizer.

(II) Narrator: I hope the energizer was fun! Mentor, ask participants to share what they learnt during the last session. Remember to add anything that they have left out and clarify any confusing issues. You can now pause, listen and provide feedback.

(II) Narrator: We will begin this session by defining the word puberty. Girls, what is puberty? Mentor, pause and listen to the responses.

Narrator: Puberty is the period between childhood and adulthood. It is a very exciting time in life filled with many positive feelings and changes. These changes are both physical and emotional. Sometimes they can be challenging to deal with.

(II) Narrator: To understand the changes that occur during puberty, will do a group work activity. Mentor, please pause and divide the girls into 3 groups.

Narrator: I hope we are all in groups. I will now read out your group work. Please listen carefully;

19 Johns Hopkins Bloomberg School of Public Health/Center for Communication Programs. 2011. Go Girls! Community-based Life Skills for Girls: A Training Manual. Baltimore, Maryland. Developed under the terms of USAID Contract No. GHH-1-00-07-00032-00, Project SEARCH, Task Order 01; Kenya Adolescent Reproductive Health Project (KARHP), PATH, Population Council (2005). Tuko Pamoja: Adolescent Reproductive Health and Life Skills Curriculum. 
$\checkmark$ Group 1, Write or draw the changes Boy's physical change,

$\checkmark$ Group 2, Write or draw the changes Girl's physical changes,

$\checkmark$ Group 3, Write or draw the changes Emotional changes for boys and girls.

(II) Narrator: Mentor, this activity should take 15 minutes. Ensure that each group chooses a representative who will present on behalf of the group. Mentor, pause and provide every group with a flipchart and marker.

(II) Narrator: Mentor, pause and invite each group (one by one) to present. Remember to ask if the participants from other groups have any changes to add to the list. Help differentiate between physical and emotional changes. Point out any other changes that were not mentioned.

Narrator: From your discussion with the mentor, you will note that some of the physical changes during adolescence in boys;

$\checkmark$ Shoulders broaden

$\checkmark$ Facial hair

$\checkmark$ Voice deepens

$\checkmark$ Sperm production and ejaculation

$\checkmark$ Wet dreams

Narrator: Physical changes in girls are;

$\checkmark$ Hips widen

$\checkmark$ Breasts develop

$\checkmark$ Ovulation and menstruation

Narrator: Physical changes in both boys and girls are;

$\checkmark$ Grow in size

$\checkmark$ Weight gain

$\checkmark$ Pubic and underarm hair

$\checkmark$ Genitals enlarge

$\checkmark$ pimples

$\checkmark$ Sexual feelings

$\checkmark$ Changes in mood

$\checkmark$ Feel embarrassed easily 
$\checkmark$ Feel closer to friends than family

$\checkmark$ Feel shy

$\checkmark$ Better able to reason and solve problems

$\checkmark$ Rebel against parents, want to be independent

$\checkmark$ Concerns about being normal

$\checkmark$ Try new things

Narrator: While puberty is an exciting time of change, it can also be challenging. We will now talk about making puberty easier. To make the discussion interesting, I will ask you a number of questions.

(II) Narrator: The first question is what are some things that could help one get through changes during puberty? Mentor, pause and discuss the response.

Narrator: A girl can get through puberty easily by; getting social support from peers, talking to a mother, sister, aunt, or friend, getting knowledge and information about bodily changes from health providers or books, keeping busy to distract her mind.

(II) Narrator: What is one of the most embarrassing or challenging aspects of puberty for girls? Mentor, pause and discuss responses.

Narrator: Some examples of embarrassing moments for girls during puberty; soiling pants/dress during menstruation, unwanted attention due to growing breasts among others.

(II) Narrator: What can your peers do to help minimize the embarrassment and make you feel more comfortable? Mentor, pause and discuss responses.

Narrator: Peers can help to minimize embracement by; always carry extra menstrual hygiene items, bringing extra clothes in case pants/dress is soiled, going shopping for bras or facial cleaners together among others.

(II) Narrator: What can you do to help each other to overcome embarrassment? Mentor, pause and discuss the responses.

Narrator: It is important to remember the following key things about puberty; 
1. Puberty begins and ends at different ages for everyone. This cannot be controlled and is biological (it is programmed in your body). This variation in change from person to person is normal.

2. Girls often begin puberty changes before boys. This difference in changing is also biological and is therefore normal.

3. During puberty, the body produces increased hormones that cause physical changes in the body as well as changes in feelings and behavior. It is possible to feel very energetic and excited one moment and tired and upset or anxious the next. This emotional up and down is normal.

4. During puberty, both girls and boys experience sexual desires. These feelings may involve physical changes, such as a rapid heart rate, a warm flush in the face and/or genitals when sexually excited. It is important to remember that these feelings of desire and/or night sexual excitement are normal and signs of a healthy body.

5. During puberty, boys' and girls' bodies change. Young people should be aware that as their bodies change, they may attract wanted and unwanted attention. The important thing is to remember to feel good about you. Use strong communication skills to let someone know if the attention they are giving you makes you feel uncomfortable.

(II) Narrator: Girls, we are almost coming to the end of today's session. Please ask the mentor any questions or to clarify any confusing issues. Mentor, pause and respond.

Narrator: Thank you for participating in today's session. Hope you enjoyed. See you next week. 


\section{Session 2: HOW MENSTRUATION HAPPENS ${ }^{20}$}

Narrator: Welcome to today's session! In this session, we will learn about the menstrual cycle and conception.

Narrator: Mentor, for this session you will need;

$\checkmark$ A blackboard and chalk OR flipchart and markers.

$\checkmark 4$ large pieces of blank paper and pens, pencils or markers

$\checkmark$ Training aids "The Process of Menstruation" You will find the female reproductive health system in the Health and life skills curriculum. You will need to draw the images on a flipchart or blackboard before the session.

Narrator: The session will take about 1 hour and 30 minutes.

(II) Narrator: We will begin today's session with an energizer from a volunteer. Mentor, pause and request for a volunteer to lead the energizer.

(II) Narrator: I hope the energizer was fun! Mentor, ask participants to share what they learnt during the last session. Remember to add anything that they have left out and clarify any confusing issues. You can now pause, listen and provide feedback.

Narrator: Females begin menstruation during puberty. When a female begins menstruation, it means that she is capable of becoming pregnant. This does not mean that she is physically, emotionally, or financially ready to become a mother.

Narrator: Menstruation happens for most women about once a month, and that is why it is commonly called the "monthly period." It usually lasts between three and seven days. It is a sign that a girl or woman can become pregnant if she has sexual intercourse.

(II) Narrator: Girls, why does menstruation happen? Mentor pause and discuss responses.

\footnotetext{
20 Johns Hopkins Bloomberg School of Public Health/Center for Communication Programs. 2011. Go Girls! Community-based Life Skills for Girls: A Training Manual. Baltimore, Maryland. Developed under the terms of USAID Contract No. GHH-1-00-07-00032-00, Project SEARCH, Task Order 01; Kenya Adolescent Reproductive Health Project (KARHP), PATH, Population Council. 2005. Tuko Pamoja: Adolescent Reproductive Health and Life Skills Curriculum; National Institutes of Health, Eunice Kennedy Shriver National Institute of Child Health and Human Development, "Menstruation and the Menstrual Cycle."; Population Council (2010). Safe Space Curriculum. Lusaka, Zambia
} 
Narrator: Menstruation happens when every month the ovaries release an egg that waits in the fallopian tubes between 5-7 days to see if it will be fertilized with sperm. If the egg does not meet sperm, the lining of the womb is shed and comes out as blood through the woman's vagina. This is the monthly period or menstruation. The mentor will explain this process using images.

II Narrator: Mentor, draw/ show the female reproductive system on a blackboard/ flipchart and explain the menstruation process. You can now pause and explain.

Narrator: Some girls may begin to menstruate at age nine or ten; others may not get their first period until a few years later. A woman knows that she has started her period when a little blood comes out of her vagina. The blood comes out slowly, like a dribble. It is important to anticipate when each month she will start bleeding, so she can wear a sanitary pad or other protection to prevent clothing stains.

(II) Narrator: What are the physical and emotional changes around the time of menstruation? Mentor, pause and discuss the responses.

Narrator: Some of the physical and emotional changes during menstruation are;

$\checkmark$ Cramping, bloating, and sore breasts

$\checkmark$ Food cravings

$\checkmark$ Mood swings and irritability

$\checkmark$ Headache and tiredness

Narrator: While most girls menstruate monthly, some girls will be irregular. It may take the body a while to adjust to all the changes taking place. Her menstrual cycle will probably become more regular with time.

(II) Narrator: What are some of the reasons that can make a girl miss her period? Mentor, pause and discuss the responses.

Narrator: A girl can miss her period in case of change of weather, If she is pregnant, stress, change of diet, among other reasons.

(II) Narrator: What do girls use when they are menstruating or on their periods? Mentor, pause and discuss the responses. 
Narrator: During menstruation, girls can use;

$\checkmark$ Clean pieces of cloth: These are cut to fit in the panty area by sewing several layers of cotton cloth on top of each other. These must be clean. They must be washed thoroughly and hung in a private but sunny place to dry. They should not be shared.

$\checkmark$ Pads: These are designed to fit the panty area close to the body. They have strips of tape that keep them attached to the panties, and the panties help to hold the pads close to the opening of the vagina. Pads have a plastic lining to minimize the spill of blood. If a woman uses pads, she needs to throw them down a pit latrine, bury them, or burn them after use. They should not be left in the garbage pile or flushed down the toilet.

Narrator: Whatever a girl uses, she should change it frequently to avoid staining or odor. If a girl's panties or clothes get stained with blood, she can soak them in cool, mildly salty water. Hot water will cause the blood to set and remain as a permanent stain.

Narrator: I will wind up the session by giving you a few tips to how keep external female reproductive organs clean:

$\checkmark$ Use soap and water to wash the external genitalia (private parts) and under your arms every day, especially during menstruation.

$\checkmark$ Use either a disposable pad made of cotton, which has a nylon base, or a clean piece of cotton cloth to absorb blood during menstruation.

$\checkmark$ Properly dispose of the pad after each use. Or, wash and dry the piece of cloth used as menstrual pad before reuse.

$\checkmark$ Wash only the external genitalia (private parts). Do not try to clean the inside part of the vagina.

$\checkmark$ While washing, wash starting from the vagina towards the anus.

$\checkmark$ Do not wash from the anus towards the vagina. This will protect germs that easily cause infection from penetrating the inner genitalia.

$\checkmark$ Be aware of abnormal fluids from your vagina. Do not confuse this with normal vaginal fluids.

$\checkmark$ If you see any changes in the vaginal fluid - a change in color or odor, please visit a health professional.

(II) Narrator: Mentor, pause and respond to any question or clarify any confusing issues. 
Narrator: We have now come to the end of today's session. Thank you very much for your active participation. See you next week, same time and the same place. Goodbye! 


\section{Session 3 - Abstinence}

Narrator: Welcome to today's session. In this session, we will learn about abstinence and identify the values that the community has on virginity.

Narrator: Mentor, for this session you will need a blackboard and chalk OR flipchart markers.

Narrator: The session will take about 1 hour.

(II) Narrator: Mentor, pause and ask the participants to share what they learned in the last session. Be sure to clarify any confusing issues.

II Narrator: Before, we begin the session, let us have a volunteer to lead us in an energizer. Mentor, pause and invite one of the participants to lead the rest in an energizer. Remember you can pause at any point of the recording to engage participants in an energizer.

Narrator: Thank you for participating in the energizer.

Narrator: Abstinence means refraining from sexual activity until one is married; it is the only 100 percent effective method of avoiding unplanned pregnancy and sexually transmitted infections, including HIV.

(II) Narrator: Mentor, in the next activity, you will pause and pair up participants.

(II) Narrator: I hope we are all in pairs. I will now ask you a number of questions, you will discuss in your pairs and write down the responses in your note book. Mentor, pause and give the participants time to remove their note book and pens.

II Narrator: Are you ready? The first question is, what are the consequences of not abstaining from sex before marriage? Mentor, pause and allow the pairs 5 minutes to discuss.

(II) Narrator: Thank you for the fruitful discussion. The mentor, will now pause and allow each pair to share with the larger group.

Narrator: Some of the consequences of not abstaining that you might have mentioned are;

1. The Somali culture and religion promotes sex only in a marriage union, therefore sex before marriage is not allowed

2. One may get an unintended pregnancy,

3. Early and forced marriage because one may be forced to marry the man who may not necessarily be the one the girl would like. 
4. The parent's and family may disown the girl, leaving her stigmatized. In some instances, children born out of wedlock are disposed of or killed to cover the shame.

5. School drop out

(II) Narrator: The next question is what are the advantages of abstinence? Mentor, pause and allow the pairs 5 minutes to discuss.

(II) Narrator: Mentor, please pause and allow the pairs to share with the larger group.

Narrator: Some of the advantages of abstinence are;

1. If you don't engage in sex before you are married, you will not get unwanted pregnancy.

2. You will get a chance to complete your education without any problem.

3. Allah will punish anyone who engages in sex before marriage.

4. Abstinence builds one's self esteem

5. Abstinence earns respect for a person who practices.

(II) Narrator: The last question is, what can make a girl not to abstain from sex? Mentor, pause and allow the pairs 5 minutes to discuss.

(II) Narrator: Mentor, please pause and allow the pairs to share with the larger group.

Narrator: A girl might fail to abstain if;

1. She is tempted by a boy or man - either from curiosity or something he promises to give her

2. She is raped

Narrator: Abstinence is the only 100 percent effective method (sure way) for preventing unwanted pregnancy and sexually transmitted infections, including HIV. Abstinence allows girls to concentrate on their education and build their future. Islam advocates for sex only in a union of marriage. Abstinence is recommended for girls who are not yet married.

(II) Narrator: We have now come to the end of today's session. The mentor will now pause and allow you to ask any questions and clarify any confusing issues. Mentor, please pause.

Narrator: I hope you learnt something useful in today's session. See you next week. Goodbye! 


\section{Session 4 - CHILD SPACING METHODS FOR MARRIED WOMEN AND GIRLS}

Narrator: Hello, welcome to today's session. The session will focus on child spacing methods for married women and girls.

Narrator: Mentor, for this session you will need;

$\checkmark$ A blackboard and chalk OR flipchart and markers.

$\checkmark 4$ large pieces of blank paper and pens, pencils or markers

$\checkmark$ List of resources/ places where participants can assess child spacing methods and counselling.

$\checkmark$ A resource person (health worker) to explain the child spacing methods (if you have one in your community).

Narrator: Mentor, please note that this session is for married women and girls ONLY.

Narrator: The session will take about 1 hour and 30 minutes.

(II) Narrator: We will begin today's session with an energizer from a volunteer. Mentor, pause and request for a volunteer to lead the energizer.

(II) Narrator: I hope the energizer was fun! Mentor, ask participants to share what they learnt during the last session. Remember to add anything that they have left out and clarify any confusing issues. You can now pause, listen and provide feedback.

Narrator: When a woman gets married, it is expected that she will bear children. However it is important to space children to safe guard the health and the well-being of the mother and the child. In order to do this, there are various methods that can be used to prevent pregnancy, they are widely called child spacing. If one is in a marriage, one can safely use any child spacing method. However, while all methods are medically safe for young people, some may be more appropriate than others

Narrator: Today's session will focus on one of the key obligations of a married woman, which is to have children. We will discuss the benefits of child spacing in the context of marriage, and about the different methods that can be used for child spacing. Feel free to ask questions during the presentation about the different methods.

(II) Narrator: What are some reasons why a married woman, especially an adolescent who is married, should space her children so that they are at least two years apart? Mentor, pause and discuss the responses. 
Narrator: A married woman or girls needs to space her children for at least two years to make it easier for her to fulfil responsibilities as wife. A woman plays many roles in the society and in the family and needs to have proper health and even time to be able to carry out roles. Sometimes a woman may not effectively be able to carry out family tasks especially if she has young children at home that she needs to care for.

Narrator: From a medical perspective, it is recommended that a woman should "rest" her body for two years in between each pregnancy. This has been shown to result in a healthier pregnancy and baby.

Narrator: Now that we understand why it's important for married woman and girls to space their children, we will now discuss the different methods for Child Spacing.

(II) Narrator: Which child spacing methods do you know or have you heard of? Mentor, pause and discuss the responses.

Narrator: There are several temporary methods that can be used to block the sperms from reaching the egg. Today, we will discuss some temporary and traditional methods of child spacing. Mentor, if you had invited a guest speaking, introduce the speaker to explain the different types of childe spacing methods. If not, please continue with the recording.

Narrator: The first temporary method is the male condom. A male condom is a thin latex sheath rolled onto the erect penis before intercourse that prevents sperm from entering the vagina. If used correctly and consistently, a condom can prevent STIs and HIV. A male condom;

$\checkmark \quad$ Is one of the two methods that offer double protection, against pregnancy and infection, thus may also protect against infertility and cervical cancer.

$\checkmark$ Enables men and boys to protect themselves and their partners.

$\checkmark$ Is easily available.

$\checkmark$ Must be put on during sexual activity prior to intercourse.

$\checkmark$ Some people find that it reduces sensation.

$\checkmark$ May break or leak, especially if used incorrectly. 
Narrator: The second method is the female condom. A female condom is a lubricated plastic sheath with two rings. One remains outside the vagina, covering part of the labia, and the other is placed in the vagina, covering the cervix. It forms a pouch that collects the semen. If used correctly and consistently, a female condom can prevent STIs and HIV. A female condom;

$\checkmark$ Can be inserted hours before sexual activity begins.

$\checkmark$ Enables women and girls to protect themselves and their partners.

$\checkmark$ Is noticeable during sex, and insertion may require practice.

$\checkmark$ Is expensive in comparison with the male condom.

Narrator: The third method is oral contraceptives (pill) which are small pills containing synthetic hormones (estrogen and progestin, or only progestin) that prevent ovulation and interfere in sperm migration by thickening the cervical mucus. They are taken orally every day by the woman for 21 or 28 days, depending on the brand and type. Pills cannot protect one from STI's and HIV. It is important to note the following things about the pill;

$\checkmark$ Does not require the woman to insert or apply anything at the time of sexual relations.

$\checkmark$ May reduce menstrual cramps and the risk of certain kinds of cancer, anemia, breast problems, and pelvic inflammatory disease.

$\checkmark$ The woman must remember to take the pill regularly.

$\checkmark$ Typically, fertility resumes quickly after the woman stops taking the pill

Narrator: The fourth method is injectable which is an injection given at regular intervals, usually every one or three months. The injections contain progestin, a synthetic hormone that prevents ovulation and thickens the cervical mucus. Injectable cannot protect one from STI's and HIV. It is important to note the following things about the injectable;

$\checkmark$ The method can be used without the knowledge of others.

$\checkmark$ It does not require the woman to insert or apply anything at the time of sexual relations.

$\checkmark$ It may decrease the risk of certain kinds of cancer.

$\checkmark$ Fertility resumes within a few months after stopping use.

Narrator: The fifth method is implants. Implants are one or two small, soft rods implanted in the woman's upper arm that release a steady low dose of progestin over a period of three to five years. Implants thicken the cervical mucus and inhibits ovulation. Implants cannot protect one from STI's and HIV. It is important to note the following things about the implants;

$\checkmark$ Implants can be removed at any time, but they must be inserted and removed by a trained provider.

$\checkmark$ It does not require the woman to insert or apply anything at the time of sexual relations.

$\checkmark$ Fertility resumes immediately upon removal 
Narrator: The sixth method is the Intrauterine devices (IUDs). The IUD is a small device, commonly shaped like a T that are placed in the uterus by a health care provider. Some IUDs release progestin (a hormone), while others contain copper, which has antifertility effects. They keep the sperm from reaching the egg. Some types of IUDs can work for as long as ten years. IUDs cannot protect one from STI's and HIV. It is important to note the following things about the IUD;

$\checkmark$ This method does not interrupt sex; it is not noticeable during intercourse.

$\checkmark \quad$ If an infection is present during insertion, or if the conditions for insertion are not sterile, insertion may lead to pelvic infection and increased risk of infertility.

$\checkmark$ The body sometimes expels the IUD.

$\checkmark$ It must be inserted and removed by a trained provider.

(II) Narrator: We will now take a break and conduct an energizer before we discuss about "Natural"/Traditional Methods of child spacing. Mentor, pause and conduct an energizer.

Narrator: Welcome back! I hope you enjoyed the energizer. We will now discuss several natural or traditional child spacing methods. It is important to note that this methods require specific behaviors and an understanding of one's body; which will be discussed in this section.

Narrator: The first natural method is lactational amenorrhea method. This method is for breastfeeding women only. Breastfeeding causes the body to produce hormones that can prevent ovulation. As contraception, this method is effective only during the first six months of breastfeeding or until the woman has resumed menstruation (whichever comes first), and only if the baby is fed only breast milk and on demand. This method cannot prevent one from STIs and HIV. It is important to not the following about the breast feeding method;

$\checkmark$ Breastfeeding is free and has positive health effects for the mother and the baby.

$\checkmark$ The lactational amenorrhea method (LAM) may be difficult for women who need to be away from their baby regularly.

Narrator: The second natural method is withdrawal. Withdrawal is simply pulling the penis out of the vagina and away before ejaculating prevents sperm from entering the vagina. This method can be effective if used correctly and consistently. Withdrawal cannot prevent one from STIs and HIV. It is important to note the following about withdrawal;

$\checkmark$ Withdrawal is always available and free.

$\checkmark$ It is considerably more effective than not withdrawing.

$\checkmark$ It depends on the man's self-control and ability to predict ejaculation; women have no control with this method.

$\checkmark$ It interrupts sex and may lessen pleasure. 
Narrator: The last natural method that we will discuss today is calendar or cycle Beads method. Many women have menstrual cycles that are predictable in terms of how often a new cycle starts. Cycle Beads (used for the Standard Days Method) and the calendar are two methods that can identify the fertile days during which she can abstain from sex or use a barrier method of contraception. This method cannot prevent one from STIs and HIV. It is important to note the following about calendar or cycle Beads method;

$\checkmark$ This method is most practical for women with regular cycles.

$\checkmark \quad$ It can also help couples that are trying to become pregnant to identify the most fertile days of the cycle.

$\checkmark$ It requires the woman's partner's cooperation

(II) Narrator: Now that we know the different types of child spacing method, I would like you to discuss one myth and fact that you know about child spacing methods. You will discuss with the person on your left for about 5 minutes. Mentor, pause and explain the exercise.

(II) Narrator: Mentor, give each pair a chance to share their discussion on myths and facts with the rest of the participants. Be sure to correct any misconceptions. Mentor, pause and lead the discussion.

Narrator: Mentor, share with the participants the places in the community where they can access and get more information on child spacing methods and counselling. This information will be helpful to those who are married and should be in consultation with their partners/husband.

(II) Narrator: It's now time to ask the mentor questions and clarifications. Mentor, pause and respond to questions.

Narrator: Girls, hope you enjoyed the session! See you next week. Bye bye! 


\section{Session 5: Reproductive Myths 21}

Narrator: Hello, welcome to today's session which is reproductive health myths. We will discuss myths about reproduction, and learn that some myths can be harmful

Narrator: Mentor, for this session you will need a blackboard and chalk OR flipchart and markers.

Narrator: The session will take about 1 hour and 30 minutes.

(II) Narrator: We will begin today's session with an energizer from a volunteer. Mentor, pause and request for a volunteer to lead the energizer.

(II) Narrator: I hope the energizer was fun! Mentor, ask participants to share what they learnt during the last session. Remember to add anything that they have left out and clarify any confusing issues. You can now pause, listen and provide feedback.

(II) Narrator: We will begin the session by understanding the meaning of word fact and myth. Facts are things that we know to be true. For example: "The sun rises every day" or "there are seven days in a week." What are some other examples of facts that you know? Mentor, pause and discuss the responses.

(II) Narrator: On the other hand, a myth is something people may believe to be true, but has not been proven to be true. For example, "if you eat a lot of potatoes your breasts will grow big" or "if a girl is touched by a boy it will make her breasts and hips grow big". What are some other examples of myths that you know? Mentor, pause and discuss the responses.

Narrator: There are many myths and misconceptions about reproduction, and other areas in life, and acting on them can have negative consequences. When making decisions about reproduction, only consider the facts. If someone is not sure about the facts, they should ask a knowledgeable person, such as a counselor, doctor, or nurse, and not rely on friends who may not have accurate information.

\footnotetext{
${ }^{21}$ Kenya Adolescent Reproductive Health Project (KARHP), PATH, Population Council. 2005. Tuko Pamoja: Adolescent Reproductive Health and Life Skills Curriculum.
} 
(II) Narrator: We will now participate in an activity to discuss and clarify some of the menstruation, reproduction, and child spacing myths. Mentor, pause and divide participants into 3 groups. Then draw 3 columns on a flip chart or black board. The first column should be written group one. The second group 2 and the third group 3.

(II) Narrator. I hope you are all in a group. Now, listen carefully to the instructions of the activity. I am going to read a statement to the first member of one group. Then that member should consult with the rest of the team for 2 minutes to determine whether the statement is a "myth" or "fact." Then the member who I asked the question reports the team's response. If the response is correct, that team gets one point. Then I will ask for an explanation of why the statement is a "myth" or "fact." Have you understood the instructions? Mentor, pause and clarify.

(II) Narrator: I hope the instructions are now clear. The first question goes to the first member of group one. The blood coming from a woman during menstruation means that she is sick is it a myth or a fact. Mentor, pause and listen to the response and explanation.

(II) Narrator: The answer is that it is a myth. If an egg is not fertilized, the body dispels blood and tissue during a woman's monthly menstruation. Mentor, pause and award 1 mark to group one; if the participant answered correctly.

(II) Narrator: The second question goes to the first member of group two. Cold drinks do not cause menstrual cramps. Is it a myth or a fact? Mentor, pause and listen to the response.

(II) Narrator: It is a Fact. Menstrual cramps are caused by muscle spasms in the uterus during or between menstruations. Mentor, pause and award 1 mark to group two; if the participant answered correctly.

(II) Narrator: The third question goes to group 3. Women should not eat spicy or sour foods during menstruation. Is it a myth or a fact? Mentor, pause and listen to the response.

(II) Narrator: It is a myth. Women can eat any food they want during menstruation. Mentor, pause and award 1 mark to group three; if the participant answered correctly.

(II) Narrator: Now, the forth question goes to group 1. If a woman misses her period, this could mean she is pregnant. Is it a myth or a fact? Mentor, pause and listen to the response. 
Narrator: It is s fact. Monthly periods signify that a woman's egg has not been fertilized. Missing a monthly period may mean that the woman's egg has been fertilized, in other words, she is pregnant.

(II) Narrator: The fifth question goes to group 2. If men do not ejaculate, sperm will collect and make their penis or testicles burst. Is it a myth or a fact? Mentor, pause and listen to the response.

Narrator: It is a myth. If men do not ejaculate, sperm are stored until they fatigue, at which point they break down and are reabsorbed by/recycled into the body in the same way food or old blood cells are absorbed by the body.

(II) Narrator: The sixth question goes to group 3: It is perfectly safe for a woman to wash her hair or take a bath during her period. Is it a myth or a fact? Mentor, pause and listen to the response.

Narrator: It is a fact. There is no risk to a woman washing anything during her period. In fact, it is very important to keep the body clean during this time, to avoid infection of the reproductive tract.

(II) Narrator: Question number seven goes group number 1. Is having menstrual blood means a woman is dirty. Is it a myth or a fact? Mentor, pause and listen to the response.

Narrator: It is a myth. Having menstrual blood is a healthy and normal occurrence in women signifying that her egg has not been fertilized.

Narrator: Question number eight goes to group 2.When a man has an erection, he must always ejaculate.

Narrator: It is a myth. Many times men have erections without ejaculating; if the man waits for some time, the erection will go away without ejaculation.

Narrator: The last question goes to group 3. Using child spacing methods is harmful to your health 
Narrator. It is a myth. Using child spacing methods improves the health of the mother and her children.

Narrator: Hope you enjoyed the exercise. Mentor, make sure you award the marks correctly and calculate the total marks for each group and announce the winning group.

(II) Narrator: It's now time to ask the mentor questions and clarifications. Mentor, pause and respond to questions.

Narrator: Girls, hope you enjoyed the session! See you next week. Bye bye! 


\section{Gender-Based Violence}

\section{Session 1: Gender Based Violence 22}

Narrator: Hello girls! Today's session will focus Gender-Based Violence. We will learn about the different types, causes and consequences of Gender based Violence. Issues discussed in this session might be somewhat sensitive. Please feel free to talk privately with your mentor in case you have any personal questions.

Narrator: Mentor, for this session you will need a blackboard and chalk OR flipchart and markers. You will also need a list of community resources/ places where a girl can report in case they are violated/ experience gender based violence.

Narrator: The session will take about 1 hour and 30 minutes.

(II) Narrator: We will begin today's session with an energizer from a volunteer. Mentor, pause and request for a volunteer to lead the energizer.

(II) Narrator: I hope the energizer was fun! Mentor, ask participants to share what they learnt during the last session. Remember to add anything that they have left out and clarify any confusing issues. You can now pause and listen and provide feedback.

(II) Narrator: Thank you girls for sharing what you learnt last time! We will begin the session by defining Gender Based violence. Girls, what is Gender Based Violence? Mentor, pause and listen to the feedback.

Narrator: GBV is any act that results in, or is likely to result in, physical, sexual or psychological harm or suffering to someone (boy or girl) based on gender-role expectations and assumption.

(II) Narrator: What are some examples of gender-based violence (GBV) in addition to rape? Mentor, pause and listen to the feedback.

\footnotetext{
22 Kenya Adolescent Reproductive Health Project (KARHP), PATH, Population Council. 2005. Tuko Pamoja: Adolescent Reproductive Health and Life Skills Curriculum.
} 
Narrator: Examples of GBV other than rape are; battering/beating, intimidation at school - i.e. a teacher threatening a female student with rape or unwanted sexual touching in order to get a good grade, female genital cutting deprivation of food or water, deprivation of education, trafficking of women, sexual assault among others.

(II) Narrator: Now, we will talk about sexual exploitation. Girls, what is sexual exploitation? Mentor, pause and listen to the feedback.

Narrator: Sexual exploitation is when someone uses sex, or the threat of sexual violence, to get something from the other person without concern about how that person feels. Sometimes, people trick or pressure others into sexual activity - whether it be sex, kissing, etc. - to get what they want. For example, a man may tell a girl that he will give her new clothes, or pay her school fees, if she agrees to have sex with him, or let him touch her in unwanted ways. Or, a teacher may tell a girl that she will fail her exam unless she lets him touch her breasts. Sexual exploitation can be considered a form of sexual violence or abuse as well.

Narrator: We will now talk about good, confusing and bad touches. In our community, there are different kinds of touching between people - between a mother and her child, between friends, between men and women. Some of these are good touches. Some are bad touches. And some are a little bit confusing. Let's talk about these different kinds of touches so that you can understand what they mean.

(II) Narrator: Mentor, pause and draw 3 columns on the blackboard/ flip chart. Write good touch on the first column, bad touch on the second column and confusing touch on the last column. You will feel up the appropriate column as the girls give feedback on the different types of touches. Girls, what do you think are some examples of good touches, confusing touches, and bad touches? Mentor, listen to the feedback as you fill the appropriate column.

Narrator: Some examples of the good touches you have mentioned are;

\begin{tabular}{|l|}
\hline Good touches \\
\hline Hugging \\
Holding hands \\
Hair brushing \\
A pat of the back \\
A doctor's examination \\
\hline
\end{tabular}


Narrator: Some examples of bad touches you have mentioned are;

\begin{tabular}{|l|}
\hline Bad touches \\
\hline Kicking \\
Biting \\
Punching \\
Slapping \\
Pinching \\
Forced sex \\
\hline
\end{tabular}

Narrator: Finally, some examples of confusing touches you have mentioned are;

\begin{tabular}{|l|}
\hline Confusing touches \\
\hline Kissing \\
Tickling \\
Touching private parts \\
Handshake with a pinch \\
Back rubs \\
\hline
\end{tabular}

Narrator: Remember, Some of these touches could be good touches or bad touches depending on the intent of the touch. If an older man starts a kiss with a child, it could be a bad touch, but if a mother kisses her child, it is a good touch. If a back rub is intended to lead to sexual activities it could be a bad touch, but if a sister pats the back of a baby, it is a good touch

Narrator: Sexual exploitation usually happens gradually. It starts with a good touch, goes to a confusing touch and into a bad touch. It also usually involves tricks, threats, or treats. Most often, involves a person known to the exploited, even though it also happens with strangers. Many times it can involve a pact of secrecy and it can affect both boys and girls.

Narrator: We are now in the final section of today's session. In this session, we will talk about how to get out of an exploitative situation. I will begin by telling you a very interesting story about two girls called Halima and Aden. At the end of the story, I will ask you some questions. 
(II) Narrator: Girls, how do you think Halima and Aden felt? Mentor, pause and listen to the feedback.

Halima and Aden were sent by their mother to get a packet of sugar from their neighbor. They have been sent there many times before. Upon arrival, the neighbor (an elderly man) invites them for some fruit in the house. While they are eating the fruit, the elderly man started tickling Halima'.

Narrator: Thank you for your feedback. Now, I am going to tell the second part of the story.

Just before Halima and Aden left, the neighbor offered to give them some money if Halima would tickle him too.

(II) Narrator: The second question is, what would you have done if you were Halima? If you were Aden? Would you have said NO, left or be rude to the neighbor since he was also rude and therefore no need to consider his feelings, even though he is older. Mentor, pause and listen to the feedback.

Narrator: I am now going to narrate the last section of the story. Please listen keenly.

After Halima refused, the neighbor left them alone but then gave them the money he had offered so that they would not tell anyone about the incident.

(II) Narrator: Girls, what would you do now if you were Halima and Aden? Mentor, pause and listen to the feedback.

Narrator: It is important for Halima and Aden to report the incident so that they can protect themselves from a repeat incident with the neighbor, and to protect other children from the neighbor.

(II) Narrator: We are now going to discuss more about reporting gender based violence. Who does one report to in case they are violated? Mentor, pause and listen to the feedback. 
Narrator: When one a girl is violated, she can report to community members (especially community leaders), teachers, mentor, parents, healthcare providers, friends, older siblings, or any other trusted adult.

(II) Narrator: Where one can report? Mentor, pause and share a list of places and contacts where one can report if they are violated/ experience gender based violence.

(II) Narrator: What difficulties might an adolescent experience in deciding who to report to? Mentor, pause and listen to the responses.

Narrator: Adolescent girls might experience; fear of punishment, fear that they will not be believed, fear of stigma and discrimination, fear of attitude of those reporting to, feelings of shame, blame, or powerlessness, lack of support, fear of revenge, unreliability of public services to respond to the reporting. It is however important to overcome those fears and report bad touches to a parent, guardian, teacher, or trusted relative as soon as possible because these touches do not normally end there - they can develop into actions such as forced sex. Reporting helps to protect yourselves and others.

(II) Narrator: We are about to end today's session. Before we do so, please ask the mentor any questions. Mentor, pause and respond to any questions and clarify any confusing issues.

Narrator: Thank you for your questions and active participation in today's session. Goodbye and see you next week. 


\section{Session 2: How to Report and Avoid Cases of Sexual Violence 23}

Narrator: Hello! Today you will learn about how to report and avoid cases of sexual violence. The session will help you to identify trusted adults with whom you can easily open up to and share problems and learn about avoiding and reporting cases of sexual violence or abuse.

Narrator: Mentor, for this session, you will need;

1. Blackboard and chalk OR flipchart and markers

2. List of organization contacts

3. Papers and pencils (for each participant)

4. A list of sexual violence or abuse focused organizations in the community

Narrator: The session will take about 1 hour and 30 minutes.

(II) Narrator: Mentor, pause and request for a volunteer to lead the group in an energizer.

(II) Narrator: I hope the energizer was fun! Mentor, ask participants to share what they learnt during the last session. Remember to add anything that they have left out and clarify any confusing issues. You can now pause and listen to feedback their girls.

Narrator: The first activity for this session will help us to understand who a trusted adult is. I will begin by reading a letter from a girl called Ebla to her mentor. Listen carefully because I will ask you questions at the end.

\footnotetext{
23USAID. 2006. Doorways I: Student Training Manual on School-Related Gender-Based Violence Prevention and Response; USAID. 2009. Doorways III: Teacher Training Manual on School-Related Gender-Based Violence Prevention and Response.
} 


\section{Ebla's Letter}

Dear Mentor,

My name is Ebla and I am 13 years old. I walk to and from school using the same route every day. The route passes by the bus stop, and each day an older man approaches me with an offer to buy me soda. He said he would buy me whatever I wanted and that a schoolgirl needs a special treat from time to time. One day he gave me a nice perfume and I took it. Last week, he asked me if he could escort me home after school. I said no, but he still persisted. Sometimes he gets close to me, and it is hard for me to get away from him. Walking to school became a nightmare, because I was also scared of the man who harassed me.

The man continued harassing me until I decided one day that I had to tell my elder sister who I trusted. It was difficult for me to speak to my sister at first about my problem but I told her that a man had approached me while I was walking to school. I told her I was scared and wanted to avoid the man, but did not know what to do because the man was persistent. She asked me if I had taken any gifts from the man. I admitted that I had. She told me that I should not take gifts from strangers, because sometimes people use gifts to get favors or to trick young girls. She then advised me to walk to and from school in the company of other students or teachers and she offered to help me identify students or teachers who used the same way I used to school. Although I was scared, I was glad that I had my sister about my problem because she listened to me and offered me help. I feel so relieved now that the situation has been resolved and I can walk to school safely.

(11) Narrator: Who is the trusted adult was in this story? Mentor, pause and listen to the feedback.

(II) Narrator: Well done, the trusted adult was Elba's elder sister. Mentor, pause and listen to the feedback.

(II) Narrator: The second question is, what makes someone a trusted adult? Mentor, pause and listen to the feedback. 
Narrator: Very good, a trusted adult is;

$\checkmark$ someone you know who will help them if they need help

$\checkmark$ someone you can talk to about anything, especially your problems, or if you are feeling scared, confused or uncomfortable

$\checkmark$ someone you feel happy being around

$\checkmark$ someone who listens to you and cares about your problems

$\checkmark$ someone who has helped you before, or

$\checkmark$ someone who would help you solve a problem, be understanding, get help and work to keep you safe]

(II) Narrator: What steps did Ebla take to get help? Mentor, pause and listen to the feedback.

Narrator: Elba identified an adult in her family/community whom she could trust and one who could help her.

(II) Narrator: How did her sister help Ebla? Mentor, pause and listen to the feedback.

Narrator: Elba's sister advised her not to get gifts from strangers and offered her a solution to her problem.

(II) Narrator: How did Ebla feel when her sister helped her? Mentor, pause and listen to the feedback.

Narrator: Elba was glad because her sister offered her help and advice.

Narrator: If anyone approaches you and tries to hurt you, touches you in a way that makes you feel scared, uncomfortable, or confused, or if you feel that you are in danger, you should tell a trusted adult immediately.

(II) Narrator: Who are some of the trusted adults in your lives? Mentor, pause and listen to the responses.

Narrator: Some of the trusted adults are; mother, uncle, police officer, father, neighbor, coach, grandmother, big brother/sister, church person, grandfather, principal/headmaster, friend's parent, aunt, teacher among others.

Narrator: You are now going to identify a list of trusted adults that you can talk to in case you have a problem. Please take your note books and write a list of your own trusted adults. Mentor pause, and allow the participants 5 minutes to develop the list. 
(II) Narrator: What role could trusted adults play if a girl reported a case of sexual abuse or violence to them? Mentor, pause and listen to the feedback.

Narrator: The trusted adult will console the survivor, help the survivor find medical care, ensure the case is followed up, seek justice for the survivor, among other key roles.

Narrator: Remember that not all adults are trustworthy. While there are adults who may try to harm you, there are also many adults who will help you. You should go to someone you feel comfortable and secure around. If anyone does anything to you that is not appropriate, you should go to a trusted adult for help immediately. If the first person you tell does not believe you, you should keep on trying until someone does.

Narrator: I am now going to read a letter from a girl called Zulekha. Listen carefully because I will give you an exercise at the end.

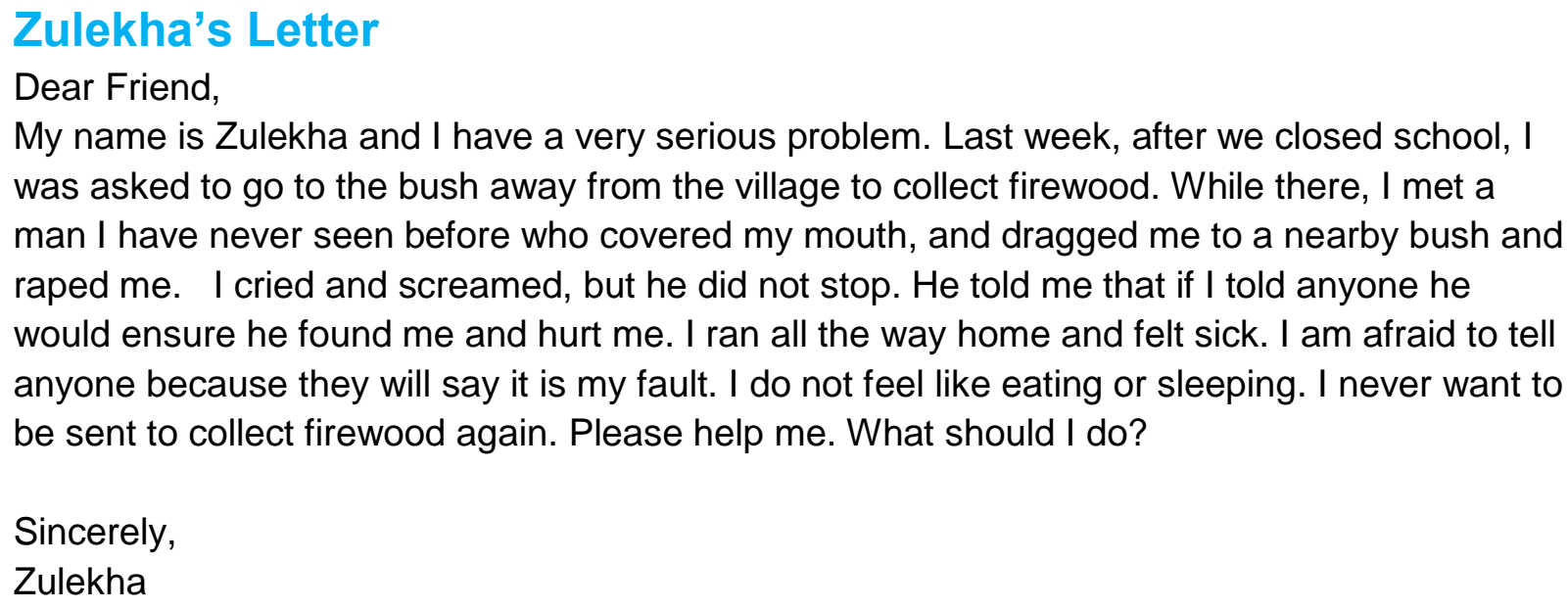

(II) Narrator: Girls, you will work in pairs and write a letter to Zuleka telling her what she should do. Mentor, pause and divide the girls in pairs. Explain the exercise and allow them 5 minutes to write a letter to Zulekha.

(II) Narrator: Girls from your letter, please share what Zuleka should do. Mentor, pause and listen to the responses from a few pairs. 
Narrator: Zulekha should;

$\checkmark$ Zulekha should not be afraid to tell a trusted adult. It was not her fault. No matter what, no one should blame Zulekha. If the trusted adult is someone other than Zulekha's parents, someone should contact her parents.

$\checkmark$ The trusted adult will help her by going to the police. A stranger raped Zulekha. Rape is a crime. The trusted adult should look for someone in the police unit who has been trained to deal with sexual violence and abuse. The police will file a report against the crime and offer a medical report, which will enable medical examinations at the clinic or hospital to be conducted.

$\checkmark$ The trusted adult should also take Zulekha to a hospital or clinic for medical treatment and to collect any evidence needed by the police. At the clinic/hospital medical personnel will check for pregnancy and offer emergency contraceptives and tablets are given to help reduce the risk of HIV infection.

$\checkmark$ Advise Zulekha that the best thing to do is not to take a bath until she has been examined by a medical person to avoid washing away the evidence. This is why Zulekha should tell a trusted person as soon as she is defiled/raped. The trusted person will escort her to the police station and later go to the medical center to be examined.

$\checkmark$ The trusted adult together with the parent's will also report the case to the area chief or the elder's committee, who will then work with the police to ensure the perpetrator is apprehended. This will also help the community committee to ensure prevention mechanisms are put in place to safe guard women and girls in the village. If possible, Zulekha should also go to see a counselor. The counselor can help her process her feelings and understand it was not her fault. Talking to a counselor will also increase her courage and help her be more resilient.]

Narrator: Please not that it is VERY important to report cases of sexual abuse within 72 hours of the incident. Tablets to prevent pregnancy if rape took place during the abuse work more effectively within 72 hours. Also a delay in reporting may result in loss of some evidence.

(II) Narrator: Please pause and lead the group in an energizer.

(II) Narrator: Welcome back to the session. I hope you enjoyed the energizer. How can children and adolescents avoid being sexually abused? Mentor, pause and listen to the responses. 
Narrator: Children and adolescents can avoid being sexually abused by;

$\checkmark$ Avoiding moving or playing outside the house at night,

$\checkmark$ Avoiding using lonely roads when you are not accompanied,

$\checkmark$ Asking a friend to accompany you when visiting male relatives in homes where there are no female adults,

$\checkmark$ Walking in groups of girls or be accompanied by trusted men or older boys in the community when going to unfamiliar places especially when herding, collecting firewood, or fetching water, among other places

Narrator: Adults should always protect young people. If adults ever ask a girl to do anything that makes her uncomfortable, she has the right to refuse. She should not be in isolated places at school or walking to and from school. She should always walk with a group or another student. If a teacher or anyone asks to look under her clothes, she should not let that person do it. If a teacher or anyone touches her or gets too close, she must tell a trusted adult immediately. Adults need to ensure children's safety. It is not the student's entire responsibility.

Narrator: We are now in the final section of this session where we will practice how to report violence. It is not always easy to speak up and report violence. In this section, you are going to practice telling someone that you have experienced violence.

(II) Narrator: The mentor will divide you into groups where you will create a 3 minutes role-play in which a girl experiences violence or abuse and reports it. Be sure to identify a trusted adult to whom the character in the role-play reports the incident. You will have an opportunity to present the role play to the rest of the participants. Mentor, you can now pause, divide the participants into groups and explain the activity once more. Give the groups 10 minutes to create the role play.

Narrator: Mentor, after participants have had a chance to prepare the role-play, let each group present their role-play. After each group has presented their role-play, discuss the following questions with them. You can write the questions on a flipchart or blackboard;

$\checkmark$ What happened to the girl in the role-play?

$\checkmark$ What action did the girl take after the incidence?

$\checkmark$ How did the steps taken by the girl help her?

$\checkmark$ What were some of the things the girl used as evidence to report the incidence?

$\checkmark$ Who was the trusted adult in the role-play?

$\checkmark$ What did the adult do?

$\checkmark$ Do you have any suggestions for the girl? For example, was there anyone else she could have told? 
(II) Narrator: Mentor, pause and allow each group to present their role play as you discuss the questions.

(II) Narrator: I hope you enjoyed the role plays. Mentor, pause and give the girls an opportunity to ask any questions. Remember to clarify any confusing issues.

Narrator: We have now come to the end of today's session. I hope you enjoyed it. See you next week. Bye bye! 


\section{Session 3: Safety planning}

Narrator: Hello! Today you will learn about safety planning. The session will help you to identify when and where you are more and less safe and understand ways of increasing safety in the different aspects of their lives.

Narrator: Mentor, for this session, you will need a blackboard and chalk OR flipchart and markers

Narrator: The session will take about 55 minutes.

(II) Narrator: Mentor, pause and request for a volunteer to lead the group in an energizer.

(II) Narrator: I hope the energizer was fun! Mentor, ask participants to share what they learnt during the last session. Remember to add anything that they have left out and clarify any confusing issues. You can now pause and listen to feedback their girls.

Narrator: We will begin the session by an activity to help us think about different situations when you, as girls, feel very safe, maybe safe, or not safe at all. Then we can use that information to make sure that you stay as safe as possible.

(II) Narrator: The mentor will divide you into groups then I will give each group a task. Mentor, pause and divide participants into 4 groups. Girls, you will begin the activity once all the groups are assigned their activity.

Narrator: Group 1, you will do an activity to discuss Safety at Different Times of the day. Group 1, discuss where usually you are during early morning, mid-morning, mid-day, afternoon, evening and night. For each time of the day, indicate whether you are always safe there, never safe and what would make/ needs to be done to make the place safe.

(II) Narrator: Mentor, pause and clarify the activity.

Narrator: Group 2, you will do an activity to discuss Safety in Different Seasons. Group 2, think about different seasons, and for each season, if there are safety risks in that season and what can be done to make them safer. Seasons can be - rainy season, dry season, migration with the cattle, when school fees are due, Ramadhan, other holidays/festivals, when school is in session, etc.

(II) Narrator: Mentor, pause and clarify the activity. Encourage participants to identify additional seasons. 
Narrator: Group 3, you will do an activity on Safety in Different Situations. Think about different situations in which you might find yourselves at risk or feel unsafe. Once you have identified the situations, think of what can be done to reduce that risk or make you feel safe. Situations may include: going to a shop/market on your own, getting stopped by a police man/security officer, , going to fetch water or firewood, herding the cattle, walking to school.

(II) Narrator: Mentor, pause and clarify the activity.

Narrator: Group 4, you will do an activity on Safety by Day. Think about each day of the week- Monday through Sunday, and decide which days in the week you feel most safe and relaxed, and why, and which days of the weeks they feel the least safe and why.

(II) Narrator: Mentor, pause, clarify the activity and give the groups 20 minutes to complete the group work.

(II) Narrator: You now take 20 minutes to complete your group activity. Mentor, pause.

(II) Narrator: You will now present and discuss your group work. Mentor, pause and led the discussion and emphasis on how to make unsafe situations safe.

Narrator: The world that we live in is mostly a good one, but there are various places, situations and people that may make us feel unsafe. While you cannot control the behavior of people who want to hurt you, by being aware what certain places, situations or people make you less safe, you can do the best you can to take control of your own safety. Remember that your friends here in the safe space, and me your mentor, are here to help you.

(II) Narrator: We are almost coming to the end of today's session. Mentor, pause and give the girls an opportunity to ask any questions. Remember to clarify any confusing issues.

Narrator: I hope you enjoyed today's session. See you next week. Bye bye! 


\section{Session 5: Preventing Unwanted Advances24.}

Narrator: Hello girls! Today we will learn about unwanted advances and what you can do to protect themselves.

Narrator: Mentor, for this session, you will need a blackboard and chalk OR flipchart and markers and cards with different colors.

Narrator: The session will take about 1 hour 25 minutes.

(II) Narrator: Mentor, pause and request for a volunteer to lead the group in an energizer.

(II) Narrator: I hope the energizer was fun! Mentor, ask participants to share what they learnt during the last session. Remember to add anything that they have left out and clarify any confusing issues. You can now pause and listen to feedback their girls.

Narrator: I will begin today's session by telling you a story about a girls called Fartuun. Please listen carefully because at the end of the session I will ask you some questions.

\section{Fartuun's Story}

Fartuun is 14 years old. She lives with her parents not very far from the nearest urban center which has many people and businesses. Her home is also near the road, where many busses and taxis pass as they ferry passengers. One of the bus drivers always passes by and gives her some juice and sweets.

(II)

Narrator: What do you think might happen next? Mentor, pause and discuss to the responses.

(II) Narrator: What are some possible endings for Fartuun's story? Mentor, pause and discuss to the responses.

(II) Narrator: What could Fartuun do to improve her situation? Mentor, pause and discuss to the responses. Emphasize the possibility of an ending in which Fartuun is able to escape the threat from the bus driver.

\footnotetext{
24 Johns Hopkins Bloomberg School of Public Health/Center for Communication Programs. 2011. Go Girls! Community-based Life Skills for Girls: A Training Manual. Baltimore, Maryland. Developed under the terms of USAID Contract No. GHH-1-00-07-00032-00, Project SEARCH, Task Order 01.
} 
Narrator: I am now going to tell you the second story of a girl called Ummy. Please be attentive.

Ummy's Story

Ummy is 13 and has four younger brothers and sisters. The family is experiencing financial difficulties and Ummy's mother is pregnant. Ummy helps her mother by walking to the market each day to sell/buy goods on her way to school. She is always approached by an elderly neigbour on her way to school, who professes his love for her. He is older and often ill. When she shares with her mother and auntie, her mother and aunt tell her it is an honor to receive the attention of this man and urge her to talk to him. She refuses because he is old and she doesn't like him, but they keep pushing her.

(II) Narrator: What could happen to Ummy? Mentor, pause and discuss the responses.

II Narrator: What are some possible endings for Ummy's story? Mentor, pause and discuss the responses,

(II) Narrator: What could Ummy do to improve her situation? Mentor, pause and discuss the responses.

(II) Narrator: What do the stories of Fartuun and Ummy have in common? Mentor, pause and discuss the responses.

Narrator: Although physical force was not used in Ummy's situation, people were using emotional force to push her in a direction she didn't want to go.

(11) Narrator: What are other situations or places where girls are in danger of coercive/unwanted sex in our community? Mentor, pause and discuss the responses.

(II) Narrator: How can girls in our own community avoid these situations or dangerous places? Mentor, pause and discuss the responses.

Narrator: Girls can avoid danger by; being alert to the surroundings, avoiding dark, lonely places at night, keep doors and windows locked, keep a loud whistle on a key ring, take a self-defense class, walk in groups, or scream for help if cornered

(II) Narrator: What do you think boys, girls, parents, leaders, the police, and the community can do to help stop unwanted sex from happening? Mentor, pause and discuss the responses. 
Narrator: Boys, girls, parents, leaders, the police, and the community can help to stop unwanted sex by: learning to respect others, having a stronger law enforcement systems, becoming educated on the topics of rape and gender-based violence, among other.

Narrator: We will now, go into our last activity today which will focus on getting help when faced with unwanted advances.

(II) Narrator: What are some of the problems that might happen to girls who have unwanted or forced sex? Mentor, pause and discuss the responses.

Narrator: If forced into sex, girls might; get pregnancy, contract STIs/HIV, suffer low self-esteem, feel sad/down/helpless etc.

(II) Narrator: Who could Fartuun or Ummy from the stories go to for help? Mentor, pause and discuss responses. Share with the girls the list of Community Resources and Contacts where they can get help.

(II) Narrator: What can they do if the people they go to for help don't at first believe them or don't take any action? Mentor, pause and discuss the responses.

Narrator: If the first person you tell does not believe you, you should keep on trying until someone does. Mentor, remind participants to find and identify helping adults in and outside the family who they can talk to.

(II) Narrator: We are almost coming to the end of today's session. Mentor, pause and give the girls an opportunity to ask any questions. Remember to clarify any confusing issues.

Narrator: I hope you enjoyed today's session. See you next week. Bye bye! 


\section{Harmful Traditional Practices}

\section{Session 1 - Early and Forced Marriages}

Narrator: Hello and welcome to today's session! In this session, we will understand the causes and consequences of early and forced marriage.

Narrator: Mentor, for this session you will need flipchart and marker pens and pencils of different colors.

Narrator: The session will take about 1 hour and 45 minutes.

(II) Narrator: We will begin today's session with an energizer of about 5 minutes. Mentor, pause and ask a volunteer to lead the group in an energizer.

(II) Narrator: I hope you enjoyed the energizer! Mentor, pause and ask the girls to share what they learnt during the last session. Please remember to clarify any confusing issues.

Narrator: Today we will talk about early marriage and forced marriage.

(II) Narrator: I will start the session by asking you some questions. Mentor pause after each question and get feedback from the girls.

Q 1. What do you think "early marriage" is? Mentor pause and get responses from girls.

Narrator: Thank you for your feedback. You are correct, early marriage is getting married before 18 years.

Q 2. What is the difference between "early marriage" and "forced marriage"? Mentor pause and get responses from girls.

Narrator: Correct, forced marriage happens against the girl's desire, an early marriage happens before a girl turns 18 , even if she wants to get married. 
Narrator: In addition, forced marriages occur when a girl does not give consent to get married, she is convinced by her parents or father to get married. This denies the girl a chance to pursue her education and get a meaningful job to sustain herself and her family. It is important to note that forced and early marriage is not allowed under the laws of Kenya. Girl's parents may be arrested if this is known.

\section{Q 3. What are some reasons why girls in Wajir get married before they are $\mathbf{1 8}$ ? Mentor pause and get responses from girls.}

Narrator: Parents not wanting to cater for girls' expenses anymore, parents pressuring girls for religious reasons, parents thinking girls will be taken care of if they get married, it is the social/cultural expectation, It is a waste of time to educate a girl, no girl in Wajir gets good grades so there's need to educate a girl are among the reasons girls in Wajir get married before 18 years.

\section{Q 4. Can someone share a story of a girl they know who got married before she turned $\mathbf{1 5}$ ? $\mathbf{1 7}$ ? Mentor pause and let 1 or 2} girls share.

\section{Q 5. Thank you for sharing, we are almost done with the Questions, what are some of the disadvantages of getting married early? \\ Narrator: You are correct, End of schooling, not having control in a relationship if the girl is quite young, getting pregnant early which has physical and mental consequences and not established herself financially are some of the disadvantages of getting married early.}

\section{Q 6. At what age do you want to get married and why? Mentor pause and get responses from girls.}

(II) Narrator: For Our second activity, we will try to understand how early marriage looks like. You will be divided into two groups and each assigned a scenario from which you will prepare a 5-minute role play. Mentor pause and divide the girls into two groups.

Narrator: I will now read out the scenario for each group, listen carefully.

Group A: act out a scene of Amina who has been forced into marriage by her parents when she was 14 . Amina is very unhappy because she is just about to be married off to a very old man who is thrice her age and older than her own father. Luckily for Amina, she is a beneficiary of the AGI program, she has not only been taught on the ill effects of early marriage but she has also learnt communication skills with adults. She hopes to talk to one of her aunties who appreciate education to convince her adamant parents. One early morning while on her way to fetch water and collect firewood she decides to talk to her auntie who lives a few kilometers 
away. Her auntie immediately accompanies Amina home and talks at length to her parents. She manages to convince them and eventually Amina pursues her education. Mentor pause and clarify.

Group B: Act a scene of Fatuma who is a brilliant girl and being forced into marriage because she is 15 and her parents want more camels and goats. However, the mother is at a loss because she knows if her daughter proceeds with her education without interruption, she is going to have a bright future and become a medical doctor like she desires. The mother consults a school mentor where her daughter goes to school and the mentor reports the issue to the police and chief. The parents are summoned by the chief and the area education officer who warn Fatuma's parents against early and forced marriage. Fatuma is happy that she will be able to continue with her education and eventually fulfill her career dreams.

(II) Mentor pause and clarify. Give the groups 20 minutes to prepare their work and present to the bigger group. After each role play, ask questions on the disadvantages of early and forced marriage

Narrator: Thank you for participating in the role play. You have highlighted the following as disadvantages of early and forced marriages

- Dropping out of school

- Bearing children at an early age predisposing girls to threats of reproductive health problems

- Unable to provide for family

- Unable to make decisions as one is considered a child

- Low self-esteem and confidence

- Battered career dreams/opportunities

Narrator: In the next activity, we are going to make a plan for handling early marriage. While we hope that you and your friends will not be put in a situation where you have to marry early or against your will, but it is important to be prepared and have a plan for who you will talk to in this scenario.

Narrator: Mentor, Divide the girls into groups and have them develop a plan of who they can talk to when threatened with early marriage. They should make a list of different people that is unique for each girl. They should make three copies of each plan. One will remain with the girl, one will remain with the mentor, and one she should give to a trusted friend in the group.

After about 10 minutes ask for 2-3 volunteers to share their lists.

Then, give girls five more minutes to make any changes to their list based on what they heard. 
(II) Narrator: We have come to the end of today's session. You can now ask the mentor any questions. Mentor, pause and respond to questions and or clarify confusing issues.

Narrator: Thank you for participating in today's session. See you next week 


\section{Session 2: Female Genital Cutting (FGC)}

Narrator: Hello girls! Welcome to today's session. We are going to learn about Female Genital cutting. By the end of the session you will be able to;

- Define what FGC is

- Understand the health consequences of FGC

- Know what to do when one is at risk of FGC

\section{Narrator: Mentor, for this session you will need;}

- Pictures/Diagrams of female anatomy. Which can be found on the health and life skills curriculum in the female genital cutting session.

- Flip Charts, marker pens,

- Pens and pencils of different colors

Narrator: The session will take approximately 1 hour and 30 minutes.

(II) Narrator: Before we begin let us do an energizer, Mentor, pause the recording and ask a volunteer to lead the group in an energizer of their choice. This should take you 10 minutes.

(II) Narrator: Thank you for participating in the energizer. Hope it was fun! Mentor, ask participants to share what they learnt during the last session. Add anything that they have left out and clarify any confusing issues. You can now pause and listen to feedback from the girls.

(II) Narrator: We will begin the session by defining Female Genital cutting or what is commonly known as female genital mutilation. Girls, what is your understanding of the term female gential cutting? Mentor pause and listens to responses from girls.

Narrator: Thank you for your response Female genital mutilation (FGM/C), also known as Female Genital Cutting (FGM/C) or Female Circumcision comprises all procedures involving partial or total removal of the female external genitalia, or other injury to the female genital organs for non-medical reasons.

(II) Narrator: Girls, what are the different types of FGM/C you know? Mentor, pause and listen to the girls' feedback. 
Narrator: From your discussion, there are 3 main types of FGM/C;

Type I is Clitoridectomy- This involves removal or splitting of the clitoral hood. Mentor, pause and show and explain to the participants the image of clitoridectomy. The image can be found in in your health and life skills curriculum; on the Female genital cutting session.

Type Ilis Excision:(this involves removal of the prepuce and the clitoris plus the partial or total removal of the labia majora. Type II circumcision is a more extensive form of FGM compared to Type I and due to the sewing together of the leftover labia minora epidermis, which contains sweat glands, a buildup of sweat and urine in the closed off space beneath this closure can lead to local or urinary infection, septicemia, hemorrhaging and cyst formation. Mentor, pause and show and explain to the participants the image of excision. The image can be found in in your health and life skills curriculum; on the Female genital cutting session.

Type III is Infibulation - this is the most severe form which involves cutting off the female genitalia and stitching to leave a pencil-size hole. The cutting and stitching is repeatedly done when a woman marries and has children. Mentor, pause and show and explain to the participants the image of infibulation. This image can be found in your health and life skills curriculum; on the female genital cutting session.

(II) Narrator: What do you think are some of the physical or health effects of FGC? Mentor, pause and listen to the feedback.

Narrator: Some of the physical or health effects of FGC are;

1. Recurrent bladder and urinary tract infections

2. Cysts. Which are growths around the female reproductive organ which can cause difficulty in getting pregnant.

3. Child birth complications. Which can cause the mother or child to die during delivery.

4. Vagina/Rectal Fistula. This is where a girl is unable to control the urge to either go for a short or long call.

5. Severe pain

6. Excess bleeding

7. Tetanus

8. Septicemia. Which is an infection of the blood due to an infection. This can lead to death.

9. HIV Infection. In cases where the FGC practitioner uses the same equipment for all the girls. If one girl is infected with HIV, she can infect the other girls.

(II) Narrator: What do you think are some of the psychological consequences of FGC? Mentor, pause and listen to the responses, 
Narrator: From your discussion, you have noticed that FGM/C is an occasion marked by fear, submission, inhibition and the suppression of feelings. The experience is a vivid "landmark" in the mental development of girls, the memory never leaves them. FGM/C is commonly performed when girls are young and uninformed, and is often preceded by acts of deception, intimidation, and coercion by parents, relatives and friends that the girl has trusted.

Narrator: Girls may suffer feelings of betrayal, bitterness and anger at being subjected to such an ordeal, even if they receive support from their families immediately following the procedure. This may cause a crisis of confidence and trust in family and friends that may have long-term implications. It may affect the relationship between the girl and her parents, and may also affect her ability to form intimate relationships in the future, even perhaps with her own children. Symptoms of psychological stress, due to FGC, include; sleeplessness, nightmares, loss of appetite, weight loss or excessive weight gain, as well as panic attacks, instability of mood, and difficulties in concentration and learning.

(II) Narrator: So, girls, why do we think our communities practice FGM? Mentor pause and listen to feedback from the girls.

Narrator: It is important to note here that even though this is a very common practice, it doesn't mean that it must carry on forever or that the girls in your group must have their daughters cut once they become mothers. FGM can take many different forms and in our community, it is a widespread practice.

(II) Narrator: What happens to girls who are not circumcised? Mentor, pause and listen to the feedback.

Narrator: it is a girl's right not to undergo FGC. If this is a practice that has happened to you, the best thing to do is seek the necessary medical and psychosocial support if necessary and not pass on the practice to the next generation

(II) Narrator: What are some of the Myths and Facts FGC? Mentor pause and take responses from girls.

(II) Narrator: From your discussion, there are a number of myths around FGC. Now, I will like to read out some statements then you will tell the mentor if the statement is a myth or a fact. Mentor pause after each statement and ask the girls to tell you if the statement is a myth or a fact.

II Narrator; The first statement is; If not cut, the clitoris will continue to grow, is this a myth or fact, Mentor pause and listen to the girls' responses. 
Narrator: This is a myth since the clitoris stops growing after puberty

(II) Narrator: Number two; To control the moral behavior of a woman is this a myth or fact, Mentor pause and listen to the girls' responses.

Narrator: This is a myth since FGC cannot control the moral behavior of a woman. These are values that one adopts in life but not though FGC

(II) Narrator: If her woman is not circumcised, her body will smell. Is this a myth or fact? Mentor pause and listen to the girls' responses.

Narrator: This is a myth. FGC will not make the vagina more hygienic, in fact it can make it less hygienic

(II) Narrator: FGC assures faithfulness of women to their husbands. Is this a myth or a fact? Mentor pause and listen to the girls' responses.

Narrator: This is a myth because FGC does not assure faithfulness between a husband and wife. A woman who has undergone FGC can still be unfaithful if she wishes to

(II) Narrator: FGC is required by my religion. Is this a myth or a fact? Mentor pause and listen to the girls' responses.

Narrator: This is a myth; FGM is not required by Islam

Narrator: As we discussed earlier, some communities practice FGC on girls at an age younger than you are now. However, some do it around the age of puberty.

(II) Narrator: We will now get into groups of 3-4 girls each and talk about what we can do about FGC. We will then present to the bigger group. Mentor pause and divide the girls into groups 
Narrator: Mentor, please write the group work questions on a flipchart or blackboard;

1. What can you do if you or someone you know is at risk of FGC?

2. Where can someone go if they have already had FGC practiced on them to get more information or if they want to talk to someone about it?

(II) Narrator: Mentor, pause and explain the group work to the girls. Allow the participants 10 minutes to discuss. Each group should be given an opportunity to present after the discussion. Mentor, please remember to clarify any confusing issues during the presentation.

Narrator: Thank you for participating in the group activity. We know that FGC is a common practice in our community, but it is not necessarily the most advantageous for a woman's health and it does not have to be passed down to the next generation.

Narrator: We have now come to the end of our session today. Thank you for your active participation. see you next week same place, same time. Good bye. 


\section{Human Rights}

\section{Session 1: Human Rights and Children's Rights ${ }^{25}$}

Narrator: Hello! Today we will learn human rights and child rights.

Narrator: Mentor, for this session you will need a blackboard and chalk OR flipchart and markers, a copy of Children's Rights cut into pieces and Copies of Children's Rights for each participant. You will find the list of rights in the Health and life skills curriculum.

Narrator: The session will take about 1 hour and 30 minutes.

(II) Narrator: We will begin today's session with an energizer of about 5 minutes. Mentor, pause and ask a volunteer to lead the group in an energizer.

(II) Narrator: I hope you enjoyed the energizer! Mentor, pause and ask the girls to share what they learnt during the last session. Please remember to clarify any confusing issues

(II) Narrator: Thank you for participating in the energizer, I hope it was fun! We will begin this session my defining human rights. What are human right? Mentor, pause, listen and record responses on the flipchart or blackboard.

Narrator: Rights are things every person should have or be able to do. All children have the same rights. To uphold rights means to stand up for, maintain or help maintain rights. These rights are listed in the United Nations Convention on the Rights of the Child . Almost every country, including Kenya, has agreed to these rights. All the rights are connected to each other, and all are equally important. Human rights are about respect for everyone. It does not matter if the person is old or young, a man or woman, a girl or boy or where he or she lives. Everyone has a right to have his or her needs met, to be safe and to have a say in what happens in his or her life.

(II) Narrator: What are some of the human rights that you know? Mentor, pause, listen and record responses.

Narrator: Some examples of human rights are;

25 USAID. 2006. Doorways I: Student Training Manual on School-Related Gender-Based Violence Prevention and Response; UNICEF. Fact Sheet: A Summary of the Rights Under the Convention on the Rights of the Child. 
$\checkmark$ Right to education (go to school),

$\checkmark$ Right to employment (have a job),

$\checkmark$ Right to movement (travel from one place to another),

$\checkmark$ Right to ownership of property (own land, a house, a shirt, etc.),

$\checkmark$ Right to government services (use roads, parks, hospitals, schools, etc.),

$\checkmark$ Right to clean water (drink water that will cause disease),

$\checkmark$ Right to access to information (research and learn any information, not including private information),

$\checkmark$ Right to practice religion (go to any church, believe in any god (or not)),

$\checkmark$ Right to live free from violence (not have to worry about being hurt),

$\checkmark$ Right to health care (access medial services),

$\checkmark$ Right to vote (in country or local elections), and

$\checkmark$ Right to be protected from economic or sexual exploitation (protected from being scammed, robbed, raped, and abused)

Narrator: There are many rights and they fall into three basic categories:

1. Rights to things they need, such as a home, food, health care and places to stay and learn.

2. Rights to keep them safe from harm.

3. Rights to take part in decisions that affect their lives.

Narrator: Rights come with responsibilities. Examples of responsibilities that are associated with rights are;

$\checkmark$ With the right to be treated equally comes the responsibility to treat others equally.

$\checkmark$ Children have the right to be protected from abuse, cruelty, exploitation and neglect, but they also have the responsibility not to bully or harm others.

$\checkmark$ Children also have responsibility for their own learning, which includes respecting their teacher and the rules in the classroom.

$\checkmark$ Children have a right to a clean environment. They also have a responsibility to do what they can to look after their environment.

Narrator: Remember that Rights and Responsibilities are inseparable!

(II) Narrator: We are now going to do a very interesting group activity of creating posters/ drawings of some rights. Mentor, Pause and divide participants into groups of three or four. 
Narrator: Group 1, you will create a poster/ drawing on;

$\checkmark$ Right to education ( go to school)

$\checkmark$ Right to health care (access medial services),

Narrator: Group 2, you will create a poster/ drawing on;

$\checkmark$ Right to practice religion (go to any church, believe in any god (or not)),

$\checkmark$ Right to live free from violence (not have to worry about being hurt),

Narrator: Group 3, you will create a poster/ drawing on;

$\checkmark$ Right to movement (travel from one place to another),

$\checkmark$ Right to ownership of property (own land, a house, a shirt, etc.),

Narrator: Group 4, you will create a poster/ drawing on;

$\checkmark$ Right to government services (use roads, parks, hospitals, schools, etc.),

$\checkmark$ Right to clean water (drink water that will cause disease),

Narrator: On your posters/ drawings, don't forget to include information about the responsibilities that come with the rights too

(II) Narrator: Mentor, you will need to distribute a flipchart and markers of different colors for this activity. Mentor, pause and explain the activity.

(II) Narrator: Girls, I hope you have understood the activity. Mentor, pause for 30 minutes to allow girls to develop their posters/ drawings.

Narrator: Very good job girls! Am sure that was fun! Mentor, let the groups share their posters. Mentor, you can work with the girls to display the posters/ drawings around the community to inform their peers about human rights.

Narrator: Now that you know about your rights, we will now talk about what you can do if your rights are violated. I will begin by telling you a story about a girl called Maryan. Please pay attention. 


\section{Maryan's Story}

Maryan is a class 8 pupil who is very dedicated to achieving her academic goals. She is an orphan and lives with her paternal uncle. Maryan assists her uncle at hotel by washing dishes to support the family income. Unfortunately she was married off to Juma and became pregnant before her final exams. Juma is very abusive and often beats her up; she has been unable to report the battering incidents of fear. She recently talked to a friend and she had been advised to report to the police and seek medical help in case of any injuries.

(II) Narrator: Which human rights violations happened in the story? Mentor, pause and listen to the responses.

Narrator: Some of the human rights that were violated are; the right to education, the right to live free from violence, the right to employment, the right to healthcare, the right be protected from economic or sexual exploitation

(II) Narrator: Who was the survivor of the violations? Mentor, pause and listen to the responses.

Narrator: The survivor of the violations was Maryan.

(II) Narrator: Who is responsible to ensure that children's rights are not violated? Mentor, pause and listen to the responses.

Narrator: Everyone has a responsibility to work together to uphold rights, and that includes:

- students.

- family,

- community,

- school, and

- government]

(II) Narrator: We have come to the end of today's session. You can now ask the mentor any questions. Mentor, pause and respond to questions and or clarify confusing issues.

Narrator: Thank you for participating in today's session. See you next week 


\section{Leadership}

\section{Session 1: Leadership 26}

Narrator: Hello, today we will learn about leadership, understand the importance of leadership and identify qualities of good and bad leadership.

Narrator: Mentor, for this session you will need a blackboard and chalk OR flipchart markers.

Narrator: The session will take about 1 hour and 30 minutes.

(II) Narrator: Mentor, pause and ask the participants to share what they learned in the last session. Be sure to clarify any confusing issues.

(II) Narrator: Before, we begin the session, let us have a volunteer to lead us in an energizer. We. Mentor, pause an invite one of the participants to lead the rest in an energizer. Remember, you can always pause the recording at any point of the session and conduct an energizer.

Narrator: I hope you enjoyed the energizer.

Narrator: Young women are change agents and their leadership can bring vitality, creativity and courage for social change. Young women have the power to inspire and mobilize others for positive action. They can encourage the questioning of systems and beliefs that limit lives and choices. With courage they can confront even the injustices that have been in place long before our lives began. By supporting one another, young women ensure that their leadership remains strong in the face of unfair gender and age biases, and maximize our power to change

Narrator: As they continue to develop and define leadership, the advice and example of older, more experienced women are invaluable. By working together, women of all ages can help each other grow, maximize their strengths and fulfill our potential as change makers.

26 UNFPA, World YWCA. 2006. Empowering Young Women to Lead Change: A Training Manual. 
Narrator: Leadership is the art of motivating a group of people to act towards achieving a common goal or a state of being in control of a group of people.

(II) Narrator: Now, we are going to participate in a very interesting activity about a car and a driver. Mentor, pause and divide the participants into pairs. Assign one participant from each pair to be the car. The other participant will be the driver.

Narrator: I hope we are all in pairs. For this activity, the role of the participant who is the car is to keep her eyes closed and follow the driver's instructions. The role of the participant who is the driver is to keep her eyes opened and protect the car from collisions. Talking is not allowed in this activity so the drivers must communicate to the cars with the following touch signals.

1. A touch on the middle of the back means walk

2. Subsequent touches on the middle of the back mean walk faster

3. A touch on right shoulder means turn right

4. A touch on left shoulder means turn left

5. A touch on head means stop

Narrator: Remember, cars should be touched gently and all cars and drivers should be very careful!

Narrator: Mentor, to make the exercise more challenging you can scatter obstacles like chairs and tables throughout the space and pair girls together who do not know each other well. Mentor, you can now pause make sure everyone understands their roles and the signals, and then start the exercise. Ensure that there is no talking during the exercise - or that talking is at least kept at a minimum. After one or two minutes stop the exercise and have each pair switch roles. Cars become drivers and vice versa. Stop the second round after one or two minutes and have the group return to their seats

Narrator: I hope you enjoyed the activity. I am now going to ask you a few questions related to the activity.

(II) Narrator: How did it feel being a car? Mentor, pause and guide the discussion.

(II) Narrator: How did it feel being a driver? Mentor, pause and guide the discussion.

II Narrator: Did you prefer being a driver or car and why? Mentor, pause and guide the discussion.

(II) Narrator: What were some of the challenges of being the car? Mentor, pause and guide the discussion. 
(II) Narrator: What were some of the challenges of being the driver? Mentor, pause and guide the discussion.

(II) Narrator: What did you enjoy most about each role? Mentor, pause and guide the discussion.

(II) Narrator: What did this exercise teach you about leadership? Mentor, pause and guide the discussion.

(II) Narrator: What does it mean to be an effective leader? Mentor, pause and guide the discussion.

(II) Narrator: Is there any value in following? Mentor, pause and guide the discussion.

(II) Narrator: Does following have a role in leadership? If yes, what is it? Mentor, pause and guide the discussion.

Narrator: Now, we will do another activity about good leader and bad leader.

Narrator: Mentor, you can now pause and arrange seats in a circle and place flipchart paper where everyone in the circle will see it or use a blackboard visible to the circle of participants. Draw two columns on a sheet of flipchart paper. Write 'Good Leader' at the top of one column and 'Bad Leader' at the top of the other.

(II) Narrator: I hope we are all in a circle. What do you think leadership means? Mentor, pause and lead the discussion.

Narrator: Very good, leadership is the action of leading a group of people or an organization.

(II) Narrator: Why is it important for everyone to have some good leadership skills? Mentor, pause and lead the discussion.

Narrator: As you might have mentioned, good leadership skills enables one to advance their goals, use resources to reach their vision, they strengthen communication and decision-making, increase productivity, among others.

(II) Narrator: Girls, please open a blank page in your book and take out your pens. Mentor pause give participants time to open a blank page. 
(II) Narrator: Now, girls, think of a leader you admire for example your mother, community leader, celebrity, politician and write (or think of) three qualities you believe makes that person an effective leader. Mentor, pause and allocate participants 5 minutes for this activity.

(II) Narrator: Mentor, pause and request each participant to share what they have written. Record the qualities listed on the blackboard or flipchart paper under the column 'Good Leader'

(II) Narrator: Now, think of a leader you dislike for example Arawela, a celebrity or politician, or a character from a well-known story and write (or think of) three qualities that make that person a bad leader. Mentor, pause and allocate participants 5 minutes for this activity.

II Narrator: Mentor, pause and request each participant to share what they have written. Record the qualities listed on the blackboard or flipchart paper under the column 'bad Leader'

Narrator: We will now discuss similarities and differences in the good and bad qualities that have been listed on the flip chart/ blackboard.

(II) Narrator: Was anything surprising? Mentor, pause and lead the discussion.

(II) Narrator: Are there any similarities with the qualities for a good leader and for a bad leader? Mentor, pause and lead the discussion.

(II) Narrator: Do the leaders we do not admire have similar qualities to ones we do admire? Mentor, pause and lead the discussion.

II Narrator: How can we avoid becoming bad leaders? Mentor, pause and lead the discussion.

(II) Narrator: What can we do to be effective leaders? Mentor, pause and lead the discussion.

(II) Narrator: Girls, please open a blank page in your book and take out your pens. Mentor pause give participants time to open a blank page.

(II) Narrator: On your blank page, list a positive quality that you believe you already have. Mentor pause and give the participants time to record.

(II) Narrator: Now, write a positive quality that you would like to develop. Mentor pause and give the participants time to record. 
(II) Narrator: Now, write a negative quality that you would like to manage or eliminate. Mentor pause and give the participants time to record.

(II) Narrator: We have now come to the end of today's session. Mentor, pause and allow participants time to ask questions and clarifications.

Narrator: Thank you girls for participating in the session. See you next week. 


\section{Session 2: Community Service - Putting Leadership into Action 27}

Narrator: Hello girls, today we will talk community service.

Narrator: Mentor, for this session you will need a blackboard, chalk OR flipchart markers and a community map that should be prepared in advance. Try to draw the map in a creative way. It does not have to be a literal map of the community but can be a representation through symbols, such as a town represented as a flower with different petals.

Narrator: The session will take about 1 hour and 30 minutes.

(II) Narrator: Mentor, pause and ask the participants to share what they learned in the last session. Be sure to clarify any confusing issues.

(II) Narrator: Before, we begin the session, let us have a volunteer to lead us in an energizer. We. Mentor, pause an invite one of the participants to lead the rest in an energizer. Remember, you can always pause the recording at any point of the session and conduct an energizer.

Narrator: Community leaders take responsibility for the well-being and improvement of their communities. Community leaders want to improve their communities and feel they have something to contribute to doing so. They do not wait around for someone else to get the job done. You don't have to run for office or be given a title to be a leader. All you need to do is decide to take responsibility for some corner (or bigger chunk) of your community. Community leaders are often self-appointed. Even people who run for office first make a decision that they want to be a leader. You can probably take as much responsibility for your community as you are willing to.

(II) Narrator: What are some examples of communities? For example, family, school, village, clan, world among others. Mentor, pause and lead the discussion.

(II) Narrator: What are some characteristics of a community? What makes a community a community? For example, common needs and interests, respect, a population, set of governing rules. Mentor, pause and lead the discussion.

27Peace Corps. 2001. Camp GLOW (Girls Leading Our World): Handbook for Volunteers. 
(II) Narrator: Do you think that we have formed a community in this group with our regular meetings? Why? Mentor, pause and lead the discussion.

(II) Narrator: Mentor, pause and show the participants the map of the community that you have drawn. Explain your map if necessary.

Narrator: Community assets are positive characteristics, aspects that benefit our communities.

(II) Narrator: Mentor, pause and divide the participants into 5 groups or so. There should be an even number of groups. Give each group a flip chart and markers of different colors.

(II) Narrator: Now, you and your group should draw a map of your community. Be creative! Mentor, pause and allocate the groups 10 minutes to draw their maps.

(II) Narrator: Mentor, pause and have the small groups move around the room and partner with another small group to present their map.

Narrator: We will now add community problems, issues, and challenges to the community map you have drawn. Remember, no community is perfect. Once the participants complete their maps, ask them to hang them on the wall. Mentor, pause and allocate the participants 10 minutes for the activity.

(II) Narrator: What did the maps have in common? Mentor, pause and lead the discussion.

(II) Narrator: How does your community affect your self-esteem? Mentor, pause and lead the discussion.

(II) Narrator: How does it affect our values? Mentor, pause and lead the discussion.

(II) Narrator: What was the point in making these maps? Mentor, pause and lead the discussion.

Narrator: The point of making the maps was to remind ourselves of the many assets in our community and to learn about our problems.

(II) Narrator: What is community service? Mentor, pause and listen to the feedback.

Narrator: Community service is voluntary work to help people in a particular area. 
Narrator: The "ripple effect" is like when you throw a stone into the water and the rings spread across a pond. If we do something positive for our community, it can have a positive impact on our world just as doing something negative has an impact on our world. An example is if you throw a piece of trash in a river, it will make the river look ugly, kill the liver, people won't have anything to eat, pollute the drinking water among other.

(II) Narrator: Mentor, pause and give the participants an example of some volunteer work that you (the mentor) have done. Tell the participants who you worked with, when you did it, what the work was, where the work took place, why you did it, and how it made an impact on the lives of others. List the positive and negative outcomes of your experience. For example, maybe you felt stressed or worked in the hot sun, but you were able to provide hungry citizens with food). Stress the fact that the positives outweigh the negatives.

(II) Narrator: Girls, why should one do community service? Mentor, pause and lead the discussion.

(II) Narrator: What can you learn from community service? Mentor, pause and lead the discussion.

(II) Narrator: In the next activity, we develop action plans for conducting community service. Please remain in your small groups. Mentor, pause and make sure the participants are in their small groups.

(II) Narrator: In your groups, choose one issue, problem, or challenge to work on in your community over the next year. Mentor, pause and allocate the participants 5 minutes to choose.

(II) Narrator: Mentor, pause and allow each group to share the issue, problem, or challenge they have chosen as you record on a flipchart or blackboard.

(II) Narrator: Now as one group, we will agree on one issue - out of all those that you brainstormed - that we want to address. Mentor, pause and allow the participants to choose one issue.

Narrator: To address the issue we have identified, we will use the skills that we learned in the goal setting sessions, including

1. Identifying a mission statement

2. Answering the questions who, what, when where, why, and how,

3. Listing the positive and negative outcomes, and

4. Drawing a timeline. 
(II) Narrator: We will begin by identifying a mission statement for example, over the next year we will teach students in our school about the dangers of smoking. Mentor, pause and lead the discussion of identifying a mission statement.

(II) Narrator: Who will benefit from the project? Mentor, pause and lead the discussion.

(II) Narrator: What are the benefits of the project? Mentor, pause and lead the discussion.

(II) Narrator: When will the activity happen? Mentor, pause and lead the discussion.

(II) Narrator: Where will the activity take place? Mentor, pause and lead the discussion.

(II) Narrator: Why is there a need for the project? Mentor, pause and lead the discussion.

(II) Narrator: How will the project be conducted? Mentor, pause and lead the discussion.

(II) Narrator: What are the positives things about the project? Mentor, pause and lead the discussion.

(II) Narrator: What are the negatives things about the project? Mentor, pause and lead the discussion.

III Narrator: Which period will the project take? Mentor, pause and lead the discussion.

Narrator: Mentor determine when the community service activity will begin or take place, and make necessary plans for the execution of the plan.

Narrator: We have now come to the end of today's session. The mentor will pause and allow you to ask questions. Mentor, please pause respond to any issues and clarify any confusing issues.

Narrator: I hope you enjoyed today's session. See you next week! 


\section{References}

All sessions were adapted from the guides and curricula referred to below. Other publications referenced below were used to enhance content of the sessions.

Abstinence Focus Poster No. R045, Scotts Valley, CA: ETR Publishing, 2002.

Austrian, K. and Ghati, D. 2010. Girl Centered Program Design: A Toolkit to Develop, Strengthen and Expand Adolescent Girls Programs. Population Council. http://www.popcouncil.org/publications/books/2010 AdolGirlsToolkit.asp

Central Statistical Office (CSO) Ministry of Health (MOH) Tropical Diseases Research Centre (TDRC) University of Kenya, and Macro International Inc. "Kenya Demographic and Health Survey 2007." (2009).

Dwyer, J. 1993. "Legislative AIDS Away: The Limited Role of Legal Persuasion in Minimizing the Spread of HIV", in 9 Journal of Contemporary Health Law and Policy 167.

Elizabeth Glaser Pediatric AIDS Foundation (EGPAF), Uganda. A Guide on How to Start and Implement Ariel Children's Clubs. www.pedaids.org

Exhale. 2005. Teaching support: A guide for training staff in after-abortion emotional support. Oakland, CA, Exhale.

Global Press Institute, “Unsafe Abortion on the Rise in Kenya Despite 'Liberal' Law,” by Chanda Katongo, February $22,2012$. http://www.globalpressinstitute.org/africa/Kenya/unsafe-abortion-rise-Kenya-despite-"liberal"-law

Grossman L, Kowal D. Kids, Drugs, and Sex. (1987) Preventing Trouble. Brandon, VT: Clinical Psychology Publishing.

Guttmacher Institute. In Brief: Unsafe Abortion in Kenya. 2009 Series, No. 3. http://www.guttmacher.org/pubs/IB-Unsafe-AbortionKenya.pdf

Health Promotion Unit, 2007. Stages of behaviour change: Queensland Stay On Your Feet Community Good Practice Toolkit. Division of Chief Health Officer, Queensland Health.

International HIV/AIDS Alliance. 2002. 100 ways to energize groups: Games to use in workshops, meetings and the community. http://www.icaso.org/vaccines toolkit/subpages/files/English/energiser guide eng.pdf 
International HIV/AIDS Alliance. 2008. Sexuality and Life-Skills: Participatory activities on sexual and reproductive health with young people. http://www.ibe.unesco.org/fileadmin/user upload/HIV and AIDS/publications/Alliance Sexuality lifeskills.pdf

International HIV/AIDS Alliance, Academy for Educational Development, and the International Center for Research on Women. 2006. Understanding and challenging HIV stigma: a toolkit for Action. http://www.icrw.org/files/images/Understanding-andchallenging-HIV-stigma-Picture-Booklet.pdf

International Labor Organization. 2007. A Special Module On HIV and AIDS and Child Labor: Scream-Stop Child Labor. http://www.ilo.org/public/english/region/afpro/daressalaam/download/specmod hiv rev.pdf

International Sexuality and HIV Curriculum Working Group. 2009. It's All One Curriculum: Guidelines and Activities for a Unified Approach to Sexuality, Gender, HIV and Human Rights Education. Edited by Nicole Haberland and Deborah Rogow. http://www.popcouncil.org/publications/books/2010 ItsAllOne.asp

Johns Hopkins Bloomberg School of Public Health/Center for Communication Programs. 2011. Go Girls! Community-based Life Skills for Girls: A Training Manual. Baltimore, Maryland. Developed under the terms of USAID Contract No. GHH-1-00-07-0003200, Project SEARCH, Task Order 01. http://archive.k4health.org/toolkits/go-girls/go-girls

Kenya Adolescent Reproductive Health Project (KARHP), PATH, Population Council. 2005. Tuko Pamoja: Adolescent Reproductive Health and Life Skills Curriculum. http://www.popcouncil.org/pdfs/frontiers/Manuals/KARHP guide1.pdf

Marais, Thea. 1996. Abortion values clarification training manual. Melrose, South Africa, Planned Parenthood Association of South Africa. Family Life Peer Education manual and Resource book: Margaret Sanger Centre International - South Africa.

Mobilizing Access to Maternal Health Services in Kenya-MAMaZ (2012). Community Discussion Guide for Maternal and Newborn Health Care: A Training Manual for Safe Motherhood Action Groups.

National Institutes of Health, Eunice Kennedy Shriver National Institute of Child Health and Human Development, "Menstruation and the Menstrual Cycle." http://www.nichd.nih.gov/health

One Love Southern Africa Campaign. http://www.onelovesouthernafrica.org

Peace Corps. 2001. Camp GLOW (Girls Leading Our World): Handbook for Volunteers. http://www.peacecorps.gov/multimedia/pdf/library/M0056 campglow.pdf

Peace Corps. 2001. Information Collection and Exchange Publication: Life Skills Manual. http://www.peacecorps.gov/multimedia/pdf/library/M0063 lifeskillscomplete.pdf 
Pick, S., M. Givaudan, V. Olicon and M. Beltrum. My Voice, My Life Curriculum. The Mexican Institute for the Research of Family and Population (IMIFAP). http://www.imifap.org.mx/imifap/portal/cfpages/contentmgr.cfm?fuente=nodo\&docld=40\&docTipo=1

Population Council. 2010. Safe Space Curriculum. Lusaka, Kenya.

Project Concern International - Kenya, Africa KidSAFE. 2006. Street Life - The Story of Sufi and Site. A Life Skills Guide for Children 'on' and 'of' the Street.

Quigley, Maria, et al. 1997. "Sexual behavior patterns and other risk factors for HIV infection in rural Tanzania: a case-control study." Aids 11.2: 237-248.

RAPIDS/Consortium in Kenya. RAPIDS Youth Life Skills Training Manual. Prepared by Motivational Centre for Africa's Transformation (MoCAT) for AFRICARE.

Republic of Kenya. 2000. First Draft, Reproductive Health Policy, Ministry of Health. http://www.k4health.org/sites/default/files/Kenya\%20Reproductive\%20Health\%20Policy.pdf

Sport in Action, International Alliance for Youth Sports. 2010. Game On! Life Skills Manual. http://www.iays.org/programs-andservices/game-on-youth-sports/life-skills-activity-guide/

Sustainability Through Economic Strengthening Prevention an Support for Orphans and Vulnerable Children, Youth and Other Vulnerable Populations (STEPS OVC/Consortium) Kenya. STEPS OVC Youth Services Training Manual.

The sexual offences Act 2006: The Laws of the Government of Kenya

Turner, Katherine L. and Kimberly Chapman Page. 2008. Abortion attitude transformation: A values clarification toolkit for global audiences. Chapel Hill, NC, Ipas.

UNFPA, World YWCA. 2006. Empowering Young Women to Lead Change: A Training Manual. http://www.unfpa.org/upload/lib pub file/628 filename empowering-young-women eng.pdf

UNFPA. 2005. State of World Population. http://www.unfpa.org/swp/2005/english/ch7/

UNHCR and UNAIDS. 2002. HIV/AND Human Rights International Guidelines: Third International Consultation on HIV/AIDS and Human Rights. Geneva. http://data.unaids.org/publications/irc-pub02/ic905-guideline6 en.pdf 
UNICEF Harare. 1995. Think About It! An AIDS Action Programme for Schools. http://catalogue.safaids.net/publications/thinkabout-it-aids-action-programme-schools-form-4-students-book

UNICEF. Fact Sheet: A Summary of the Rights Under the Convention on the Rights of the Child. http://www.unicef.org/crc/files/Rights overview.pdf

USAID. 2006. Doorways I: Student Training Manual on School-Related Gender-Based Violence Prevention and Response. http://www.usaid.gov/our work/cross-cutting programs/wid/

USAID. 2009. Doorways III: Teacher Training Manual on School-Related Gender-Based Violence Prevention and Response. http://www.usaid.gov/our work/cross-cutting programs/wid/

World Health Organization. 1994. School Health Education to prevent AIDS and STD: A Resource Package for Curriculum Planners. http://library.unesco-

iicba.org/English/HIV AIDS/cdrom\%20materials/navigation\%20pages/School\%20Health\%20Education.htm 